\title{
All100 987935
}

NBS

PUBLICATIONS

NAT'L INST OF STANDAROS \& TECH R.I.C.

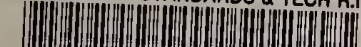

A11100987935

Selected A11100987935

Selected papers desiling with regulatory
QC100 U57 V536;1979 C.1 NBS-PUB-C 19 ?

\section{PUBLICATION 536}

National Bureau of Standards

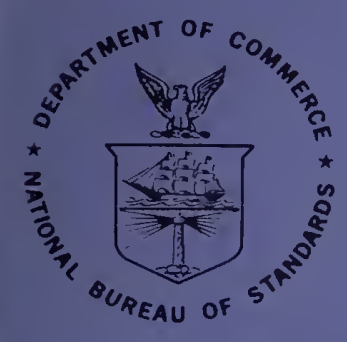

\section{selected papers dealing with}

\section{Regulatory Concerns \\ of Building Rehabilitation}

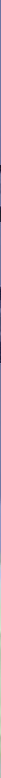




\title{
NATIONAL BUREAU OF STANDARDS
}

The National Bureau of Standards' was established by an act of Congress March 3, 1901. The Bureau's overall goal is to strengthen and advance the Nation's science and technology and facilitate their effective application for public benefit. To this end, the Bureau conducts research and provides: (1) a basis for the Nation's physical measurement system, (2) scientific and technological services for industry and government, (3) a technical basis for equity in trade, and (4) technical services to promote public safety. The Bureau's technical work is performed by the National Measurement Laboratory, the National Engineering Laboratory, and the Institute for Computer Sciences and Technology.

THE NATIONAL MEASUREMENT LABORATORY provides the national system of physical and chemical and materials measurement; coordinates the system with measurement systems of other nations and furnishes essential services leading to accurate and uniform physical and chemical measurement throughout the Nation's scientific community, industry, and commerce; conducts materials research leading to improved methods of measurement, standards, and data on the properties of materials needed by industry, commerce, educational institutions, and Government; provides advisory and research services to other Government Agencies; develops, produces, and distributes Standard Reference Materials; and provides calibration services. The Laboratory consists of the following centers:

\section{Absolute Physical Quantities ${ }^{2}$ - Radiation Research - Thermodynamics and Molecular Science - Analytical Chemistry - Materials Science.}

THE NATIONAL ENGINEERING LABORATORY provides technology and technical services to users in the public and private sectors to address national needs and to solve national problems in the public interest; conducts research in engineering and applied science in support of objectives in these efforts; builds and maintains competence in the necessary disciplines required to carry out this research and technical service; develops engineering data and measurement capabilities; provides engineering measurernent traceability services; develops test methods and proposes engineering standards and code changes; develops and proposes new engineering practices; and develops and improves mechanisms to transfer results of its research to the utlimate user. The Laboratory consists of the following centers:

\author{
Applied Mathematics - Electronics and Electrical Engineering ${ }^{2}$ - Mechanical \\ Engineering and Process Technology ${ }^{2}-$ Building Technology - Fire Research - \\ Consumer Product Technology — Field Methods.
}

THE INSTITUTE FOR COMPUTER SCIENCES AND TECHNOLOGY conducts research and provides scientific and technical services to aid Federal Agencies in the selection, acquisition, application, and use of computer technology to improve effectiveness and economy in Government operations in accordance with Public Law 89-306 (40 U.S.C. 759), relevant Executive Orders, and other directives; carries out this mission by managing the Federal Information Processing Standards Program, developing Federal ADP standards guidelines, and managing Federal participation in ADP voluntary standardization activities; provides scientific and technological advisory services and assistance to Federal Agencies; and provides the technical foundation for computer-related policies of the Federal Government. The Institute consists of the following divisions:

Systems and Software - Computer Systems Engineering - Information Technology.

'Headquarters and Laboratories at Gaithersburg, Maryland, unless otherwise noted; mailing address Washington,D.C. 20234.

${ }^{2}$ Some divisions within the center are located at Boulder, Colorado, 80303.

The National Bureau of Standards was reorganized, effective April 9, 1978. 


\section{selected papers dealing with \\ Regulatory Concerns of Building \\ Rehabilitation}

Patrick W. Cooke, Editor

Building Economics and Regulatory

Technology Division

Center for Building Technology

National Engineering Laboratory

National Bureau of Standards

Washington, D.C. 20234

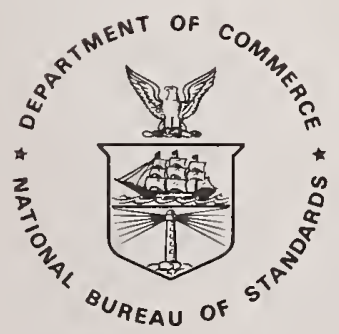

$\frac{t \text { Special ruhlican m, } 140536}{\text { U.S. DEPARTMENT OF COMMERCE, Juanita M. Kreps, Secretary }}$ Jordan J. Baruch, Assistant Secretary for Science and Technology

NATIONAL BUREAU OF STANDARDS, Ernest Ambler, Director

Issued February 1979 


\section{Library of Congress Catalog Card Number: 79-600012}

National Bureau of Standards Special Publication 536

Nat. Bur. Stand. (U.S.), Spec. Publ. 536,93 pages (Feb. 1979)

CODEN: XNBSAV

\section{U.S. GOVERNMENT PRINTING OFFICE}

WASHINGTON: 1979

For sale by the Superintendent of Documents, U.S. Government Printing Office, Washington, D.C. 20402 Stock No. 003-003-02032-0 Price \$2.75

(Add 25 percent additional for other than U.S. mailing) 
CONTENTS

PAGE

PREFACE . . . . . . . . . . . . . . . . . . . . . iv

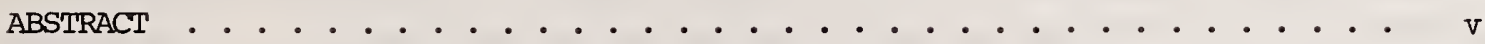

"Building Codes: Preservation and Rehabilitation"

by Robert J. Kapsch . . . . . . . . . . . . . . . . . 1

"Information Structure of Building Codes and Standards for the Needs of

Existing Buildings"

by Baird Smith . . . . . . . . . . . . . . . . . .

"Contractor Understanding Relative to Rehab Costs"

by Richard S. Harrington . . . . . . . . . . . . . . . 55

"The Role of Fire Prevention and Control on Building Construction and

Regulations"

by William H. MCLain . . . . . . . . . . . . . . . .

"Rehabilitation as an Instrument in Meeting Housing Need: Can It Really Work?" by Jane Heron . . . . . . . . . . . . . . . . . . 75

"Building Codes and Historic Preservation in Savannah,Georgia" by Mires Rosenthal . . . . . . . . . . . . . . . . . . 
A new national priority calling for the rehabilitation and preservation of our existing building stock has emerged -- primarily resulting from the energy crises and other economic problems. New programs for funding local governments are providing the supportive base for revitalizing existing urban environments and there has been significant new interest in the restoration and preservation of historic structures. It is expected that this emphasis to rebuild and preserve the Nation's neighborhoods will increase in the foreseeable future.

The complexities and difficulties involved with the building rehabilitation process, however, are numerous and not easily understood. Market forces, financial considerations, governmental policy, industry structure, and regulatory activities are but a few. In the building regulatory area, many of these older buildings were constructed prior to the existence of modern building codes. Application of building codes to these buildings poses difficulties because these regulations are primarily designed for new construction.

The papers contained in this Special Publication address some of the issues that building regulatory and related activities have on rehabilitation and historic preservation efforts. It is the intent that this collection of papers be used as a resource to further understanding and give some insight to the difficulties involved from different perspectives. The papers have been reprinted from the Proceedings of previous national. conferences dealing with building regulatory research which were held under the joint sponsorship of NBS and the National Conference of States on Building Codes and Standards, Inc. (NCSBCS) . 
This publication consists of a collection of six papers common to the subject of rehabilitation and preservation of existing buildings and how our present system of regulating construction for the public benefit presents various barriers that must be more fully understood in order that rational solutions can be developed and implemented. The papers have been reprinted from the Proceedings of previous national conferences dealing with building regulatory research held under the joint sponsorship of NBS and the National Conference of States on Building Codes and Standards. The titles of the papers are:

"Building Codes: Preservation and Rehabilitation" by Robert J. Kapsch

"Information Structure of Building Codes and Standards for the Needs of Existing Buildings" by Baird Smith

"Contractor Understanding Relative to Rehab Costs" by Richard S. Harrington

"The Role of Fire Prevention and Control on Building Construction and Regulations" by William H. McLain

"Rehabilitation as an Instrument in Meeting Housing Need: Can It Really Work?" by Jane Heron

"Building Codes and Historic Preservation in Savannah Georgia" by Mires Rosenthal

Key Words: Adaptive reuse; buildings; building codes; building safety; code enforcement; construction; fire safety; housing; preservation; regulations; rehabilitation. 
BUILDING CODES: PRESERVATION AND REHABILITATION*

by

Robert J. Kapsch, Assistant Chief**

Office of Building Standards and Codes Services

Center for Building Technology, IAT

National Bureau of Standards

Washington, D.C.

There has been a large rise in interest in the last ten years in building reuse, rehabilitation and preservation projects. This trend is expected to continue in the foreseeable future. Such projects pose difficulties for the building regulatory system since many of these buildings were originally constructed prior to the existence of building codes. Most of these buildings do not meet modern levels of building regulation and application of building regulations to them poses difficulties as these regulations are essentially designed for new construction. The potential impact of these regulations includes the increase of project costs and damage to the fabric of the building intended to be preserved. Yet safety and health must be achieved in existing buildings as well as new. This paper sumarizes studies and other activities that are presently being conducted by a number of organizations on this subject. One such study conducted by NBS has indicated that numerous State and local jurisdictions and model code organizations are adopting historic building waiver clauses and similar regulations as a partial answer to this problem. The National Trust for Historic Preservation sponsored the first national conference, in 1974, on this question and is currently cooperating with NBS in a study of the effectiveness of selected historic building waiver clauses. The National Endowment for the Arts has sponsored a grant that would identify tradeoffs that could be used in building regulations. NBS has also sponsored a study, reported in a separate paper in these Proceedings, on how a standard designed for existing buildings might be structured and formatted. NBS is also studying, for the Department of Housing and Urban Development, technological aspects of neighborhood conservation, including the role of building regulations. As of this writing, no final or definitive answer has been developed for the problem of achieving contemporary levels of safety and health in existing buildings.

Key Words: Adaptive reuse; architecture; building codes; building regulations; building safety; construction; performance; preservation; rehabilitation; renovation.

\footnotetext{
* Reprinted from NBS Special Publication 473, "Research and Innovation in the Building Regulatory Process," (Proceedings of the First NBS/NCSBCS Joint Conference held in Providence, Rhode Island, September 21-22, 1976); pp. 437-452.

** Currently Mr. Kapsch is Program Manager, Rehabilitation Guidelines Activity, U.S. Department of Housing and Urban Development, Washington, D.C. 20410
} 


\section{INTRODUCTION}

The last ten years has seen an increasing interest in the reuse, rehabilitation and preservation of existing buildings. This is a trend that is having a great impact on the building regulatory community--particularly those who write and enforce building codes and standards. The purpose of this paper is to summarize:

--The nature of this trend toward the reuse, rehabilitation and preservation of existing buildings,

--The building regulatory response to this trend,

--The building regulatory research presently being conducted in this area.

Terms that are becoming more and more frequently used in the building community are:

--Preservation,

--Restoration,

--Rehabilitation, and

--Recycling/Adaptive Reuse.

These terms are related to each other through their common concern for retaining and reusing existing buildings, but differ significantly in what actions and uses they imply for these existing buildings.

\section{PRESERVATION}

Preservation can perhaps be considered the oldest of these terms, the first preservation movement being that begun by the Mount Vernon Ladies Association, over 100 years ago. If Traditionally, preservation efforts have been directed at retaining individual buildings of historic or aesthetic merit. Recently, this direction has been broadened to include a concern for the retention of those buildings that enhance and enrich the urban fabric. This can be seen in the current widespread interest in historic districts. Traditionally, preserved buildings have been used as house museums, such as Mount Vernon. But this too has been broadened in recent years; preserved buildings now may be put to any number of uses--including the originial intended use. Thus, the building regulatory official is increasingly faced not with single house museums that will be only open during certain hours, but with a range of preserved buildings being used for housing, restaurants, retail stores, auditoriums, and other uses.

1/Charles B. Hosmer, Jr., "Presence of the Past: A History of the Preservation Movement in the United States Before Williamsburg," G. P. Putman's Sons, New York, 1965. This book is considered the standard history of preservation in the United States up to 1926. 
Restoration, the second of these terms, can be considered a smal.l subset of preservation--the modification of an historic building so as to recreate the building as it appeared at some earlier date. This is a small portion of the preservation projects encountered by regulatory officials since restoration is very expensive--for example the restoration of the Carlisle House in Alexandria, Virginia, and the restoration of the William Paca House in Annapolis, Maryland, each cost over $\$ 1$ million for restoration. $\frac{2 /}{}$ But restoration projects pose particular problems to the building regulatory official as historic and architectural authenticity are of the utmost importance. These restoration projects can be, and frequently are, as technologically advanced as new construction, including modern electrical, plumbing, heating, ventilating and air conditioning, structural and fire detection and suppression systems--all of which must be concealed to preserve the historical "fabric" of the building.

\section{REHABILITATION}

The term rehabilitation, the third of these terms, has been used in two contexts in the 1970's. The first is the rehabilitation of the 19th century rowhouses in the central cities for an increasing number of young professionals returning to the city. The second context within which rehabilitation is found is housing for the urban poor. In this second context, rehabilitation is related to conservation; rehabilitating existing buildings, so as to maintain urban areas that have not yet experienced significant physical decline. Conservation's primary thrust is to maintain jobs and housing in situ, usually in areas of little historical or architectural distinguishment. Whereas restoration projects usually have large budgets and are under the direction of trained architects, rehabilitation usually operates under extremely tight budgets and is usually undertaken by contractors or homeowners who are frequently largely unaware of pertinent building code requirements or alternative methods of satisfying these requirements.

\section{RECYCLING/ADAPTIVE REUSE}

The last of these terms are recycling and adaptive reuse. Many building professionals object to the term recycling as it tends to equate buildings with aluminum cans. But despite these potential associative shortcomings, the term clearly conveys its intended meaning--the reuse of existing buildings to meet current needs. Perhaps a more widely used term is adaptive reuse. Under the concept of adaptive reuse, old buildings are 2/The Washington Post, "A Grand House Restored," Sunday, August 29, 1976, p. I.l. 
given new functions--and thus must adhere to the requirements of the building code. Although adaptive reuse projects usually do not have the restoration project's strict requirements for authenticity, particularly in the interior spaces; neither do they have the large budgets or professional assistance usually associated with restoration projects.

\section{GROWTH OF INTEREST IN EXISTING BUITDINGS}

There is considerable evidence of the growth of interest in existing buildings during the 1970s. For example, the Urban Land Institute Study of 1975 concluded the following:

o "...Private-market renovation is fairly extensive."

- Private-market renovation, "appears substantial in relation to the amount of both subsidized and unsubsidized housing which has occurred in the past."

- "Private-market renovation, "is reported to be increasing."

o "The survey findings also demonstrate the attractiveness of older, and particularly, historic areas to a segment of the population which has grown rapidly in recent years--the relatively affluent professional and office workers...." 3 -

Most American cities can point to one or several areas within the central core that are presently undergoing such private renovation.

Other evidence of this growth of interest in existing buildings includes Congressional action. For example, Congress recently passed the Public Buildings cooperative Use Act of $1976^{4 /}$ encouraging the General Services Administration to utilize existing buildings to meet their space needs and the Tax Reform Act of $1976^{5 /}$ containing special provisions for those who preserve designated historic resources.

That existing buildings have taken on new importance in the 1970s can be judged by statements of responsible public officials. For example, secretary of HUD Carla Hills, has stated:

"...The era of clearing out whole blocks of buildings to erect new housing is ending. Instead, cities and the Federal Government should stress rehabilitating existing buildings. "틔

3/J. Thomas Black, "Private-Market Housing Renovation in Central Cities: A ULI Service," Urban Land, November 1975, p. 7.

4/Public Law 94-451, signed by President Ford on October 18, 1976.

5/Public Law 94-455, signed by President Ford on October 4, 1976.

6/The Washington Post, "Carla Hills Stresses Rehabilitation," Saturday, February 7, 1976, p. D38. 
The Advisory Council on Historic Preservation, in a report prepared for the Senate Committee on Interior and Insular Affairs, identified the growing emphasis in the last ten years on preservation. This report states:

\begin{abstract}
"The proliferation of history and preservation groups in towns and cities throughout America - from less than 2,500 in 1966 to more than 6,000 in 1975, also evidences the public conviction about the importance of historic preservation. The American Government reflected this upsurge of popular interest when, in 1973, it become the first government to ratify the World Heritage Convention. Adopted by the UNESCO General Conference of November 1972, the Convention affirms that it is the "duty" of each national government to preserve and conserve the cultural resources that collectively are the heritage of all mankind, "I)
\end{abstract}

Other evidence could be cited to substantiate the rise of interest in existing buildings in the 1970s. The fact remains that the building regulatory officials of the U.S. are reviewing more existing building projects, be they preservation, restoration, rehabilitation or adaptive reuse projects, than was the case in the past.

In general, existing buildings come under the purview of building codes when ( 1 ) there is a change of occupancy or (2) the value of alteration or damage repair work to be accomplished exceeds certain designated limits, or when the building is expanded. 8/

For example, the Basic Building code, one of the three widely used model building codes in the U.S. , I/ requires code compliance for change of occupancy: 7/Advisory Council on Historic Preservation, "The National Historic Preservation Program Today," prepared at the request of Henry M. Jackson, Chairperson, Committee on Interior and Insular Affairs, United States Senate, 94th Congress, 2nd Session, U.S. Government Printing Office, Washington, D.C., January 1976.

8/This discussion is limited to building codes. Many jurisdictions enforce housing codes which remain applicable to the buildings in that jurisdiction at all times. Building codes typically include, usually by reference, approximately 300 nationally recognized standards produced by such organizations as the American National Standards Institute (ANSI), the American Society for Testing and Materials (ASTM), and similar organizations. Some jurisdictions do have retroactive requirements in their building code, such as the District of Columbia. In these cases, existing buildings would come under the purview of building codes.

9/Produced by the Building Officials and code Administrators International, Inc., and used in the Northeast and Midwest. The other model building codes in the U.S. are tire Standard Building code (produced by the Southern Building code Congress), used in the South, and the Uniform Building code (produced by the International Conference of Building officials), used in the West. Although these model building codes are not legal documents, they frequently serve as the technical basis for building codes promulgated by the States, cities and local jurisdictions. 
"105.2 Change in use: It shall be unlawful to make any change in the use or occupancy of any structure which would subject it to any special provision of this code without approval of the building official, and his certification that such structure meets the intent of the provisions of law governing building construction for the proposed new use and occupancy, and that such change does not result in any greater hazard to public safety and welfare."10/

Similarly, code compliance is also required for major alterations:

"106.1 Application: Except as provided in this section, existing structures, when altered or repaired as herein specified, shall be made to conform to the full requirements of this code for new structures."

"106.2 Alterations exceeding 50 per cent: If alterations or repairs are made within any period of twelve (12) months, costing in excess of fifty (50) percent of the physical value of the structure, this code's requirements for new structures shall apply."

"106.3 Damages exceeding 50 per cent: If the structure is damaged by fire or any other cause to an extent in excess of fifty (50) per cent of the physical value of the structure before the damage was incurred, this code's requirements for new structures shall apply."

"106.4 Alterations under 50 per cent: If the cost of alterations or repairs described herein is between twenty-five (25) and fifty (50) per cent of the physical value of the structure, the building official shall determine to what degree the portions so altered or repaired shall be made to conform to the requirements for new structures."1ly

And, similarly, code compliance is required for additions.

"106.6 Increase in size: If the structure is increased in floor area or number of stories, the entire structure shall be made to conform with the requirements of this code in respect to means of egress, fire safety, light and ventilation."

What is the impact of these building codes and standards on preservation, restoration, rehabilitation and adaptive reuse projects? It must be recognized that many, if not most, of these existing buildings do not meet modern accepted levels of safety and health--in fact, many of these buildings were constructured prior to the existence of building codes. Even those built according to existing building codes at the time of construction may not meet modern levels of safety and health as there has been a general and widespread upgrading of these levels in building codes throughout the 20th century. This general upgrading of building codes in the U.S. continues today and includes the adoption of new cole provisions

10/The BOCA Basic Building Code, 1975 Edition, Building Officials and Code Administrators International, Inc., p. 3.

1l/Ibid., pp. 3-4.

12/Ibid., p. 4. 
and standards for areas such as fire safety, structural safety, physical safety and security, energy conservation, and others. Although these new, and generally higher, ievels of building regulation provide more safety and health for the building user; they also provide a larger impact on preservation, restoration, rehabilitation and adaptive reuse projects. This impact is of two general types: (1) larger project costs for existing building projects, and (2) disruption or destruction to the building fabric--the architectural integrity of the building that is intended to be preserved.

That modern levels of building codes impose additional project costs is apparent to all those who have participated in preservation and rehabilitation projects--enhanced safety and health for the building user usually can only be achieved at some cost. That these building regulations might also disrupt or destroy the building fabric intended for preservation may not seem as obvious. Modern building regulations are primarily written for new construction projects. These regulations contain prescriptive and performance statements. Prescriptive statements specify the allowable materials, combinations of materials, components, assemblies, or configurations and dimensions that can be included in the construction of that new building. These prescriptive statements thus prescribe building solutions and are relatively easy to meet in new construction projects since none of the building is yet existing. Yet for preservation and rehabilitation projects the building is existing and thus not amendable to the application of prescriptive statements--although it may have to be minimally or substantially modified to meet building code requirements. These same prescriptive statements, when thoughtlessly applied to existing buildings, can needlessly add additional projeci costs and destroy many of the essential architectural features of the building. For example, the building code prohibition, "(on) the use of winders or circular stairways... in stairways serving as required exits,"13/ and the related building code requirement that, "The minimm width of any stair serving as a means of egress shall not be less than forty-four (44) inches, except-that stairs serving an occupancy load for less than fifty (50) people may be thirty-six (36) inches in width, "14/ may have a tremendous impact on the large number of older buildings that use circular stairways, primarily or exclusively. In fact, what usually has to be done in such buildings is to construct a new structure adjacent to the existing building to house a new stairway or to create a space within the existing building for the required stairway.

Thus it can be seen that the objectives of safety and health can conflict with the objectives of preservation. Nevertheless, the answer to this problem is not to waive building regulations in the case of preservation, restoration, rehabilitation or adaptive reuse projects

13/Standard Building Code, 1976 Edition, Southern Building Code Congress International, Inc. Section 1115.3 (c).

14/Ibid., Section 1115.6(c). 
--society has indicated a clear need for safety and health in buildings which they use, including existing buildings. The final or definitive answer is to seek out solutions in which society can attain the objective of preservation as well as the objectives of safety and health.

Toward this end, the first conference on preservation and building codes was held in Washington, D.C., in May 1974 by the National Trust for Historic Preservation. This conference was cosponsored by a number of professional, preservation and code organizations including:

--Advisory Council on Historic Preservation

--American Institute of Architects

--American Insurance Association

--Association for Preservation Technology

--Building Officials and code Administrators International, Inc.

--International Conference of Building Officials

--National Conference of State Historic Preservation Officers

--National Fire Protection Association

--Society of Architectural Historians

--Southern Building Code Congress

The papers presented at this conference were published by the National Trust in 1975. $15 /$

Perhaps the feelings of the conferees were best summed up by Giorgio Cavaglieri, a practicing architect and a specialist in the restoration and adaptive use of urban public structures:

\begin{abstract}
"Laypersons frequently suggest that preservation commissions or design boards should obtain special waivers from the various building departments so that original designs may be preserved. Any serious technical and artistic judgment, however, must recognize that even if the requirements of the code are oppressive or disturbing at times, the safety and comfort of the users cannot be disregarded. It therefore becomes the restoration architect's duty to make preservation compatible with code requirements and when selecting the design items of secondary importance to carefully choose those that can be changed in order to permit the required or desired protection. Only when this is done can preservation for adaptive reuse be considered successful."
\end{abstract}

In the autumn of 1975, NBS sponsored a study conducted by Melvyn Green Associates to determine what actions regulatory bodies were taking with respect to preservation projects. $16 /$ 15/National Trust for Historic Preservation, "Preservation and Building codes: Paper from the Preservation and Building codes Conference Sponsored by the National Trust for Historic Preservation, May 1974," The Preservation Press, Washington, D.C., 1975.

16/Melvyn Green and Patrick W. Cooke, "Survey of Building Code Provisions for Historic Structures," National Bureau of Standards, Technical Note 918, U.S. Government Printing Office, Washington, D.C., September 1976. 
Responses were solicited from:

--Delegates to the National Conference of States on Building Codes and Standards (NCSBCS)

--State Historic Preservation Officers (SHPOs)

--Regulatory officials of the member cities of the Association of the Major City Building Officials (AMCBO)

--Model Building Codes (Basic Building Code, Standard Building Code, Uniform Building code)

--Other interested jurisdictions and organizations.

This study revealed a growing adoption and use of:

--Historic preservation waiver clauses in building codes

--Administrative regulations contained in historic district legislation and similar regulations containing similar provisions as the building code waiver clauses.

This survey revealed that of the forty-seven (47) State responses, eleven (11) reported special code provisions in effect and five (5) reported special administrative regulations (see Figure 1). This is particularly significant as twenty (20) States now have mandatory or voluntary statewide building codes.

Of the sixteen (16) States reporting special code provisions or administrative regulations for preservation, nine (9) reported special boards to regulate preservation. On many of these boards, the State Historic Preservation Officer was represented. It is also significant to note that the first such provision was only recently adopted, in 1971, by the State of Alaska.

The survey also indicated that of the twenty-four (24) Association of Major City Building officials (AMCBO) city responses that seven (7) reported special code provisions in effect and that eight (8) reported special administrative regulations (see Figure 2).

Perhaps most significantly, the survey also indicated that two (2) of the model building codes have adopted historic preservation building code provisions, the Uniform Building code and the Basic Building Code, and that the third, the Standard Building code, has a similar provision under consideration (Figure 3). These code provisions were only added in the last two years. A fourth model building code, the National Building code, just recently added special provisions for existing buildings. These model code survey results are significant as these model codes serve as the technical basis for many, if not most, of 


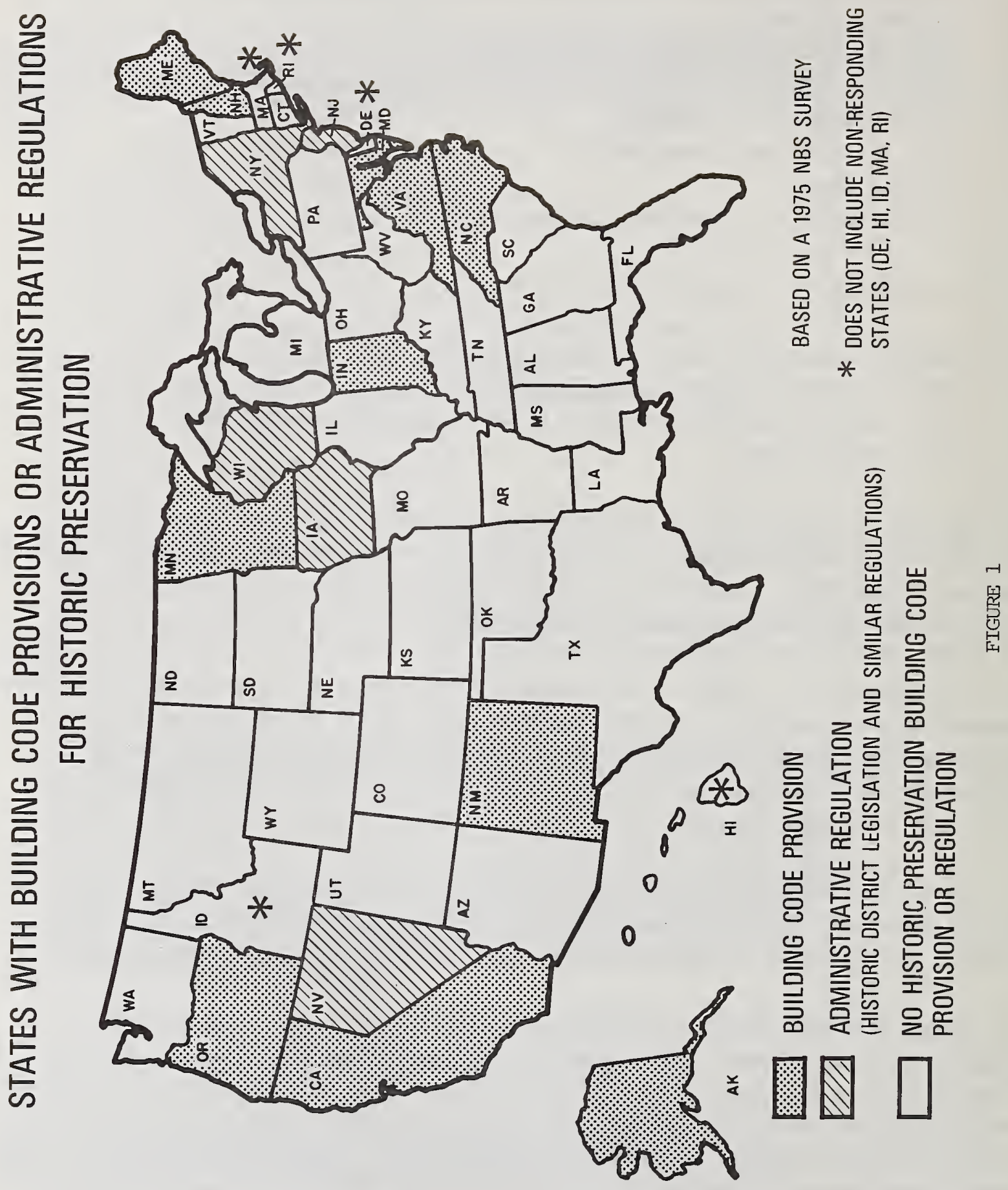




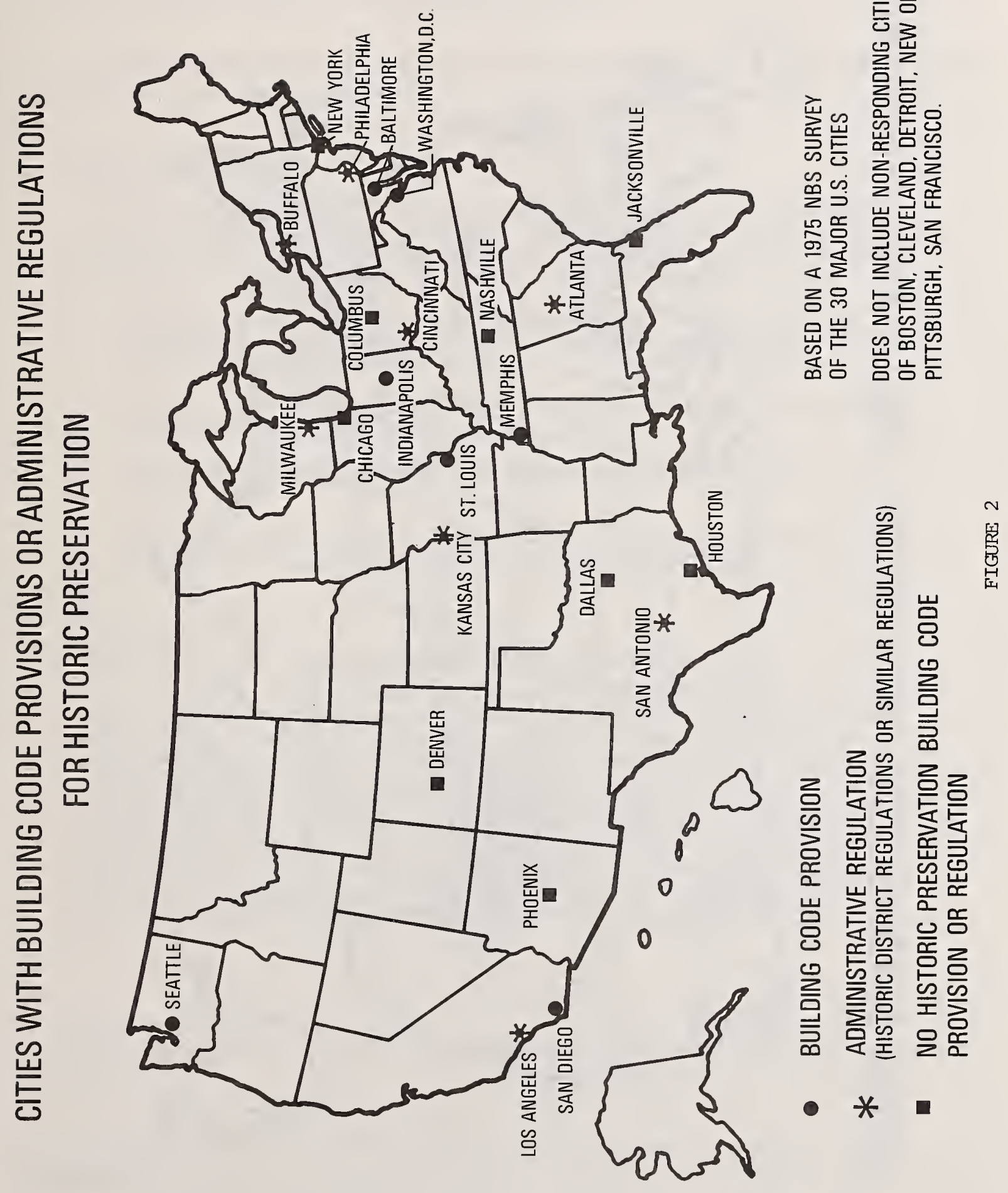




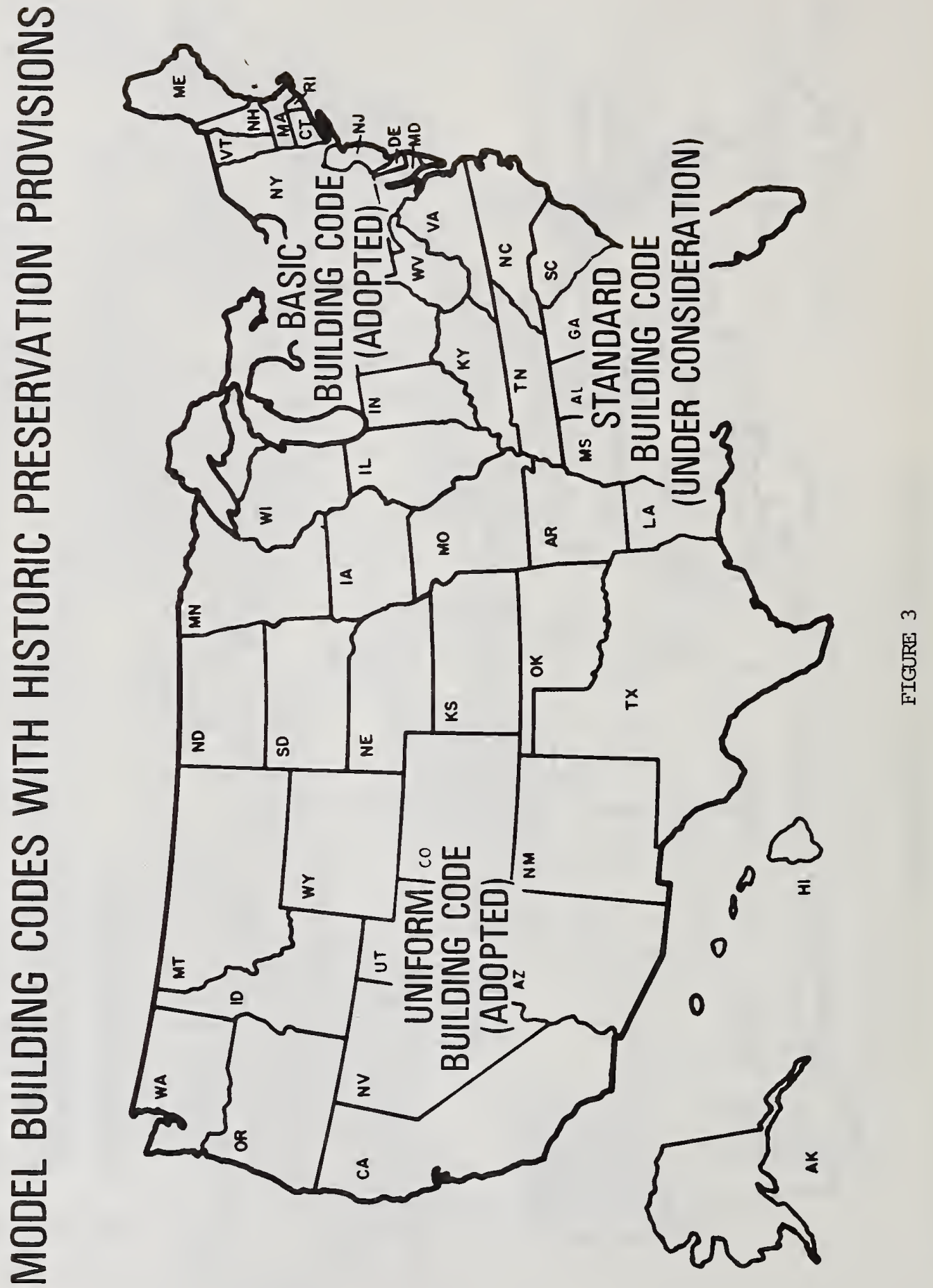


the building codes used in the United States. New provisions in the model building codes are usually adopted by State and local jurisdictions. Thus, the addition of historic preservation waiver clauses to these model building codes may well indicate a further, future use of such provisions by all building codes.

The Uniform and Basic Building Codes illustrate what typical historic preservation building code provisions contain:

\section{Uniform Building Code}

"(j) Historic Buildings. Repairs, alterations and additions necessary for the preservation, restoration, rehabilitation or continued use of a building or structure may be made without conformance to all of the requirements of this code, when authorized by the Building official provided:

1. The building or structure has been designated by official action of the legislative body as having special historical or architectural significance.

2. Any unsafe conditions, as prescribed in section 203, will be corrected in accordance with approved plans.

3. Any substandard conditions will be corrected in accordance with approved plans.

4. The restored building or structure will be less hazardous based on life and fire risk, than the existing building."17)

Basic Building code

"SECTION 317.0 SPECIAL HISTORIC BUILDINGS AND DISTRICTS

317.1 Approval: The provisions of this code relating to the construction, repair, alteration, enlargement, restoration and moving of buildings or structures shall not be mandatory for existing buildings or structures identified and classified by the state and/or local government authority as historic buildings, subject to the approval of the board of appeals when such buildings are judged by the building official to be safe and in the public's interest of health, safety and welfare regarding any proposed construction, alteration, repair, enlargement, relocation, and location within the fire limits. All such approvals must be based on the applicant's complete submission of professional architectural and engineering plans and specifications bearing the professional seal of the designer."18/

17/Uniform Building Code, 1976 Edition, International Conference of Building officials, Section 104.

18/Basic Building Code, 1975 Edition, Building Officials and code Administrators International, Inc. 
However, the existence of historic building code waiver provisions may not resolve the difficult problem area. As one building regulatory official has stated:

"It (historic building code waiver provision) is nebulous, arbitrary and $19 /$
in places that have adopted it, they have found it to be unworkable...."

What are the problems posed by historic building code waiver provisions? The answer to this question is not known definitely, particularly since these provisions are relatively recent on the building regulatory scene. However, it is widely suspected that there is inadequate existing technical information that would assist the building regulatory officials and others in making the critical decisions that affect safety and health on the one hand and preservation on the other. By far the preponderance of existing technical information, including the numerous building codes, referenced standards and other technical information, is oriented toward the needs of new construction rather than the needs of renovation and preservation of existing buildings. Moreover, building research, the basis of these codes and standards, has also been primarily oriented to new construction. Thus, the technical bases upon which to base decisions of safety and health in preservation, rehabilitation and adaptive reuse projects, although available for new construction, are almost totally lacking for existing building projects.

There are other perceived difficulties. Tradeoffs, the substitution of one adequate design solution for another, are rarely specified in the available technical information. Such tradeoffs would be particularly useful in existing building projects. Further, the effect of historic preservation waiver clauses on the professional liability of building designers engaged in such projects is presently unknown. Requiring the professional seal of a designer in instances when adequate technical information is lacking may well increase liability. Finally, the reliance of existing building codes on prescriptive requirements (adequate for new construction) effectively masks the intent or goal of the same regulations when applied to existing building projects. Making determinations of building safety and health under such conditions, as one senior building regulatory official has expressed it, "...is why building regulatory officials lose sleep at night."

Performance requirements, those regulatory statements that specify end objectives rather than allowable solutions, would better meet the needs of existing building projects. Performance requirements would tend to minimize the disruption of existing building elements in achieving safety and health. Unfortunately, little building research has been directed toward the development of performance requirements for existing buildings, so little information presently exists.

19/Melvyn Green and Patrick w. Cooke, "Survey of Building Code Provisions for Historic Structures," NBS Technical Note 918, September 1976, p. 22. 
Little information also presently exists on how historic preservation waiver clauses are working in practice. NBS, in cooperation with the National Trust for Historic Preservation, is undertaking a study of the effectiveness of these historic preservation waiver clauses from the preservation point-of-view. This study will select and examine selected case studies so as to document problem areas encountered and the needs for technical information. The results of this cooperative effort will be available in the autumn of 1977. Another related effort is the National Endowment for the Arts grant to Melvyn Green Associates to identify tradeoffs that could be included in building regulations so as to alleviate the conflict between the objectives of safety and health and the objective of preservation. The results of this study are expected in mid-winter.

The results of these and other studies might well indicate a need for a building standard designed specifically for existing building projects. The Douglas Commission recommended that model standards be developed for incorporation into local building codes with special reference to rehabilitation. The commission reported:

"There is widespread recognition among code experts that current code standards, which are intended for new construction, should not be applied literally to the alteration of existing buildings."20/

Although this recommendation was made in 1968, little work has been done in this area; largely due to a lack of applicable building research and technical information. However, with the recent establishment of the National Institute of Building Sciences (an organization recommended for establishment by the same Douglas Commission) and with the widespread interest in the problems of existing buildings the time may be ripe for the building community to address this subject area.

In the spring of 1976, NBS sponsored a study conducted by Baird Smith to investigate alternative methods of structuring and formatting a standard specifically designed for the needs of existing buildings. This study identified eight (8) problem areas in applying building codes to existing building projects and proposed a performance-based approach to structuring and formatting a standard designed for the needs of existing building projects. The results of this study are included as a separate paper by Baird Smith in these Proceedings of the NBS/NCSBCS Regulatory Research Conference.

Other studies have been undertaken. NBS is presently studying technological aspects for achieving neighborhood conservation. This study is being undertaken for the Department of Housing and Urban Development and will, among other subjects, examine the role of building regulations in achieving the objectives of conservation.

20/Douglas Commission, "Building The American City: Report of the National Comission on Urban Problems, "House Document No. 91-34, 91st Congress, 1st Session, December 12, 1968, p. 269 . 
Other work is being accomplished to better acquaint preservationists and others involved in reuse, rehabilitation and preservation projects with the building regulatory system and its requirements for existing buildings. The National Trust for Historic Preservation is sponsoring a special supplement to its publication, Preservation News, to acquaint its membership with building codes and historic preservation waiver clauses. The National Trust is also developing a brochure that will inform preservationists of the importance of including regulatory provisions in their building plans and the need for communications with the building regulatory official to overcome potential problem areas.

The adoption and growth of historic preservation waiver clauses, the development of similar administrative regulations and the conducing of conferences and studies on existing building regulations are relatively recent actions--most having been initiated in the last several years. These actions offer promising approaches to the problem of achieving adequate safety and health in existing building projects. Since most of this work is relatively recent, final and definitive answers have not been arrived at. To develop these final answers will require additional work and study on the part of the building community. 


\title{
INFORMATION STRUCIURE OF BUILDING \\ CODES AND STANDARDS FOR THE NEEDS \\ OF EXISTING BUIIDINGS*
}

\author{
by \\ Baird Smith** \\ Preservation Consultant \\ Washington, D.C.
}

With the increased occurrence of rehabilitation and preservation projects, the problem of code compliance for these buildings is growing in magnitude. We are no longer dealing with isolated historic buildings, but with both entire historic districts and an ever increasing number of recycled, adaptively used buildings. The problem of code compliance for these projects frequently causes the destruction of the historic integrity of the building, the replacement of serviceable materials and, at the same time, increases project costs. The compliance problems may stem from the organization and format of the model codes which are based on new construction materials and techniques. This study examines the present organization and format of the three model codes, and develops a decision flow chart which analyzes how these model codes are used. The regulatory problems facing rehabilitation and preservation projects are then reviewed. Fram this investigation, a proposed decision process, based on the needs of rehabilitation and preservation projects is developed. Such a decision process could be used if and when building regulations are developed for the unique needs of these type projects.

Key Words: Building codes and standards; building code structure; existing buildings; historic preservation; performance attributes; performance evaluation.

* Reprinted from NBS Special Publication 473, "Research and Innovation in the Building Regulatory Process;" (Proceedings of the First NBS/NCSBCS Joint Conference held in Providence, Rhode Island, September 21-22, 1976); pp. 453-489.

** Currently Mr. Smith is Preservation Architect, Preservation Services Division, Office of Archaeology and Historic Preservation, Heritage and Recreation Service, U.S. Department of Interior, Washington, D.C. 20240. 
There is currently a great increase in the amount of construction activity in the area of rehabilitation and preservation of the built environment. This effort to preserve old buildings goes far beyond the old concept of the restoration of a grand old mansion into an historic house museum. This enlarged effort, involving the whole spectrum of existing buildings, includes the rehabilitation, adaptive use and recycling of these valuable physical resources.

The term existing building is not interchangeable with the term historic building. The latter have been identified or recognized by some public or private organizations as having important historical or architectural merit. These historic buildings have been granted special consideration by two of the model building codes and by a number of State and City building codes. ${ }^{1}$ Because of their status as historic buildings, full compliance with the building code is left to the judgment of the local code official or a designated review board. The degree of campliance, for these buildings, is decided on a case by case basis. 2

This study, although concerned with those buildings, is primarily concerned with the much larger group of ordinary old buildings which do not have a historic building designation, but do face building code problems. They represent a true physical resource which people are beginning to turn to more and more to fill the need for housing, business and commerical space. These buildings are soundly constructed, but, using the current model codes, face very real compliance problems.

These problems are manifested in three camon camplaints which preservationists raise. First, they feel compliance to building codes cause the unnecessary destruction of aesthetically and architecturally important building features, both interior and exterior. Secondly, compliance seems to require the replacement of perfectly serviceable old materials with their modern counterparts. Finally, code compliance increases the cost of these rehabilitation and preservation projects without a proportionate increase in building performance. ${ }^{3}$

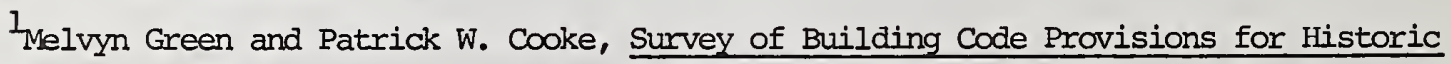
Structures, NBS Technical Note 918 (Washington: GPO, 1976), pp. 9-10.

2 For code provisions relating to historic juildings see: The Building Officials and code Administrators, Basic Building Code (Chicago: National Conference of Building Officials) Section 317; Uniform Building Code (Whittier, Ca.: I.C.B.O., 1976) Section 104 (j). 3 National Trust for Historic Preservation, Preservation and Building Codes (Washington: The Preservation Press, 1975), pp. 15-26. 
The purpose of this investigation is threefold. The basic questions of the inquiry are:

1. What is the structure of the model building codes and are they geared toward new construction projects or can they be used with similar ease with projects in existing buildings? In other words, is the structure of the codes one of the inherent causes of the problem?

2. Are standards in the codes, which are generally prescriptive in nature, applicable to existing buildings with old materials and systems?

3. Is there an alternative structure and set of standards which would more directly satisfy the conditions present with existing buildings?

The model codes with which the study concerns itself are the most recent editions of the Uniform Building Code, ${ }^{4}$ The Basic Building Code ${ }^{5}$ and the Standard Building Code ${ }^{6}$ which will be referred to as the model codes. Analysis of mechanical, electrical or other speciality codes, as well as the various State and City building codes, is beyond the scope of this study.

Certain terms used in discussing this topic need to be defined. These definitions are commonly used by those in the building regulatory process and are understood by most code officials.

Building regulations are the total set of all legal requirements which a building project must meet. These legal requirements include those promulgated by the State or local governments (usually collected together into one building code) and all other requirements--for instance, those promulgated by the Federal goverment through the occupational Safety and Health Administration and the Environmental Protection Agency.

A building requirement can be one of two types, or, what is more common, a combination of the two. They are prescriptive building requirements and performance-based building requirements.

${ }^{4}$ International Conference of Building Officials, Uniform Building Code, 1976 Edition (Whittier, Ca.: I.C.B.O., 1976).

${ }^{5}$ Building Officials and Code Administrators International, Inc., Basic Building Code/1975 (Chicago: B.O.C.A., 1975).

${ }^{6}$ Southern Building Code Congress International, Inc., Standard Building Code, 1976 Edition (Birmingham, A.: S.B.C.C., 1976). 
A prescriptive building requirement gives the allowable or permitted dimension, size, engineering type, assembly method or material which must be incorporated into the building project. These prescribe allowable design solutions.

A performance-based building requirement gives the allowable or desirable end goal to be achieved. These requirements differ from the prescriptive building requirements in that they set forth the results expected rather than the means of achievement.

A code provision is a statement in a building code setting forth a legal building requirement.

A building standard is a document, usually included by reference in a building code, covering a specific subject and developed by a nationally recognized standards organization. Two such organizations of the more than $150^{7}$ are the American National Standards Institute (ANSI) and the American Society for Testing and Materials (ASTM).

A performance attribute is a statement which indicates the desirable goals to be accomplished to satisfy certain basic human needs. Principle performance attributes include safety, health and general welfare. Other, secondary attributes, vary according to different building regulatory philosophies.

This investigation was undertaken fram the viewpoint of the designer engaged in preservation, rehabilitation or adaptive use projects. The results will tend to focus on the needs of the designer as he uses the code, not on the needs of the code official or building code producer. Hence, this study deals most directly with the decision process one follows as one uses the code when involved with code compliance in a project involving an existing building.

\section{PART I}

\section{ANALYSIS OF THE STRUCIURE OF}

THE MODEL CODES

The three model codes share the same purpose: to provide for the safety, health and general welfare of the public regarding buildings and building construction. To accomplish this, each of the codes contain building code provisions and referenced standards. These regulations govern certain physical entities of the building such as height, area, configuration, structural design criteria and materials selection. The code provisions tend to be prescriptive in that they identify the dimensions or materials which are per-

7David Falk, "Building Codes in a Nutshell," Real Estate Review, Fall, 1975, p. 83. 
mitted. Full compliance to the building codes is a fusion of the allowable physical entities, with the allowable materials, to achieve the desirable levels of performance with respect to safety, health and general welfare.

The model codes are arranged according to various chapters. Although each of the model codes have a different format and organization of chapters and provisions, the overall content and structure of the three are very similar. The decision process which the designer uses with the three is even more similar. The following discussion explains that desicion process.

USE OF THE MODEL CODES

A DECISION PROCESS

Use of the building codes begins with the determination by the designer of whether or not the project falls under the jurisdiction of the building code. All new construction and most projects in existing buildings must comply to the code. The conditions for application to projects in existing buildings using the Standard Building Code, are as follows.

\section{4 - Existing Buildings}

(a) If, within any twelve (12) month period, alterations or repairs costing in excess of fifty (50) percent of the then physical value of the building are made to an existing building, such building shall be made to conform to the requirements of this code for new buildings, also that for buildings located in fire districts the provisions of section 302.1 and 302.2 shall apply.

(b) If an existing building is damaged by fire or otherwise in excess of fifty (50) percent of its then physical value before such damage is repaired, it shall be made to conform to the requirements of this code for new buildings.

(c) If the cost of such alterations and repairs within any twelve (12) month period or the amount of damage as referred to in paragraph (b) is more than twenty-five (25) but not more than fifty (50) percent of the then physical value of the building the portions to be altered or repaired shall be made to conform to the requirements of this code for new buildings to such extent as the Building Official may determine. 
(d) For the purpose of this section physical value of the building shall be determined by the Building Official.

(e) If the occupancy of an existing building is entirely changed the building shall be made to conform to the requirements of this code for the new occupancy. If the occupancy of only a portion of an existing building is changed and that portion is separated from the remainder as stipulated in section 403, then only such portion need be made to conform.

(f) Repairs and alterations, not covered by the preceding paragraphs of this section, restoring a building to its condition previous to damage or deterioration, or altering it in conformity with the provisions of this code or in such manner as will not extend or increase an existing non-conformity or hazard, may be made with the same kind of materials as those of which the building is constructed; but not more than twenty-five (25) percent of the roof covering of a building shall be replaced in any period of twelve (12) months unless the entire roof is made to conform with the requirement of this code for new buildings.

302.1 - Existing Building Within the Fire District

An existing building shall not be hereafter increased in height unless it is of the type of construction permitted for new buildings within the Fire District or is altered to comply with the requirements for such type construction. Nor, shall any existing building be hereafter extended on any side unless such extensions are of the type of construction permitted for new buildings within the Fire District.

302.3 - Moving Buildings

Buildings shall not hereafter be moved into the Fire District or to another lot in the Fire District unless it is of a type of construction permitted in the Fire District. 8

${ }^{8}$ For reference to similar provisions in the Basic Building Code see Sections 106.1 through 106.8. See also in the Uniform Building Code, Section 104 (a) through 104 (g) and Section 105. 
Obviously, the designer has to have a pretty good idea of what work is anticipated in the existing building before he knows under which of the above cases the project falls. He would have to know the value of the building and the value of the anticipated work, whether the occupancy type were to be changed and if the height or area were to be increased.

Assuming that full compliance with the code is required, the designer begins the decision process explained here. Through this procedure, the designer will discover what actions he must initiate with respect to the building to achieve the desired levels of performance for the attributes of safety, health and general welfare. This procedure does not relate in any way to the order in which the provisions occur in the code. The procedure dictates that one jump from chapter to chapter to accomplish the task. In the Standard code and the Uniform code the procedures are well outlined. In the Basic Code, the requirements are obvious, but the procedure for use is less distinct.

The decision process explained here is a simplification and combination of the actual procedures found in the three model building codes. Although the decision process has been simplified, the concepts outlined are applicable to all three model codes.

Figure A illustrates the first stage of the decision process. In this stage, essentially, the level of risk is determined. In the two steps, the determination of the occupancy classification and the verification of the location of the building with respect to the city fire zones, the apparent level of risk is confirmed. Each of the two decision steps include code requirements which are here called primary requirements. These are requirements which are peculiar to the occupancy type and the fire zone and account for the degree of risk. The occupancies with the highest risk have the most restrictive primary requirements, as does the fire zone nearest the center of town.

These primary requirements can restrict the type of construction used, limit the building height or area or require fire extinguishing or fire alarm systems. As a rule, these primary requirements are of a general nature, establishing the allowable building size, configuration and type of construction. The detailed requirements which further define the physical entities came later in the decision process.

After that stage, the decision process moves into the second one, as shown in Figure B. This stage is one in which the physical entities are fully defined to bring building performance to a level high enough to counter the level of risk confirmed through the choice of occupancy in the first stage.

The two decision steps of this stage include the determination of the type of construction and the determination of the allowable height and area. The type of construction fixes the allowable degree of combustibility of the structural components. The structural frame, and the floor, wall and ceiling assemblies comprise the components. 


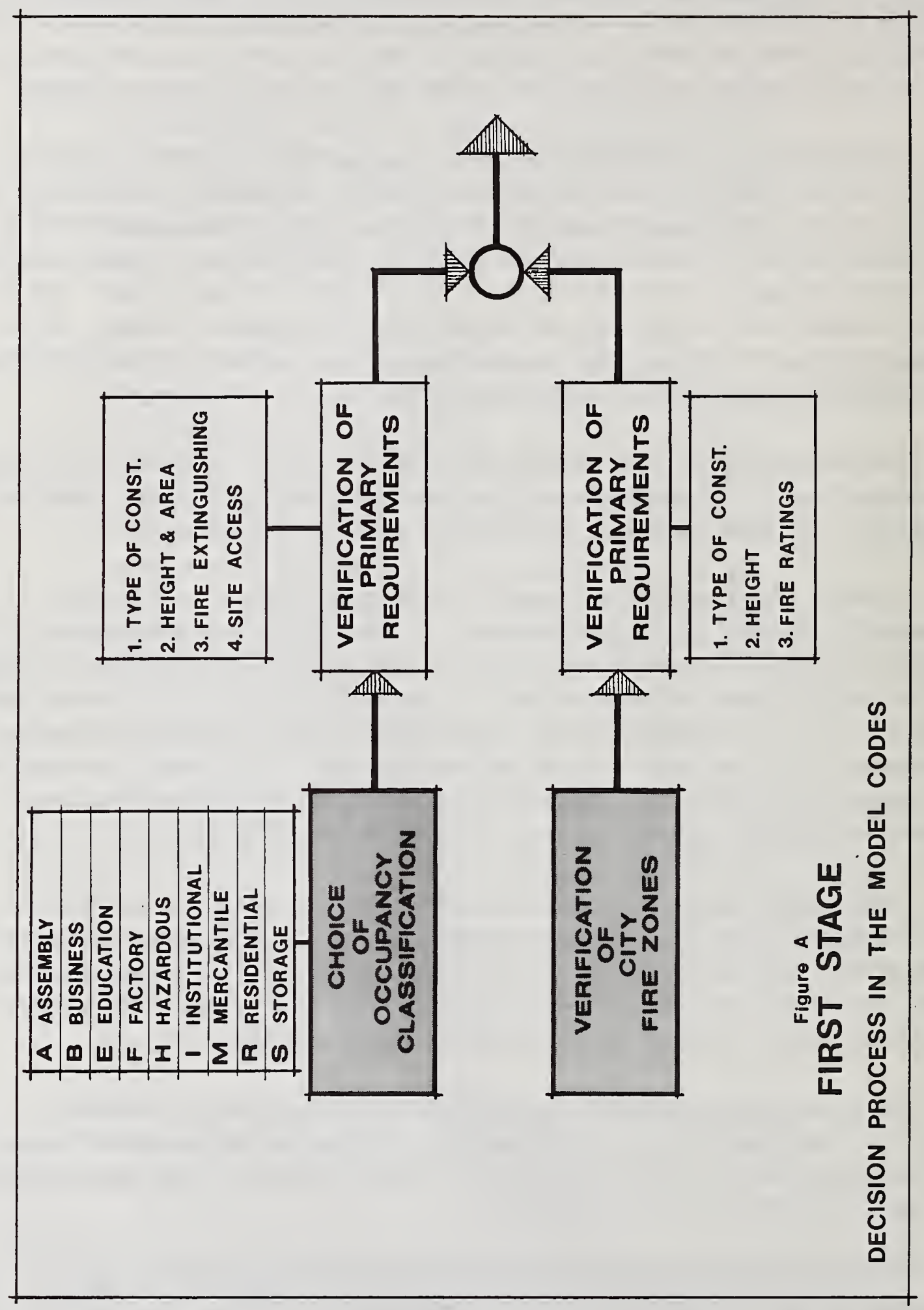




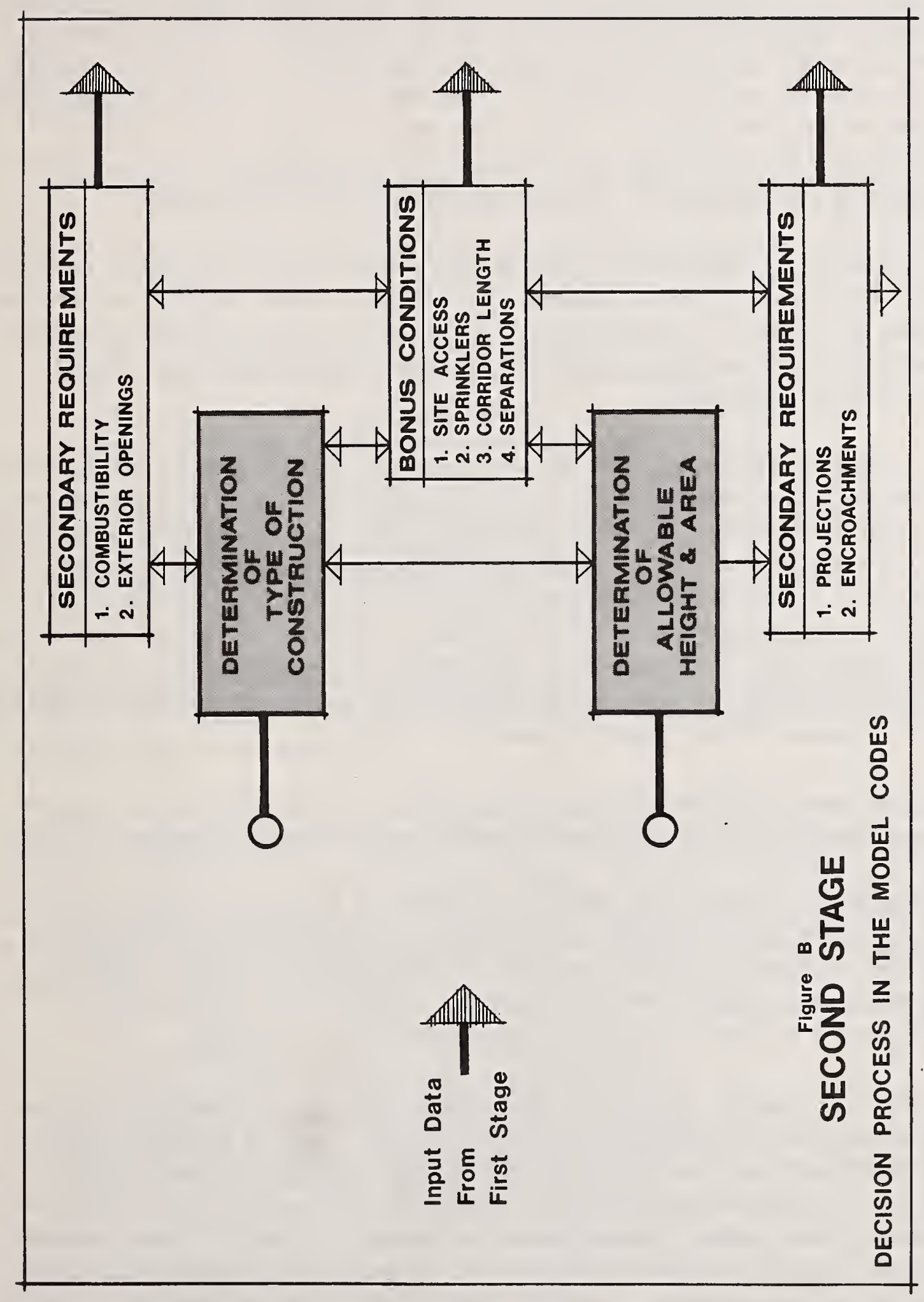


Although each of the model codes differ on how many types of construction there are, each does have a specific definition which identifies the required fire resistivity of the structural components. The allowable height and area are given in a table in the codes which compares the occupancy classification (apparent risk) with the type of construction (apparent building performance). As the height and area increase, the risk factor increases which requires an equivalent increase in the performance of the building, hence the degree of non-combustibility for the type of construction is increased.

If the type of construction and the building height and area were primary requirements of the occupancy, then the designer in this stage is merely verifying the detailed requirements of the type of construction. If that is not the case, he can use the tables for allowable height and area, to determine what type of construction he must use to attain a pre-determined area.

The final determination of the allowable building height and area is complicated with a set of bonus code provisions which allow an increase in the height or area if the overall building performance is increased accordingly. This increase is allowed if a physical entity, a trade-off, is added to the design. A good example of a common trade-off is the addition of a fire extinguishing system. With its installation in a building which was not required to have such a system, the codes permit a doubling and in some cases trebling of the building area. This trade-off is recognized as increasing the building safety performance, therefore, an increase in building area is awarded which brings the building into a new balance of risk versus performance.

Other bonus conditions include increasing access to the building site from public roadways, reducing corridor length and increasing the fire separation between buildings.

This stage has accomplished two important facets of the decision process. By establishing the allowable height and area and the type of construction, the building codes have, in effect, determined basic design criteria for the designer. Secondly, these two entities together contribute directly to achieving the desired level of performance for the attribute safety, or more specifically, fire safety.

The third stage of the process is essentially comprised of the many detailed code requirements which further define the physical entities. Some are directed toward the performance attribute of safety, while the others are to satisfy the requirements for the attributes of health and general welfare. The decision process given here has created groupings of these secondary, miscellaneous requirements. In reality, these provisions are spread throughout the model codes and often the performance attribute which they satisfy is not distinguishable. Grouping these provisions together does help to clarify the decision process. 
Figure $C$ illustrates the three decision steps of this stage. The first is the verification of safety requirements. The physical entities which are included in this element are: the fire resistivity of the surface materials, the number and size of the exits and a multitude of miscellaneous provisions which dictate various methods of construction.

These secondary requirements are largely made up of detailed concise prescriptive statements. For instance, the following floor assembly will achieve a one hour fire endurance rating. Principle materials are steel joists, concrete and acoustical ceiling tile.

Top slab - 2" concrete over 10" bar joist spaced 24 " O.C. Ceiling - Main tees are spaced 48 " or $24 "$ o.c. and supported by hanger tee wires. Cross tees are spaced 24" O.c., perpendicular to main runners. The system supports $1 / 2 "$, $24 "$ x 24" or 24" x 48" acoustical lay-in panels. Protected light fixtures may be installed in ceiling not to exceed $8 \%$ of ceiling area. Air duct openings not to exceed 25 square inches per 100 square feet of ceiling area. Listed by U.L. under Design No. 43-1 Hr., U.L. Test No. R4349. ${ }^{9}$

This perscriptive requirement indicates the material type, size, assembly method, the allowable light fixtures and air ducts and provides the reference for the standard and test which certifies the performance.

Also, in this third stage are the requirements to satisfy the performance attributes of health and general welfare. The former includes requirements for adequate heat, sanitation facilities and access for the handicapped. The latter includes requirements for adequate light, ventilation and the durability of materials. These requirements are also detailed, concise prescriptive statements. The following is the requirement to provide adequate light and ventilation.

All enclosed portions. . . used by human beings - . shall be provided with natural light by means of exterior glazed window openings with an area not less than one-tenth of the total floor area, and natural ventilation by means of openable exterior openings with an area of not less than one-twentieth of the total floor area or

${ }^{9}$ S.B.C.C., Standard Building Code, Table 7, p. B-35. 


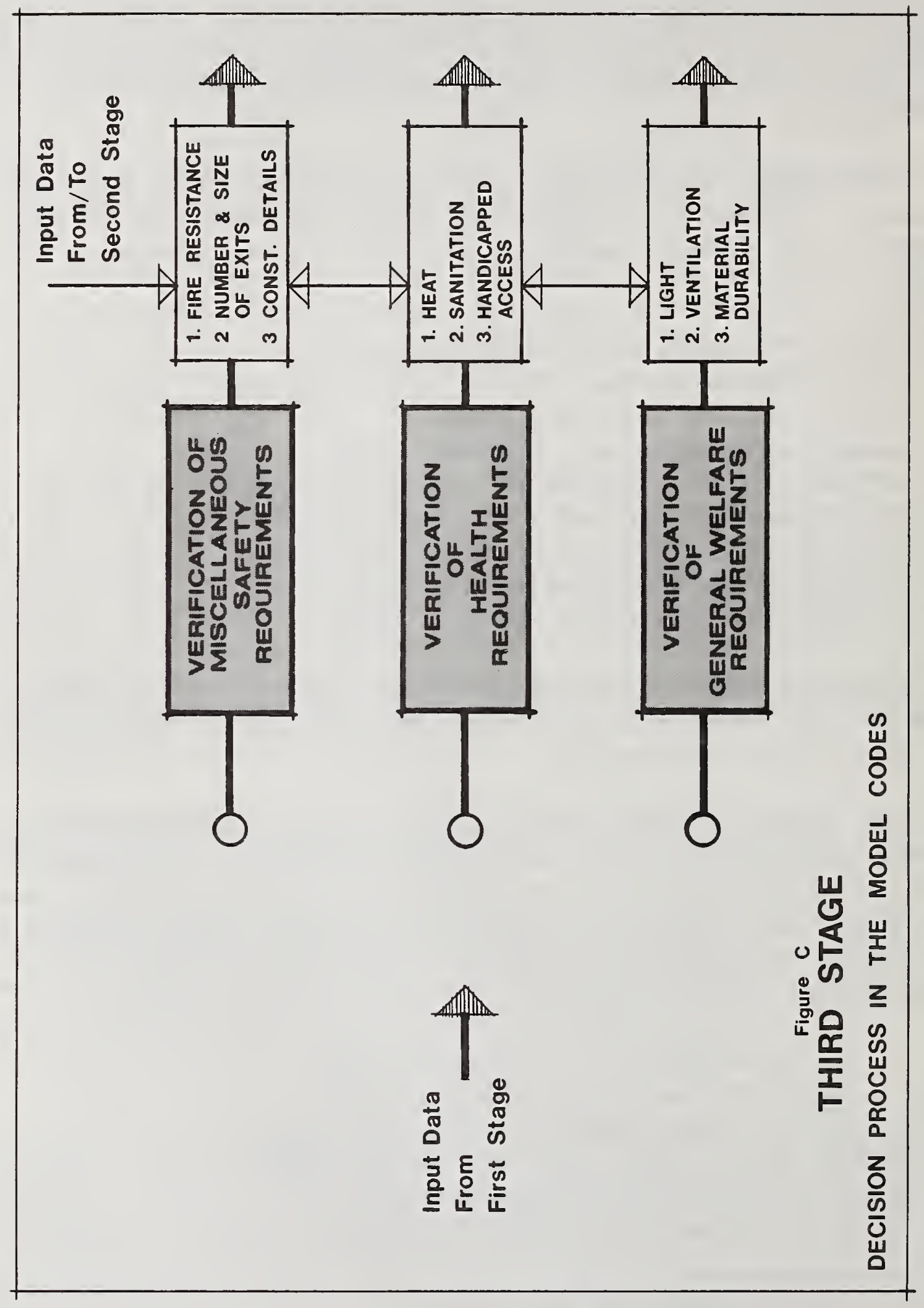


shall be provided with artifical light and a mechanically

operated ventilating system. ... 10

This and other prescriptive requirements are to satisfy the performance attributes of health and general welfare.

The entire decision process is shown in Figure D. The first stage was essentially a complete definition of the occupancy classification which confirmed the apparent level of risk. The second stage was camprised of design criteria which established the overall building size and the type of construction. In the third stage were the secondary, prescriptive requirements which fully defined all the physical entities of the building. The process moves from the general to the specific. First dealing with overall building size and ending with the minutest details of the building materials, assemblies and systems. It has yielded a multitude of prescriptive requirements which would be incorporated into the building design.

The end result is a building, still in the form of drawings and specifications, which fully satisfies all requirements.

This analysis has presented the structure and the decision process involved with using the model codes. Up to this point, this discussion has not indicated the various problems which existing buildings face in code compliance. A full understanding of how building codes work was necessary before the problems which existing buildings face could be dealt with. The following discussion attempts to answer the questions which prompted this investigation.

\section{PART II}

\section{PROBLEMS WHICH EXISTING BUIIDINGS}

FACE IN CODE COMPLIANCE

There are a number of problems which existing buildings face in relation to the building codes. These problems relate to the structure, the decision process and the code standards. The major problem areas follow.

1. The performance levels which a building must meet have risen throughout this century.

Many existing buildings were built to comply with performance levels which are now well below the required level.

${ }^{10}$ I.C.B.O., Uniform Building Code, Section 605, p.62. 


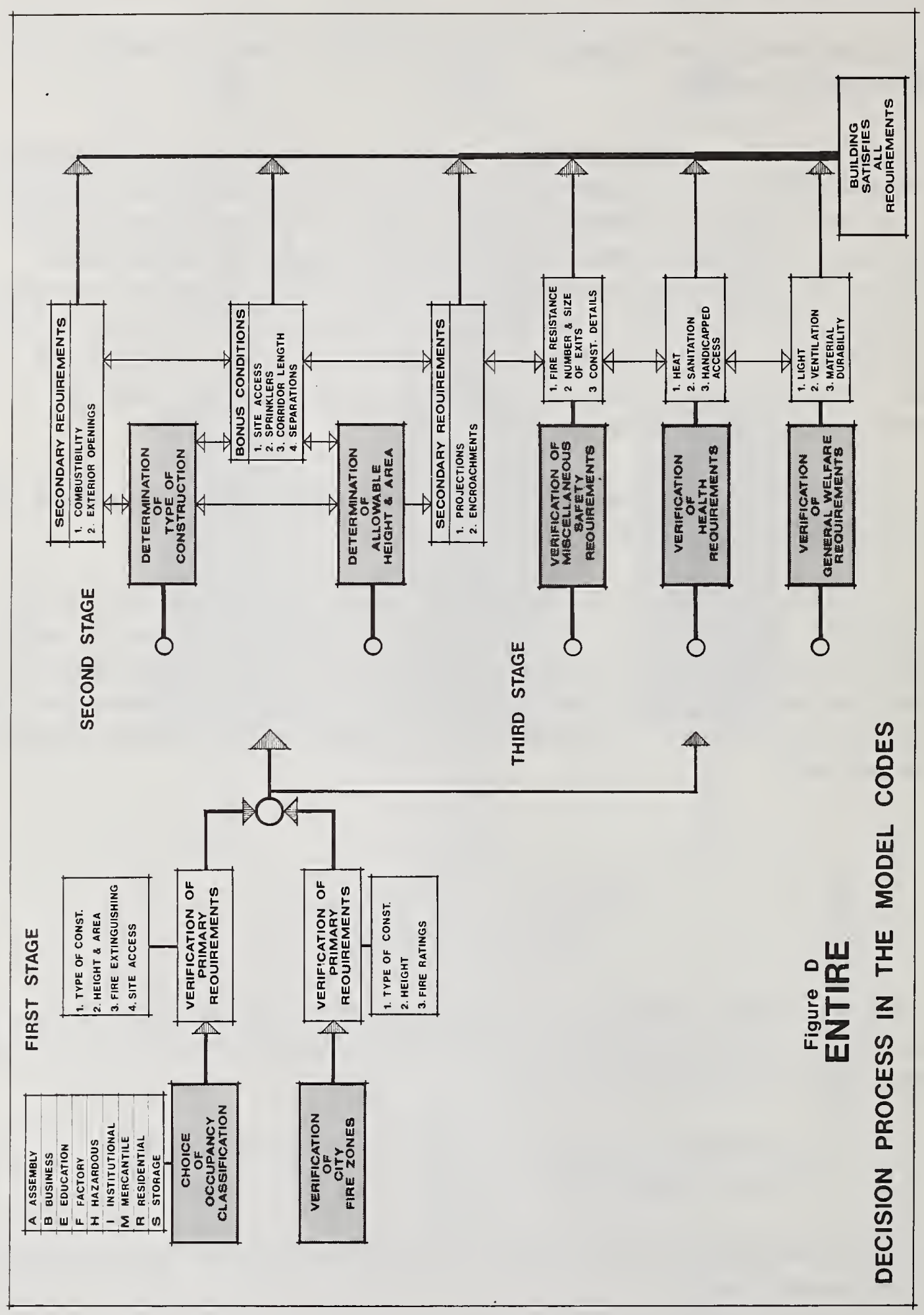


One good example is with the sizes for beams and girders permitted in heavy timber construction. In 1920, a minimu cross-sectional area of thirty-six square inches was required in the Building Code of the National Board of Fire Underwriters. ${ }^{11}$ This minimm rose to forty-eight square inches in the 1937 edition of the Uniform Building Code ${ }^{12}$ and the same code now requires a sixty square inch minimum. ${ }^{13}$ This is a clear example of the significant increases in the minimu levels of performance which have occurred.

2. New performance attributes have been added to the codes for which there are new building code requirements.

Existing buildings must conform to the requirements for newly added attributes such as convenience, (i.e., access for the handicapped) and economic welfare (i.e., conservation of energy and the durability of materials). Since these standards were not in effect until recently, vast numbers of existing buildings would not comply with these new requirements.

3. As new performance attributes were added to the model codes, problems resulted.

Specifically, the model codes do not fully recognize that some performance attributes may actually be in conflict with each other. For example, materials which are flame resistant and meet the standards for fire safety may not begin to meet the standards for energy efficiency or durability. The model codes may not have a mechanism to fully integrate the performance attributes with each other.

4. The decision process of the model codes is applicable only to new construction and does not lend itself to projects in existing buildings.

The model codes achieve the required levels of performance for the attributes of safety, health and general welfare through a process where physical entities (i.e., building height, area, configuration, structure, materials, and systems) are varied in relation to each other to reach a level of building performance. This complete flexibility, to alter any of the physical entities, is possible only in new construction, but does not in any

${ }^{11}$ National Board of Fire Underwriters, Building Code, Fourth Edition, 1920 (New York: N.B.F.U., 1920), Section 105.

${ }^{12}$ Pacific Coast Building Officials' Conference, Uniform Building Code, 1937 Edition (Los Angeles: P.C.B.O.C., 1937), Section 1908. ${ }^{13}$ I.C.B.O., Uniform Building Code, Section 2106 (c), p. 122. 
way correspond to the conditions present with existing buildings, since the physical entities there are largely fixed.

Secondarily, the designer involved with an existing building must use the model codes as if the project were new construction. He must plow through the decision process, trying to determine which provisions are applicable. He may find applicable provisions under the occupancy type, under the type of construction, under engineering regulations, detailed regulations, special regulations or miscellaneous requirements. It is a constant searching effort to determine the requirements.

Perhaps the greatest problem for existing buildings is that there is not a sound method for evaluating the existing level of performance. This is because the building standards are related to the construction of new buildings. The following are characteristics of these standards which create problems for existing buildings.

5. The various prescriptive standards of the codes are based on modern materials and do not include information about older materials.

These prescriptive standards are based on modern materials in common use today. Older materials and assemblies like cast iron, early steel and concrete sections and many early varieties of wood are not included. Many architects and code officials assume that they would not meet the standards given for new materials. Hence, they are often replaced with modern counterparts.

Apparently, as codes have been revised through the years, older materials were dropped from the standards and replaced with modern ones. A good example is wooden lath and plaster.

Information about this wall assembly is not included in any of the model codes. However, a review of out-of-date building codes yields the following. Wooden lath was not allowed in any construction as early as 1920 based on compliance to the National Board of Fire Underwriters Building Code, ${ }^{14}$ nor was it allowed in the 1937 edition of the Uniform Building Code. ${ }^{15}$ However, it was allowed in certain cases in the 1950 Building Construction Code for New York City ${ }^{16}$ and the 1953 edition of the Southern Standard

14.J.B.F.U., Building Code, Section 190.

15P.C.B.O.C., Uniform Building Code, Section 1916.

${ }^{16}$ C. W. Starbuck, Building Construction Code of New York City, Second Edition, 1950 (New York: C. W. Starbuck, 1950), Section 8.4.10.1, p. 164. 
Building Code. ${ }^{17}$ These facts don't mean much in themselves, except that they point out certain regional differences in the uses of wooden lath and plaster.

A startling fact about wooden lath is in a 1942 publication of the National Bureau of Standards entitled Building Materials and Standards. ${ }^{18}$ In this report, which includes extensive tables of the fire resistivity of a broad range of materials, one can find the ratings for wooden lath and plaster. According to those tests, made in accordance with ASTM standards, one-half inch of gypsum or lime plaster on wooden lath on either side of a $2 \times 4$ wood stud wall is given a one-half hour fire resistance rating. If the void in the wall is filled with mineral wool, the wall is given a one hour rating. The fact that wooden lath and plaster has been reported to achieve a one hour rating is certainly important for existing buildings and it is unfortunate that it is not present in the model codes.

6. The various prescriptive standards are based on what might be called standard modern building configurations.

At the top of the list for this item is the requirement that all interior exit corridors, stairways and doors be 44 " wide for most buildings. ${ }^{19}$ This minimum standard has been proved to be of little relationship to the performance which is desired, that is, the safe evacuation of the building occupants. 20 However, this standard is rigidly enforced for existing buildings, causing extensive remodeling or the entire replacement of serviceable stairways and doors which only lacked a few inches of width.

\section{Reference standards make it difficult to determine exactly what is required.}

Reference standards are a necessity with more than 150 organizations producing standards. In new construction, there is little problem because the required standard is merely included in the contract specifications. However, where existing materials are in

${ }^{17}$ Southern Building Code Congress, Southern Standard Building Code, 1953 (Birmingham, Al.: S.B.C.C., 1953), Section 1803.2.

${ }^{18}$ National Bureau of Standards, Building Materials and Standards, National Technical Information Services, COM-73-10974 (Washington: GPO, 1942), p.34. ${ }^{19}$ B.O.C.A., Basic Building Code, Sections 610.3, 616.2.1, 616.6.1.

${ }^{20}$ J. L. Pauls, "Evacuation and Other Fire Safety Measures in High-Rise Buildings," Research Paper No. 648 of the Division of Building Research, National Research Council of Canada. Reprinted fram ASHRAE Transactions, 1975, Vol. 81, Part 1, p. 530. 
question, it is frustrating for the designer when he comes to a reference standard. For instance, if the designer is trying to detemine if wall plaster on wooden lath meets the code requirement, he finds the statement. 'Interior gypsum plastering shall be done in accordance with the procedures as set forth in "Specifications for Gypsum Plastering, ANSI A 42.1'."2l The reference standards cause problems because the referenced standard may not be available locally or, even if available, adequate testing facilities may not be.

8. Information which is included about older materials, specifically fire endurance ratings, may not be an accurate indication of the performance of the material.

Take, for instance, the fire endurance ratings given to structural systems based on the standard fire test methods. In these tests, most columns are tested with a minimm length of nine feet. These columns and floor framing systems are typically tested in chambers with a floor to ceiling dimension of about nine and a half feet, closely approximating modern structural configurations.

There would seem to be a problem with these test configurations based on the research of a Canadian, T. Z. Harmathy. ${ }^{22}$ He reports that room size during a fire is one of the major factors in fire severity. His studies show that high ceilings actually contain the fire, creating a compartment, while low ceilings tend to force the fire out through openings. Therefore, it would seem, that since existing buildings often have ceilings of from twelve to sixteen feet, many of the structural systems and materials now rated with very low fire endurance ratings, may actually perform at a level significantly higher.

These materials and systems need to be retested in the configuration in which they are used, that is with twelve and sixteen foot ceilings, not in standard modern configurations.

The previous discussion reveals several facts. The decision process and the prescriptive building requirements of the model codes are most applicable to new construction. This process does not readily fit projects in existing buildings and the information about older materials and assemblies is either missing altogether or inaccurate. This lack of applicability to existing buildings does not necessarily mean that the model codes need to be revised. They certainly meet the needs for new construction. What is needed is a building code or standard which is based on the special conditions and needs of existing buildings. A proposed concept for that new code follows.

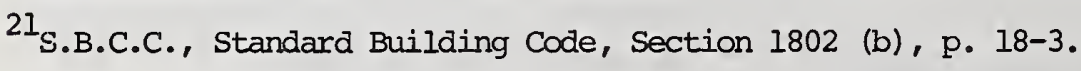

22 T. Z. Harmathy, "Design Approach to Fire Safety," Progressive Architecture, April, 1974, p. 85.
} 
Existing buildings need a building code or standard which would achieve the following. First, provide a decision process which directly relates to the conditions present. Secondly, provide a decision process which includes a mechanism to recognize and improve deficiencies and, lastly, to provide a method for the thorough evaluation of existing materials, assemblies and systems and to provide extensive information about the physical properties, fire resistance and other performance data to aid in the full evaluation. The highest priority would be to achieve the same levels of performance which are now required for new construction for projects in existing buildings.

The structure and decision process for the new code presented here is just a concept and outline. More study and investigation must be undertaken to fully test this decision process for various buildings and to fill in the numerous gaps in what is now the skeleton of an idea. This new code or standard is perceived to be a companion document to the model codes. Whether it is for national use, regional use, or to piggyback the model codes, is a policy decision beyond the scope of this investigation. This is a concept which requires, and deserves, more development.

\section{A POSSIBLE STKUCTURE OF THE NEW}

\section{CODE OR STANDARD}

The basic principle of the new code is that performance of an existing building cannot be based on the manipulation of building height, area, type of construction and choice of materials as is now required by the model codes. Rather, the new code will evaluate the performance of the existing building with respect to performance attributes and require that performance which is below the accepted levels be improved to a satisfactory level. A fuller understanding of the performance attributes is required, therefore, a discussion of that point follows.

There are three fundamental performance attributes: safety, health and general welfare. These can be further defined with the addition of eight secondary attributes. Under safety would be fire safety, structural safety and accident safety. Health would include the attributes of comfort (i.e., heat and sanitation) and convenience (i.e., access for the handicapped). Social welfare (i.e., light and ventilation) and economic welfare (i.e., conservation of energy and durability of materials) and historic preservation (i.e., retention of important building features) would be included under the attribute of general welfare. 
Historic preservation is included as a performance attribute because it should be viewed in the same manner as the rest. After all, society is now demanding that old buildings be retained because of their value as a physical resource and that important building features be preserved because of their contribution to our cultural and aesthetic heritage. For these reasons, historic preservation should be included as a performance attribute which must be achieved through a building code.

The structure of the new code is based on building occupancy and would use the same definitions as in the model codes. However, each occupancy would not have a listing of primary requirements, rather, each occupancy would have certain required performance, unique for that occupancy, for the eight performance attributes. This level of performance would be determined through the evaluation of certain physical parameters. A physical parameter is not a code requirement, it is a physical entity which, when measured, indicates the level of performance for that one aspect of the performance attribute. The parameters are the recognizable, principle factors for performance in an attribute.

An example of the use of physical parameters as the measure of a performance attribute can be seen in a publication from the Center for Fire Research, Center for Building Technology, NBS, entitled, "A System for Fire Safety Evaluation in Health Care Facilities." 23 To evaluate performance for the attribute of fire safety, the center created this list of thirteen physical parameters. 24

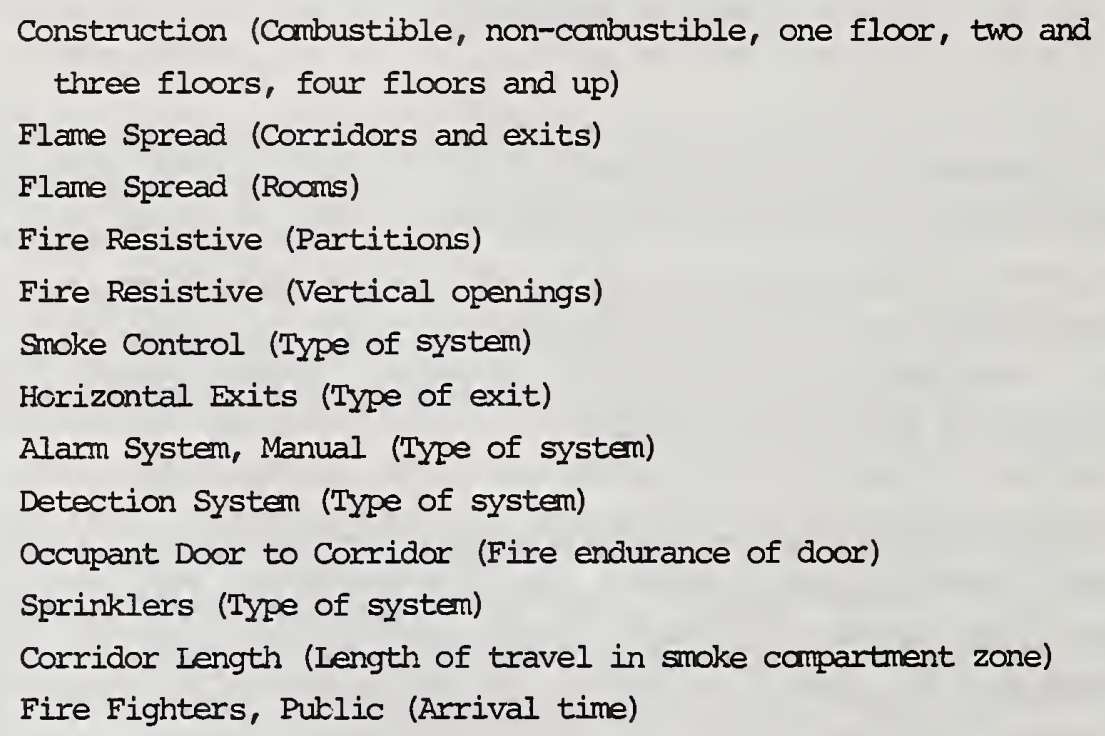

23 A. J. Shibe, I. A. Benjamin, H. E. Nelson and M. J. Slifka, "A System for Fire Safety Evaluation of Health Care Facilities," Draft report, Center for Fire Research, National Bureau of Standards, July, 1976, p. 6. 
Each of these parameters has a definition and a set of measured physical entities which describe the parameter. For instance, for the parameter corridor length, the following five entities are given: dead end with three doors, length greater than 150 feet, length between 150 and 100 feet, length 100 to 50 feet, and length less than 50 feet. These are arrangs from the least safe condition, the dead end, through a range of conditions to the safest condition. The middle condition, length of travel from 150 to 100 feet, is the minimum level required by the model code. This becomes the baseline for determination of the degree of performance for the parameter.

To determine the performance for the attribute, a weighted numerical value, of from -10 to 10 , is attached to each of the physical entities which describe the parameter. ${ }^{25}$ When the values which correspond to the various measured physical entities are added together, the level of performance for the attribute is established. Those parameters which exceed the baseline value have the effect of bringing up the performance level of the deficient ones. This means that the performance for the attribute can be at the required level while at the same time having certain individual parameters which are below the baseline value.

This method, which evaluates the performance of the attributes through the evaluation of physical parameters, is the principle concept of the new code or standard presented here. This new code would be arranged according to the various occupancies. The following is a skeleton outline for one such occupancy which includes a definition and a listing of the eight attributes, each with a set of physical parameters.

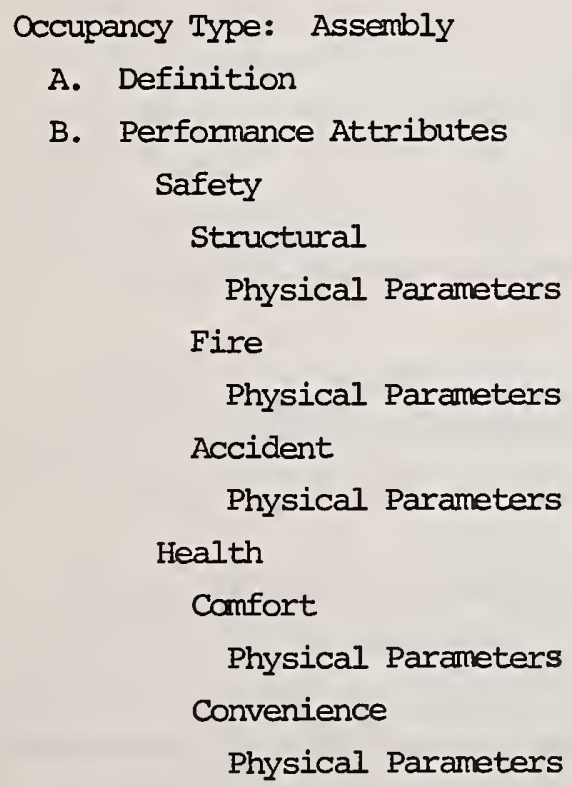

${ }^{25}$ Ibid., p. 21. 
General Welfare

Social

Physical Parameters

Economic

Physical Parameters

Historic Preservation

Physical Parameters

Each occupancy type would have a different listing of the physical parameters. Some parameters would be found in all the occupancies, others would be unique for specific ones. The occupancies which represented the higher level of risk would include physical parameters with proportionately higher baseline values. Thus, the resulting building performance could be matched to the apparent level of risk relative to a given occupancy.

HOW THE NEW CODE OR STANDARD MIGGHT

BE DEVELOPED

This report is not intended to be the definitive work on the subject, but rather, is largely intended to spark further research and development. This study could be developed into technical criteria through research under the auspices of perhaps the National Bureau of Standards of some outside research organization. This research would include:

- Determining the physical parameters to accompany each performance attribute.

- Determining the baseline values of each parameter by translating the performance level from the prescriptive requirements of the model code.

- Matching the baseline values to the apparent level of risk represented for each occupancy type.

- Interpolating these baseline values so that the performance level for each performance attribute is established.

- Integrating the performance attributes with each other to ensure that incompatibility and conflicts are reduced to a minimum.

Once this technical criteria is solidified, it could be transformed into one or more final documents by the appropriate technical committees of the voluntary consensus standards organizations, by the code change hearings of the model building codes or, possibly, by the National Institute of Building Sciences (NIBS). 
In addition to the full development of the occupancy performance requirements mentioned above, there needs to be an extensive effort to determine the physical properties, fire resistance and performance data on the various materials which are used in old buildings. This could include the many types and configurations of early structural systems; i.e., heavy timber, cast iron, steel and concrete. Also, many surface materials need to be evaluated, such as typical early plaster on wooden lath, wooden paneling, wall papers and fabric wall coverings. Certain historical devices such as dumb waiters, cage-type elevators, gas and oil lamps and a multitude of early industrial machinery should be investigated with clear, fresh thinking.

Some of this data can be uncovered through research into old building codes, standards and test data. Other information must be obtained through retesting. Since there will be little economic incentive for private industry to undertake these efforts, it will probably fall to a govermental agency such as the Department of Housing and Urban Development or the National Bureau of Standards to sponsor the necessary research and material testing.

HOW THE NEW CODE MIGHT BE USED: THE DECISION PROCESS

With the fundamental structure and concept outlined, the decision process involved when using the new code or standard can be presented.

The new code or standard would be used in any project in an existing building. Therewould be no preconditions for value of work, change in occupancy or increase in size. It is presumed that the new code or standard would be used in the preliminary design stages by the designer. The first is shown in Figure $\mathrm{E}$. In this stage the designer chooses the applicable occupancy classification and familiarizes himself with the physical parameters and the physical entities of each to be measured. The designer is essentially verifying what work he will do in the next stage.

The next three stages of the process would be undertaken for each of the eight performance attributes independently. The process separates the attributes and concentrates on satisfying the requirements of each one, one at a time.

The second stage, as shown in Figure F, includes three functions. Given the listing of physical entities for each parameter from the first stage, the designer must: identify each physical entity to be evaluated, (2) measure the performance of each and (3) evaluate the performance of each. 
In the identification function, the architect isolates which physical entities are in question for each parameter. For instance, in the earlier example of the corridor length, the designer would establish which corridors would be evaluated to fulfill the definition of the parameter.

The second function is to measure the performance of the physical entity. Performance information for numerous materials and assemblies will be included in the new code. Thus, the performance for many of the parameters can be determined either by direct measurement or by locating the value in an accompanying table.

Some of the parameters lend themselves to on-site testing or measuring. The performance of existing exit facilities, for instance, can be measured through certain test methods developed by J. L. Pauls in Canada. ${ }^{26}$ He has developed many methods for testing how fast people exit buildings under different conditions and with various stair configurations. The parameter for exit facilities would therefore measure how many people could evacuate the building in a fixed amount of time. Each exit facility would be measured to determine those values.

Many other on-site tests could be developed that could capitalize on the fact that the building is in place. For instance, the loading capability of structural frames can be verified and/or tested through a combination of on-site loading and analytical procedures. Thermal conductivity of walls and air leakage can be measured and a measurement can be developed which evaluates the capability of public fire fighters to effectively answer a fire call. These on-site test methods and others could be developed into standard test' methods for existing buildings and would become an important and unique part of the new code or standard.

The third function of this stage is to evaluate the performance of each parameter. This means that the performance measured in the previous step is now compared to the baseline value. The performance for each parameter is thereby determined to exceed, be equal to, or less than the baseline value. This data is carried on to the next stage.

In this stage of the process, as shown in Figure G, the designer determines the performance level for each of the performance attributes based on the performance of the individual parameters. Using the numerical tabulation method identified earlier, the weighted values for each parameter are added together. The resulting performance level of the attribute is thus a combination of the high and low performances of the parameters which make up that attribute. With this last evaluation, the levels of performance for all eight attributes will have been determined. Those attributes which meet the required

26 J. L. Pauls, "Evacuation in High-Rise Buildings," pp. 529-531. 


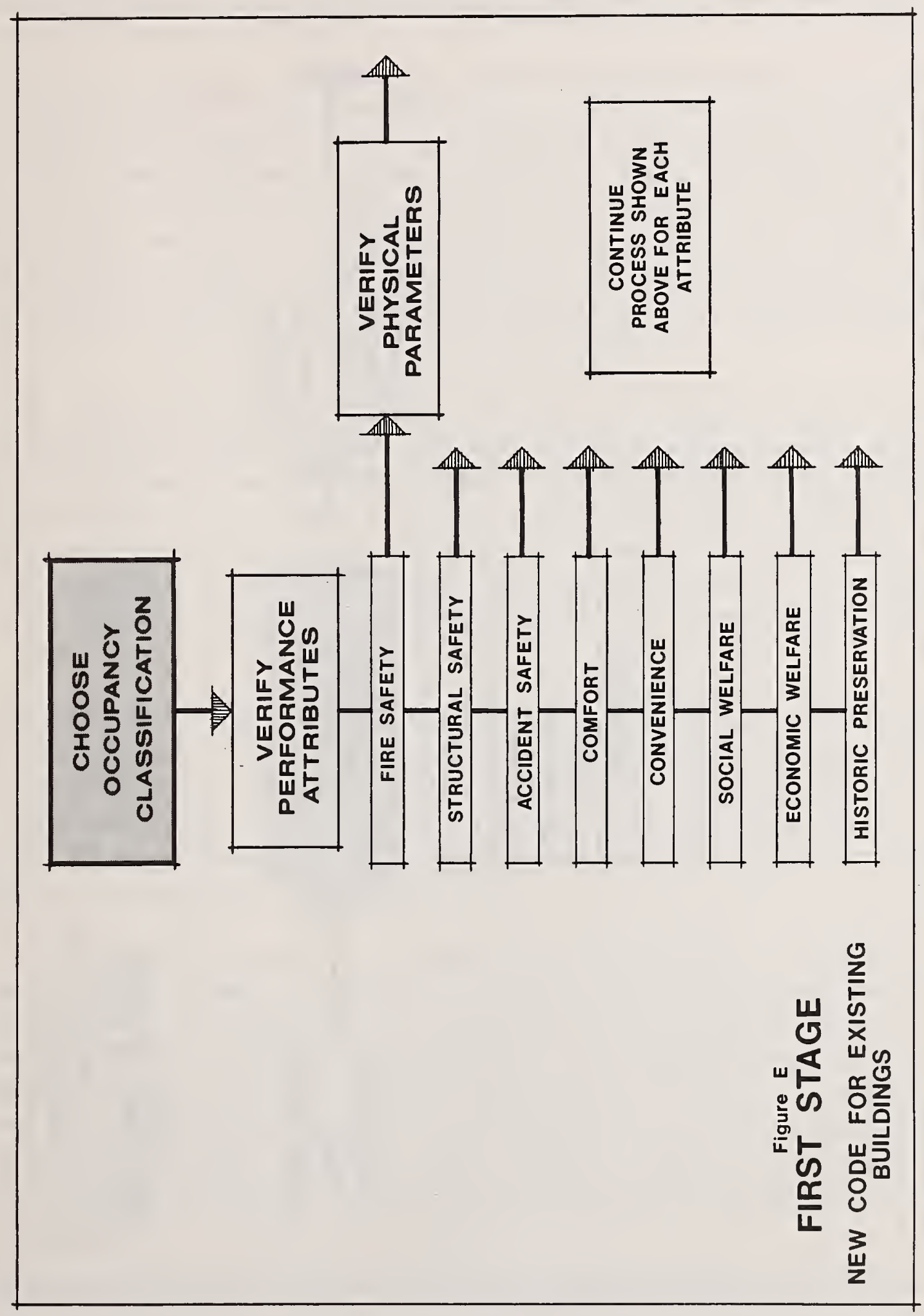




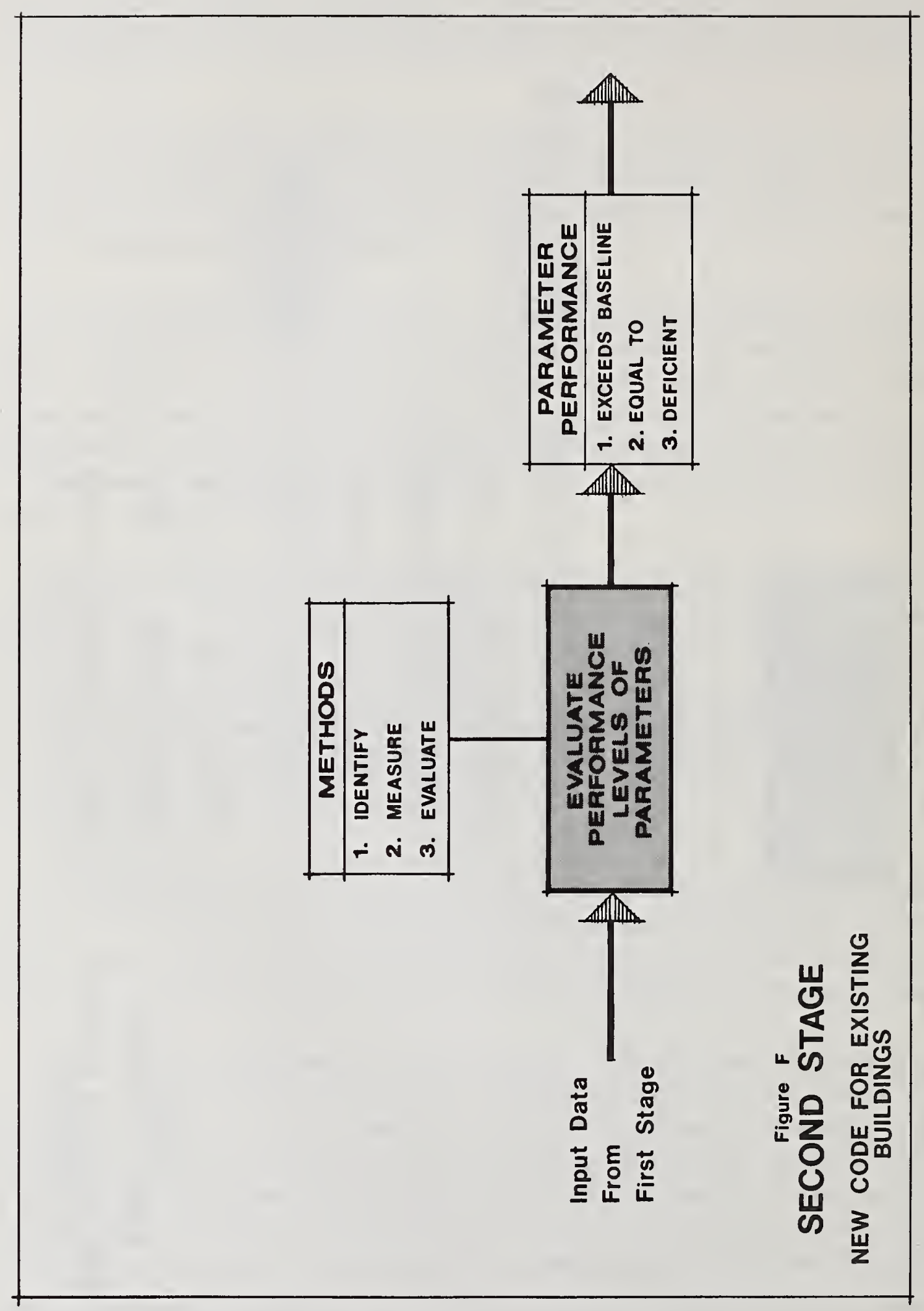


level of performance will not need remedial work. Those which are below the required level, will receive further attention through an improvement method outlined in the next stage.

The fourth stage, as shown in Figure $\mathrm{H}$, includes a mechanism by which the deficiencies can be improved to reach a minimum performance level. Normally, the designer would reanalyze the deficient parameters. In many old buildings, these deficiencies would probably include open wooden stairs, corridor partitions which did not have the necessary fire resistance, exit doors which were not fire resistant, or for instance, an overall low level of illumination. The designer could either improve the deficiency directly, using whatever modern materials and methods he chose, or in the case of the open wooden stair, for example, he could possibly increase the performance level of one of the other parameters under the safety attribute to produce the necessary counterbalancing affect.

This action to improve another physical parameter to counterbalance a deficient one can be accomplished through the addition of trade-offs. These physical entities, when added to the building, increase the performance of a specific parameter and ultimately of a performance attribute. The degree to which the trade-off will increase the performance is poorly understood at this time. One trade-off which is recognized now by the model codes is the addition of a fire extinguishing system. Most code officials will agree that this will counterbalance deficiencies in safety performance, but a quantitative value for this degree of improvement is not known at this time.

The whole topic of trade-offs warrants a good deal of investigation. Trade-offs seem to fall into two groups. The first are sometimes referred to as technical trade-offs. These include the addition of a physical entity to the building. Some items which fall into this category, besides fire extinguishing systems are: smoke detection, heat detectors, the sophisticated alarm communications systems, and chemical treatments which increase the fire resistivity of materials.

The second type of trade-off is the concept of operational controls. Generally this implies the control, guidance or manipulation of people in a building to ensure that if a disaster strikes, such as fire, that the minimum loss of life would occur. These can include the limiting of the number of people allowed in a given space, the training of the occupants in evacuation methods, or the acknowledgement that persons who are habitually in the same space, become familiar with the exit facilities and can exit more quickly than strangers could. Operational controls are, thus, a method of controlling the occupancy of certain portions of the building. Essentially, by controlling the occupancy, the apparent risk for that part of the building is controlled.

These controls have to be tested and given same quantitative value so that their counterbalancing effect on a deficiency can be known. Currently, the model codes recognize very few operational controls. The latest National Building Code, however, does permit one 


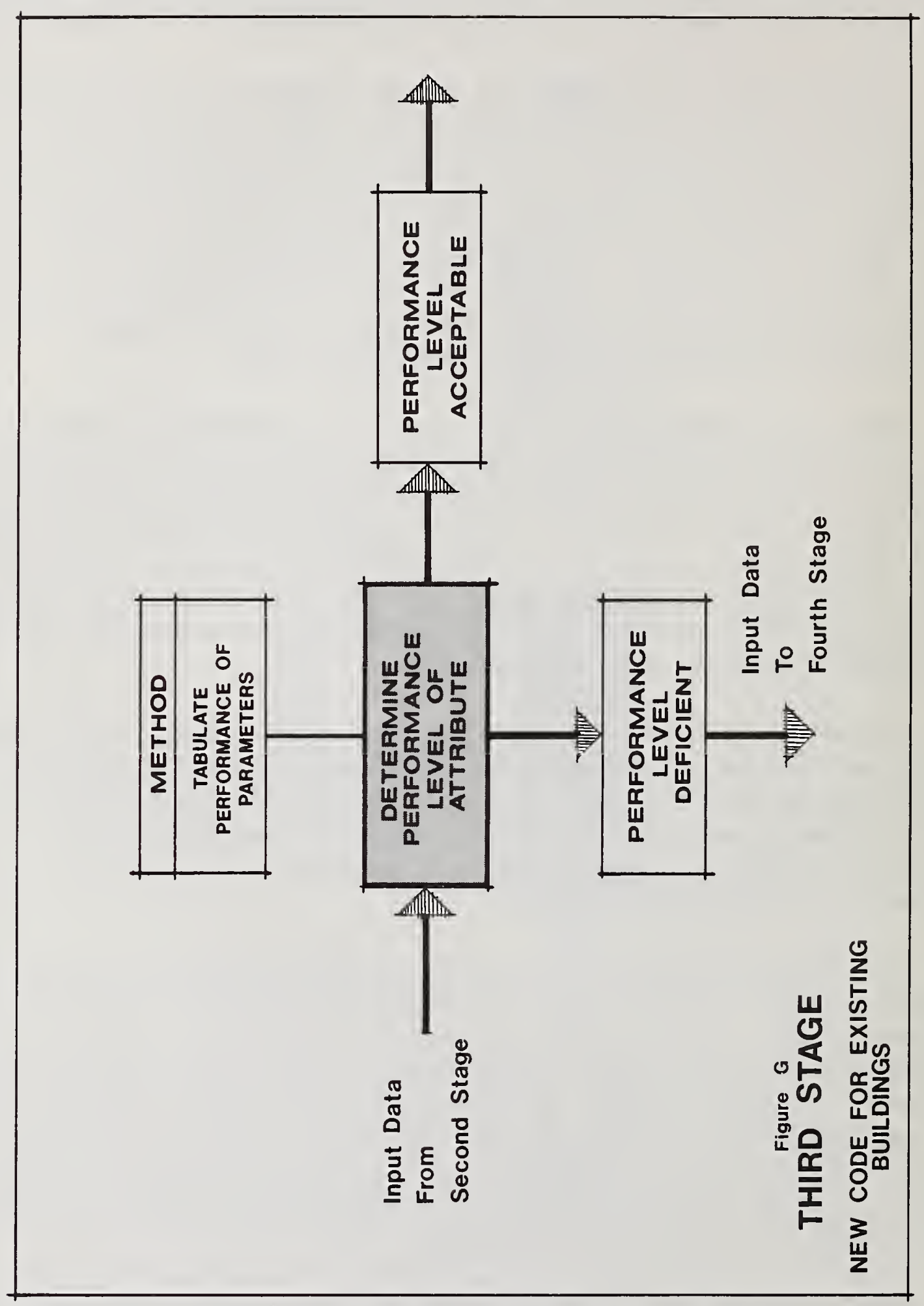




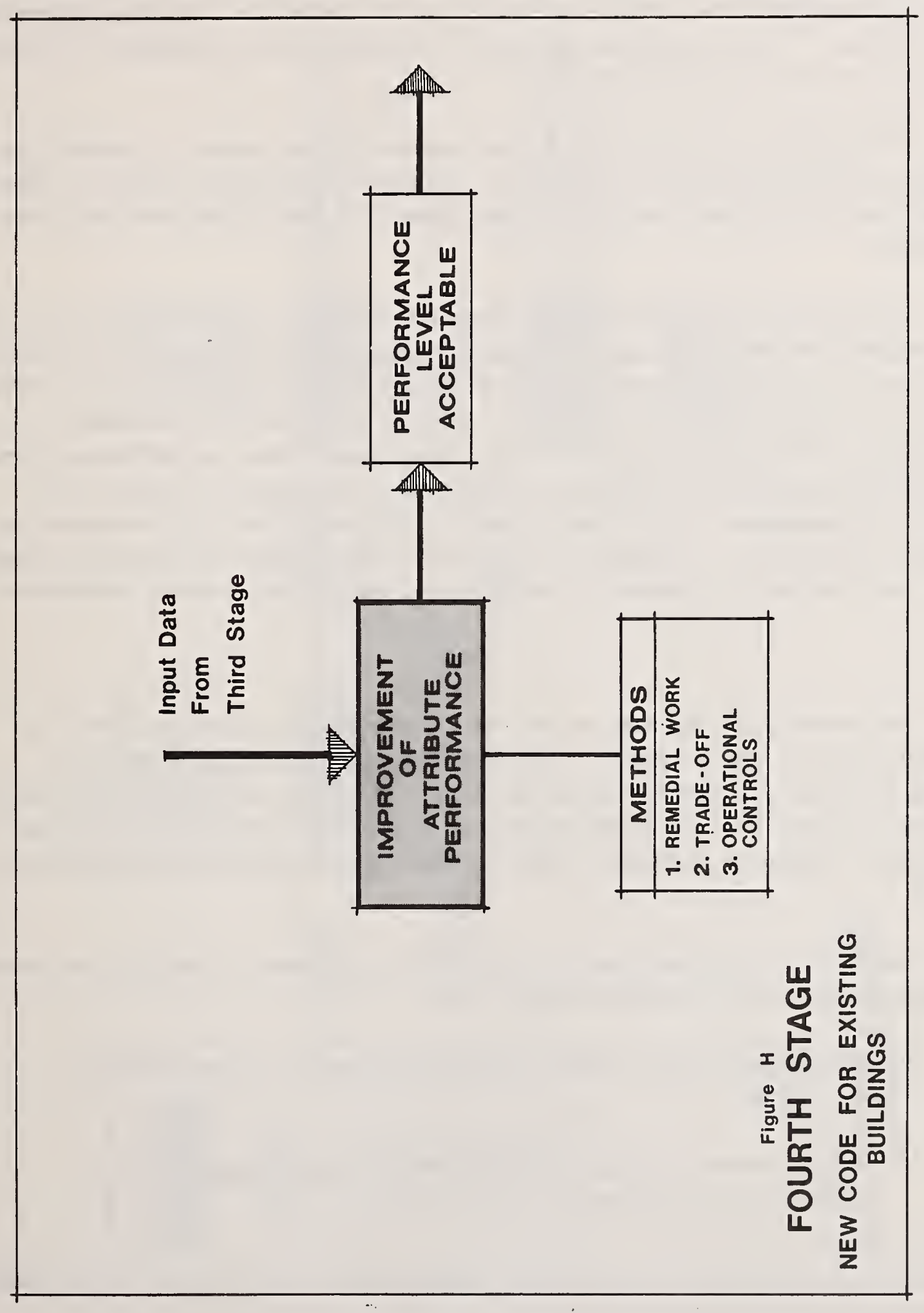


means of egress from an historic building of less than three stories if the "Visitors are admitted by guided tours or there are supervisory attendants in all the areas accessible to the visitors." 27 These operational controls, and others, need more research and testing to be developed into recognized trade-offs.

This stage of the process provides the mechanism for the designer to improve the deficiencies of the performance attributes. Trade-offs, operational controls, or remedial repair work will increase the deficient performance to a level which meets the minimm standards.

At this point, the entire decision process is complete. That process, shown in Figure $\mathrm{J}$, includes four stages. In the first stage, the designer chose the occupancy classification and verified the performance attributes and the physical parameters of each. Then, in the second stage, each of the physical parameters were identified, measured and evaluated, with the results carried into the third stage. There, the performance levels of the eight performance attributes were determined by tabulating the values of the individual parameters. In the fourth stage, through remedial work, or the addition of technical trade-offs or operational controls, deficient attribute performance was improved. The result was that all performance attributes met the required levels of performance.

\section{SUMMARY}

This investigation has made one attempt at analyzing the probems which existing buildings face in code compliance. This compliance causes, fram the viewpoint of preservationists, the needless destruction of architecturally, and aesthetically important building features, the unnecessary replacement of serviceable building materials and systems and apparently increases the costs of these preservation and rehabilitation projects.

This affect of code compliance on existing buildings seems to stem from the following eight characteristics of the model building codes.

1. The performance levels which a building must meet have risen throughout this century.

2. New performance attributes have been added for which there are new building code requirements.

\footnotetext{
27 American Insurance Association, National Building Code, 1976 (New York: A.I.A., 1976), Section 1709.6 (b), p. 505.
} 


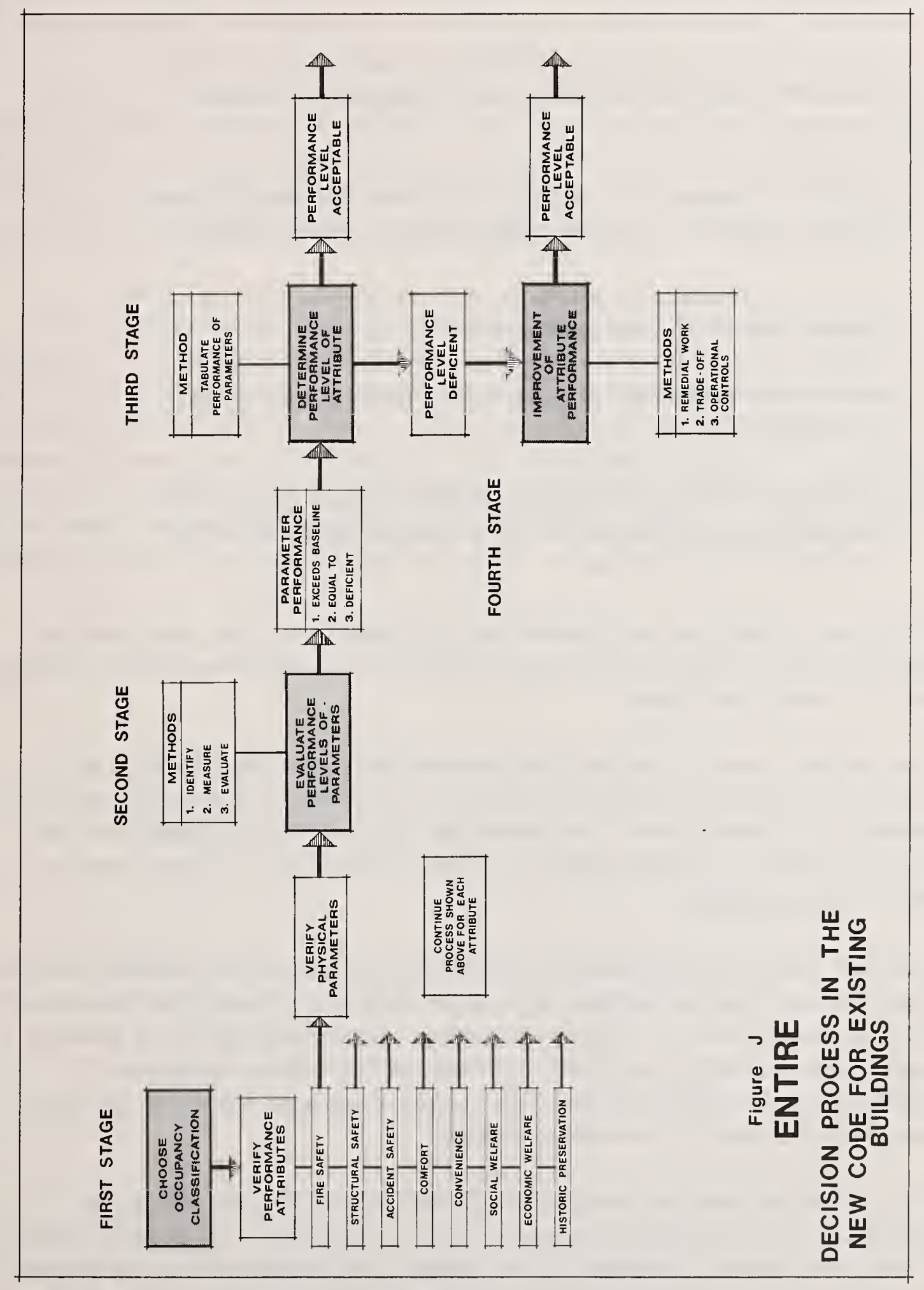


3. As new performance attributes were added to the model codes, problems resulted.

4. The decision process of the model codes is applicable only to new construction and does not lend itself to projects in existing buildings.

5. The various prescriptive standards of the codes are based on modern materials and do not include information about older materials.

6. The various prescriptive standards are based on what might be called standard modern building configurations.

7. Reference standards make it difficult to detemine exactly what is required.

8. Information which is included about older materials, specifically fire endurance ratings, may not be an accurate indication of the performance of the material.

With these problem areas and cause-effect relationships in mind, this report has presented a concept, structure, and decision process for a possible new code or standard for use with existing buildings.

The decision process of the new code presented here judges the building for its performance in the eight performance attributes, not according to the rigid prescriptive requirements of the model codes. The process was conceived to relate directly to the conditions present with existing buildings, conditions which differ markedly from those present in new construction.

This new code or standard would fully and accurately evaluate all existing materials and systems through numerous standard on-site test methods and through the inclusion of extensive information about the physical properties and performance data for these old materials. This evaluation would hopefully eliminate the needless replacement of serviceable materials, and at the same time, provide an accurate picture of the actual performance capabilities of the existing building.

This evaluation procedure identifies a spin-off value of the new code to the preservationist as he prepares a feasibility study for a project in an existing building. Just as the model codes aid designers in the design of new buildings by fixing building size, configuration and structural systems, this new code would provide a method for the 
designer to accurately assess the condition of the building and determine the amount of remedial work necessary to bring the building up to the required performance levels. This, in itself, may greatly contribute to, and increase, the preservation of old buildings.

Finally, the new code would include sound, recognized methods for identifying and improving deficient attribute performance. This improvement would be achieved through remedial work, or the addition of technical trade-offs and operational controls. These trade-offs would increase attribute performance, which would allow certain physical entities within the attribute, for instance, an architecturally important open wooden stair, to be retained.

If this concept for the new code or standard for existing buildings were fully developed into a working document, the end result ought to be an existing building, of any type or description, which would fully meet the performance levels established for new construction, while at the same time, retaining historically important building features and reusing serviceable materials, all at a reduced project cost. As was pointed out however, for this concept to be transformed into a working document, a good deal of further study, research and development would have to be undertaken. Hopefully, this investigation will stimulate just such an effort. 
Ingberg, S. H. and Nolan D. Mitchell. Building Materials and Structures. Report BMS 71. Washington: GPO, 1941.

National Bureau of Standards. Building Materials and Standards. National Technical Information Services, COM-73-10974. Washington: GPO, 1942.

- "Fire-resistance of Heavy Timber Construction." Technical News Bulletin No. 349 , May, 1946.

- "Recammended Minimm Requirements for Fire-resistance in Buildings." Building and Housing, No. 14. Washington: GPO, 1931.

National Board of Fire Underwriters. Building Code. Fourth Edition, 1920. New York: N.B.F.U., 1920.

- Fire Resistance Ratings. New York: N.B.F.U., 1959.

- National Fire Codes. Boston: N.B.F.U., 1938.

Pacific Coast Building Officials' Conference, Uniform Building Code, 1937 Edition. Los Angeles: P.C.B.O.C., 1937.

Southern Building Code Congress. Southern Standard Building Code, 1953. Birmingham, Al.: S.B.C.C., 1953.

Starbuck, C. W. Building Construction Code of New York Cit: , Second Edition, 1950. New York: C. W. Starbuck, 1950.

SOURCES PUBLISHED SINCE 1959

American Insurance Association. National Building Code, 1976. New York: A.I.A., 1976.

America Burming. The Report of the National Commission on Fire Prevention and Control. Washington: GPO, 1973.

American Iron and Steel Institute. Fire Frotection mrough :Hodern Builaing Codes. New York: A.I.S.I., 1971. 
American Society of Heating, Refrigerating, and Airconditioning Engineers, Inc. ASHRAE Standard 90-75, "Energy Conservation in New Building Design." New York: ASHRAE, 1975.

American Society for Testing and Materials. 1974 Annual Book of ASTM Standards. Philadelphia: ASTM, 1974.

Benjamin, Irwin A., et al. "A System for Fire Safety Evaluation of Health Care Facilities." Draft Report, Center for Fire Research, National Bureau of Standards, July, 1976.

Brown, Patrick. "Conversion and Building Regulations." Architectural Review, May, 1972, pp. 313-316.

Building Officials and Code Administrators International, Inc. Basic Building Code/1975. Chicago: B.O.C.A., 1975.

Dean, Andrea O. "Adaptive Use: Economic and Other Advantages." AIA Journal, June 1976, pp. 26-38.

Educational Facilities Laboratory and The National Endowment for the Arts. The Arts in Found Places. New York: Educational Facilities Laboratory, 1976.

Falk, David. "Building Codes in a Nutshell." Real Estate Review, Fali, 1975, pp. 82-91.

Field, Charles G. and Steven R. Rivkin. The Building Code Burden. Lexington, Mass.: Lexington Books, 1975.

Godfrey, David A. "Energy Conservation in Existing Buildings," Civil Engineering-ASCE. September, 1975, pp. 79-84.

Green, Melvyn and Patrick W. Cooke. Survey of Building Code Provisions for Historic Structures, NBS Technical Note'918. Washington: GPO, 1976.

Harmathy, T. Z. "Design Approach to Fire Safety." Progressive Architecture, April, 1974, pp. 83-8́7.

International Conference of Building Officials. Uniform Building Code, 1976 Edition. Whittier, Ca.: I.C.B.O., 1976.

- Uniform Building Code Standards,; 1973. Whittier, Ca.: I.C.B.O., 1973. 
Kidney, Walter C. Working Places, The Adaptive Use of Industrial Buildings. Pittsburgh: Ober Park Associates, 1976.

Langdon-Thomas, G. J. Fire Safety in Buildings. New York: St. Martin's Press, 1973. Marchant, Eric W., Ed. A Complete Guide to Fire and Buildings. New York: Harper and Row, Publishers, 1973.

National Commission on Urban Problems. Building the American City. Report of the National Cammission on Urban Problems to Congress and the President, 91st Congress, lst Session, H.D. No. 91-34. Washington, D.C.: GPO, 1968.

National Fire Protection Association. Fire Protection Handbook. Fourteenth Edition. Boston: N.F.P.A., 1976. - Life-Safety Code, No. 101. Boston: N.F.P.A., 1973.

"National Policy on Energy Standards," Architectural Record, Mid-August, 1975, pp. 94-98.

National Research Council of Canada. National Building Code of Canada, 1970. Ottawa: N.R.C.C., 1971.

National Trust for Historic Preservation. Economic Benefits of Preserving Old Buildings. Washington: The Preservation Press, 1976.

- Preservation and Building Codes. Washington: The Preservation Press, 1975.

Pauls, J. I. "Evacuation and Other Fire Safety Measures in High-Rise Buildings." Research Paper No. 648 of the Division of Building Research, National Research Council of Canada. Reprinted fram ASHRAE Transactions 1975, Vol. 81, Part 1, pp. 528-534.

"Rehabilitation and Re-use." Architectural Record, August, 1975, pp. 67-82.

Rosen, Harold J. "Developing Reference Standards." Progressive Architecture, November, 1971 , p. 126.

"Roundtable on Codes and Standards for Fire Safety." Architectural Record, Mid-August, 1974 , pp. 114-121. 
Rowland, G. A. and N. E. Gallagher. "Performance Standards--Their Compatibility with the Building Regulatory System." Unpublished Report, National Bureau of Standards, June, 1972.

Sampson, Arthur F. "The General Services Administration Systems Approach to Life Safety in Structures." Designing Buildings for Fire Safety. Boston: N.F.P.A., 1975, pp. 38-40.

Sanderson, Richard L. Codes and Code Administration. Chicago: B.O.C.A., 1969.

Shopsin, William C. Adapting Old Buildings to New Uses. New York: New York State Council on Architecture, 1974.

Shoub, Harry. "Early History of Fire Endurance Testing in the U.S." Special Technical Publication No. 301. Philadelphia: ASTM, 1961.

Southern Building Code Congress International, Inc. Standard Building Code. 1976 Edition. Birmingham, Al.: S.B.C.C., 1976.

Stevens, Richard E. "Evaluating Existing Buildings." Designing Buildings for Fire Safety. Boston: N.F.P.A., 1975, p. 71.

Wright, James R. "Performance Criteria in Buildings." Scientific American, March, 1971, pp. 16-25. 



\author{
Richard S. Harrington, President \\ TEEKTŌN, Inc. \\ Columbus, Ohio
}

The nature of rehabilitation, with its nonvisible elements and its potential for self-help, makes it extremely difficult to accurately estimate the costs involved. The uncertainty is passed on by the contractor in the fees he charges. Uncertainty exists, as well, in the standards for accomplishing the work at hand. Specifications are normally cumbersome, Work Write-Ups lacking in detail. Therefore understanding is diminished, and costs rise, while quality falls below standards.

With the pending increase in neighborhood code rehabilitation projects, there is the need to increase the supply of competent contractors interested and experienced in rehab. This requires both a method for offering standardization of specifications and work-writeups with more detail, and the ability to assure a steady flow of work into bidding channels.

Key Words: Building codes; community development; construction costs; contractors; housing; standards; rehabilitation.

* Reprinted from NBS Special Publication 473, "Research and Innovation in the Building Regulatory Process," (Proceedings of the First NBS/NCSBCS Joint Conference held in Providence, Rhode Island, September 21-22, 1976); pp. 491-497. 
Iocal ways of code Administration make coats of many colors. There is much variety, and much misunderstanding. It has taken the loss of thousands of lives and billions of dollars to get codes where they are today. Yet on a court docket comprising one murder, two rapes, and four auto thefts, a leaking drain does not sound very important!

True, to the family downstairs, that leaky pipe may mean a sinkful of sameone else's sewage. To the property owner, however, it has meant harassment, and police type enforcement. To the contractor, who will eventually be called in to repair the situation, it means simply another jab, one with some sticky red tape and possible delay in getting both payment and certification of inspection. Understanding of the code involved has gone astray. Instead, bureaucracy has been given another demerit. The family downstairs? They moved. Better plumbing meant higher rent!

our subject: "CONTRACTOR UNDERSTANDING," that is his understanding of the reasons behind the code, what the code specifies, and what he must do in order to meet those specifications. All of which is "RELATIVE TO REHAB COSTS."

What does rehab cost, and what is involved? A good example is a recent one-day processing of 57 single family owner-occupied structures by our firm. The rehab dollar in code Violations alone was $\$ 283,536.78$. There were 3,445 such deficiencies found in these properties, or an average of 60 per structure, at a repair figure of near $\$ 5,000.00$ for each homeowner. I might add, these properties were not in a so-called blighted area.

It is interesting to note that there seems to be understanding in some areas regarding the cost of rehab. Major building trade unions in New York City say they'll accept 25 percent cuts in wages and fringe benefits on HUD-sponsored rehab. First okays came from carpenters, roofers, painters, bricklayers, marble masons, plumbers and laborers. Others are considering it. Unions will take time and a half for overtime, instead of double-time, cut out travel time and expenses, and are cutting back on some other items. HUD, by the way, has approved money for rehabbing over 3,000 apartment units in that city. In anybody's book, that is a lot of code problems being cleaned up.

Actually, the nation's stock of housing has been deteriorating faster than it has been replaced or maintained. This is especially the case in core areas of older cities. At the same time, the population is increasing and the nation has goals of higher quality housing for all people. Remember, however, the single most important asset of any community is its existing housing supply. It will be there, for the most part, in the year 2005. The operation of local government, that includes many of your paychecks, is dependent, to a large degree, on residential real estate taxes. Repair and/or maintenance of it must be kept in line financially, as well as in the incent of the codes involved. 
In many areas, code agencies have come to realize that running a complaint bureau and prosecuting lawbreakers in the courts has not kept mary dwelling units in good condition. This passive and punitive approach has caused them to fall further behind. Now they are becaming more actively aggressive at establishing routine inspection periods for all dwelling units. In addition, they are shifting the emphasis from court summons to getting the property repaired via Community Development and other programs.

At this point, I hope you understand that rehabilitation programs are spurring the clean-up of major code problems. Contractor understanding is vital here, in order to keep costs at an even keel, and code concurrence of work performed at the highest level, even if sometimes, regulatory agencies must bend a little in standards.

For those of you who can see what is happening through such programs, but point out that you are in the regulation of new construction, I contend the same level of understanding is needed for contractors working with you!

Why? Iet us look very quickly at some of the great problems that will affect cities over the next few years. Perhaps the greatest problem that we will have to contend with is sheer urban growth!

Let me give you some idea of what is anticipated. At the very least, the population of the United States within the next 30 years will increase by 150 million people, even assuming that birth rates will decrease. Therefore, the population of the country is going to approximately double by the year 2005. Now, what does this imply for cities. At the very least, it means that we are going to have to build, in 30 years, some 500,000 miles of urban streets, sewers, water mains and light systems. We are going to have to supply 40 million or more dwelling units, and it may be as many as 60 or 80 million. We will need at least 100,000 primary schools, 30,000 high schools, 3,000 universities, colleges and community colleges, at least 7,000 major general hospitals, 10,000 to 20,000 municipal parks and playgrounds, and more than six billion square feet of office space. All of this adds up to a minimum public investment for the American people over 30 years of 2.5 trillion dollars, at current expenses. That is a lot of money, activity and effort demanding a lot of understanding.

In general, our review of contracting procedures across the country has revealed that there is some similarity in the approaches used, but that these represent a rather narrow range of the possible options. We have concluded that these approaches are inhibiting the growth of the industry and discouraging the entrance of larger contracting firms into the community development field. 
What we find instead, due to a lack of sufficient scale in most areas and profit potential, is the smallest of local contractors and handymen who are short of management expertise, financial capability and even craftmanship.

The nature of rehabilitation, with its non-visible elements and its potential for self-help, makes it extremely difficult for them to accurately estimate the costs involved. The uncertainty is passed on by the contractor in the fees he charges. Uncertainty exists, as well, in the standards for accomplishing the work at hand. Specifications are normally cumbersome, work write-ups lacking in detail. Therefore, understanding is diminished, and costs rise, while quality falls below standards.

With the pending increase in neighborhood code rehabilitation projects, the key ingredients would appear to be the precise definition by the housing inspector of the work to be done; an increase in the supply of competent contractors interested and experienced in rehabilitation; and the ability to assure a steady flow of work into the bidding channels. Above all, we must educate those responsible for the actual work, with respect to quality, about code standards. Samehow, the big code books must be broken down into simple terms that clearly show how the work must be done.

Our firm has taken the approach of moving the time consuming work of preparing bid documents out of the office, and into a computerized form to effect standardization. This appears to short-circuit the slowness of imput to bid, as well as providing a method of presenting the task in writing with quality and detail understandable to all.

What happens when this is done, is that administration becomes less of a chore, and therefore, more productive. Contractor understanding has improved, more properties are being fed into the bidding circle, and more contractors, large and small, are vying for work in our areas of operation thus reducing even more the rehab cost.

While the computer may hold the answer for same, we know the majority of rehabilitation will be carried out in a straightforward manner devoid of much which could be labelled high technology.

The typical rehab contractor operates in much the same way as the small house builder making the normal trade-offs between labor and materials costs in deciding between alternate construction methods and products. The usual project is nomally small in scale so that site organization in terms of men, equipment and materials is relatively simple. In fact, for a single house rehab contract it is unusual to find more than four to six men on the site at any one time. 
The contruction methods used in the work vary, of course, with which items in the house are being rehabilitated and it is not possible to describe all the techniques in detail in an overview such as this. It is of interest to note, however, that there is a market for repair and rehab products and that this demand has spurred the development of some products used almost exclusively in this type of work. These include: aluminum siding, screw-on double windows and blow-in insulation, together with numerous patching and painting materials.

It is difficult to separate the rehab products market from that of new construction. The latter is by far the larger market so that most products are developed for it primarily and rehab contractors must adapt these products to the needs of their work. So must codes be adapted to recognize the legitimate differences of age, building type and market conditions that exist in different neighborhoods. That is what I meant earlier by the word "bend" and, of course, this is the very nature of rehab. Sometimes the product called for by code can not be used in the property, without jacking the cost beyond reality. By the same token, some standards must be downgraded for rehab, since they are out of line for the building's present use or occupancy.

A good example is what is sometimes required in the electrical code. Too often we see several hundred doll.ars or more dumped into a house occupied by one elderly woman who has a life expectancy of just a few more years. Her needs are not what the standards call for in number of outlets, etc., but because of the money we spend to meet these standards, we must overlook other repair items. We should bend here, and pick these items up when the house has a new owner or tenant. This can be done as some conmunities are doing with a certificate of occupancy inspection. Meanwhile, this lady's comfort in general living conditions such as first floor bedroom and bath, fresh paint, etc., will enhance a health code requirement and be money spent in a better interest. After all, how many super hi-fi- stereo's, C.B. radios, micro-wave ovens will she be plugging in?

This is where regulatory agencies must bend a little at times, in order to get many other defiencies cleared up. By the same token, we in rehabilitation, must begin to make the contractor's job easier, and outline the task ahead as clearly as possible, with standardization of words and methods. The work write-up is the method by which the violation is to be corrected. It should be precise, especially as to quantity and completeness. Without such quality, the contractor will be unable to make an intelligent bid.

For example, if we call for replacement of rotted siding, we should be specific about the quantity. Similarily, if we not only want the siding replaced, but also painted, we should say so and not assume that the contractor will figure it in his bid. 
Also, we should avoid language like "check" roof for leaks. If the roof leaks, then we should call for its repair or replacement. How can the contractor otherwise make a bid without making his own judgement about the quality of the roof. If this approach is employed, then it is the contractor and not us who is performing the inspection.

The work write-up identifies which part of the property has to be worked on, what has to be done and the quantities involved. It does not cover things like the minimm standards to be observed in choosing materials and construction techniques. These items are essential, however, if the bids, cost estimates and owner expectations are to be comparable.

To illustrate: If the work write-up calls for painting, the contractor should have a set of standards which tells him the minimm quality of paint acceptable and the level of surface preparation required. Without this kind of direction, each contractor could conceivably base his bid on paint brands widely different in price and on surface preparation techniques with a similar price variance.

Regardless of the contractor selection techniques employed, the contractor's bid will have to be reviewed. Making this review will be easier if the contractor has to bid on an item-by-item basis as opposed to a lump sum method only. If it is lump sum, we really have no way of telling if the estimate and bid are comparable. The cost estimate total and lump sum bid could be exactly the same and yet there could be wide discrepencies in what we think will be done on the house as compared to what the contractor thinks he has to do.

For example, both the contractor and we may agree on the lump sum price of say $\$ 5,000.00$. However, if the Contractor has seriously under-estimated the amount and therefore the cost of one item, while seriously over-estimating the scope and therefore the cost of another item, the result will be dissatisfaction on our part with the work done on the item which the contractor has underestimated.

We cannot accept a bid which is either too high or too low. If we accept a bid significantly below our estimate, there is the risk that the contractor will be unable or urwilling to complete the job. Further, he may try to make up for his error by skimping on various parts of the job. Even if neither of these things happen, he may be so seriously injured economically, that he cannot continue after finishing the job.

If this were to happen, the code enforcement rehabilitation program could be deprived of a contractor who is beginning to understand, one who is doing good work, and helping to clean out the code deficiencies in the neighborhood. 
In sumation, the contractor is the vital link to rehab in the intent of the code, and to meeting our housing goals. We must bend at times to make the program work, yet we must educate all concerned as to what codes are and what is expected by compliance. We must be prepared to make the contractor understand what is expected of him, make his job easier by being precise. If he can make money, he will stay within our guidelines, and perform as often as we will need him. The message is "CONTRACTOR UNDERSTANDING. . .IT IS RELATIVE TO REHAB COSTS." 


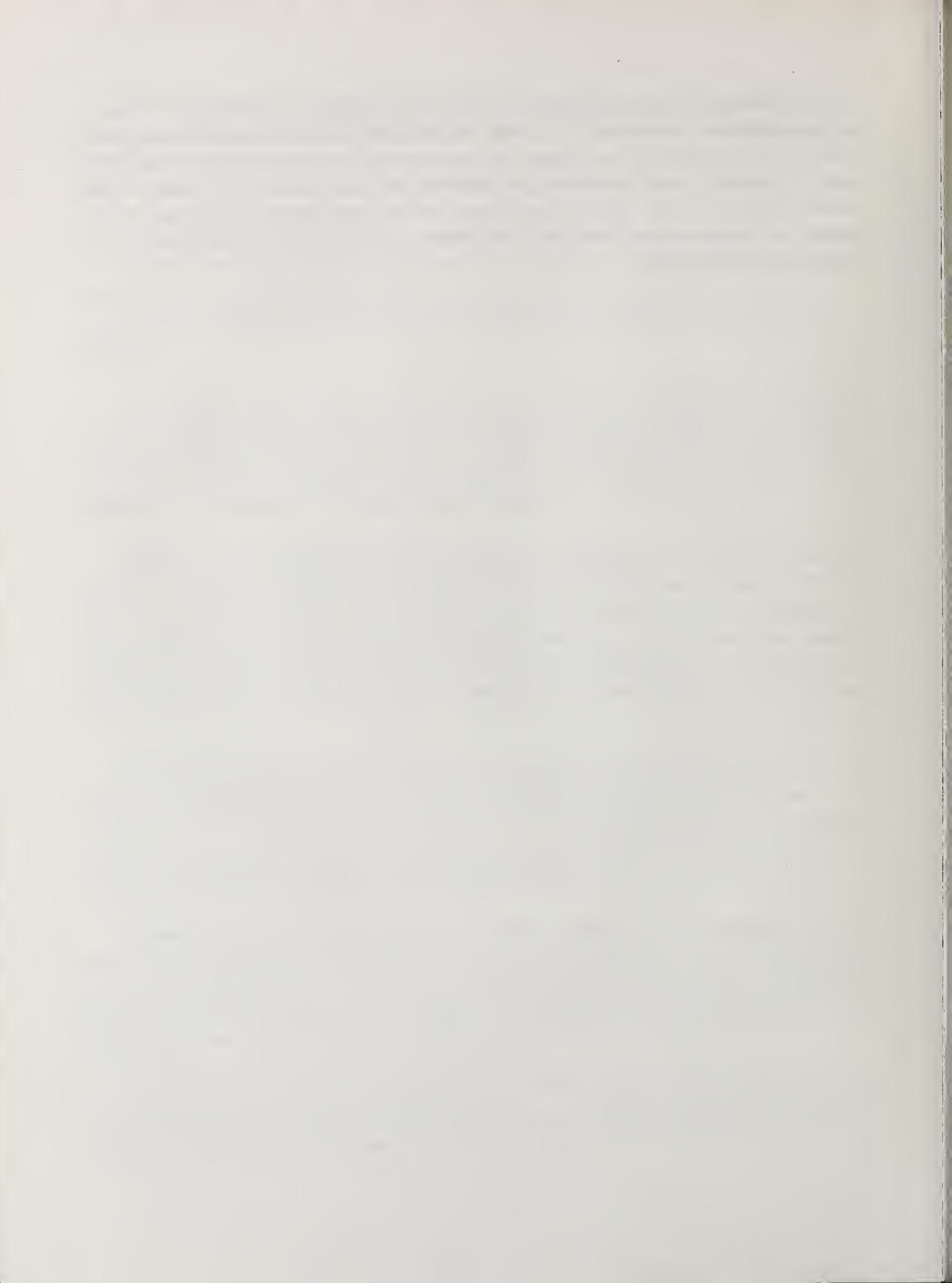


THE ROLE OF FIRE PREVENTION AND CONTROL ON

BUILDING CONSTRUCTION AND REGULATIONS*

by

William H. McLain

Institute Scientist

Southwest Research Institute

San Antonio, Texas

Fire prevention and control is an important feature of the modern building codes. Building set-back limits, structural design, and limitations on interior finish materials are among the building design parameters that reflect the public need for fire safety. Historically, codes have been developed to reduce mass urban fires and to limit property damage from the structural collapse of single building units. For example, a standard time-temperature curve has been developed and widely used (ASTM El19) for classification of building structural components in terms of a fire-time rating. More recently, there has developed an increased concern about life safety. Smoke and toxic gas produced by materials subjected to fire exposures are being evaluated and in some cases form part of a developing set of new regulations. The implementation of these new regulations poses a number of difficult problems to the local code regulatory and enforcement officials. An analysis is made of some of the alternative approaches which may be considered to aid the local building official in this important area of control.

Keywords: Building codes; control measures; fire codes; fire safety; governmental actions; life safety; regulation; risk assessment; societal goals.

* Reprinted from NBS Special Publication 518, "Research and Innovation in the Building Regulatory Process;" (Proceedings of the Second NBS/NCSBCS Joint Conference held in Bozeman, Montana, September 20, 1977); pp. 165-176. 
Fires have threatened life safety and inflicted losses to property throughout history. In the past, as now, governmental bodies have responded to these threats by developing fire service capabilities and restrictive building codes. Using these solutions effective governmental action has been implemented for many centuries.

In 80 B.C. Marcus Crassus organized a private fire brigade to protect his buildings in ancient Rome. These brigades were highly efficient and during his time fire losses were low. For political reasons after his death these brigades were disbanded and in $64 \mathrm{~A} . \mathrm{D}$. a major fire consumed Rome. At that time Rome had many of the general characteristics of a modern city being constructed of 6 to 7 story tenement buildings.

It is instructive to read the historian Tacitus' description of the rebuilt city a few years later:

"... with rows of streets according to measurement, with broad thoroughfares, with a restriction in heights of houses with open spaces, and the further addition of colonades, as a protection to the blocks of tenements... The buildings thenselves, to a certain height, were to be solidly constructed, without wooden beams, of stone, that material being impervious to fire, and to provide that the water which individuals... had appropriated might flow in greater abundance for the public use,... and everyone was to have in the open courtyard before their house equipment for stoping fires. Every building too, was to be enclosed by its own private wall, not one shared with others...."

Clearly the basic elements of a prescriptive city fire code were used. The elements consisted of fire resistive construction, set-back limits, and material specifications. These elements were supported by an active and ready voluntary fire service. It is doubtful that the modern city administrator could improve much on the rebuilding of that anclent city.

Three key elements were involved in this process: (1) technical knowledge, (2) a public awareness of risk and its willingness to commit resources to minimize this risk, and (3) an effective governmental administration and enforcement policy. In time, as public awareness dimmed and governmental administration became ineffective, Rome again became the site of major urban fires. This cyclical process of major catastrophes followed by rebullding and decay continued to the present century. Examples include the London fire in 1600, the New York fire of 1834, the San Francisco fire of 1858, the Chicago fire of 1888 and the Boston fire of 1906 .

The fact that the incidence of major urban conflagrations has declined in recent times is most probably due to a combination of increased public awareness about fire (as a result of modern communication and educational systems) and, the development of new forms of 
governmental and private regulatory institutions. Commencing in the latter part of the last century factory mutual insurance organizations were formed as a protective measure by factory owners to spread the adverse effects of an individual fire catastrophe over a wider financial base. A major output of the activities of these mutual organizations was the development of technical performance codes based on a "consensus" of technical experts. These efforts have developed into our present system of uniquely American consensus standards and codes. Effective administration of these codes was enforced by economic incentives, principally reduced insurance premiums, in the private sector as well as governmental regulations directed toward general public safety. In part because of the interests of the insurance agencies, the primary emphasis of these codes has been directed toward reducing property losses. Lesser emphasis has been placed on life safety.

For a number of reasons during the past decade there has been an increasing public awareness of hazards to life safety resulting from unwanted fires, particularly in one and two-family dwellings. Since legal responsibility for fire deaths in these occupancies has not resulted in monetary losses to the fire insurance underwriter, incentives which have effectively reduced property damage losses are not fully operative. Because of these factors there is an increasing political demand placed on public officials to develop and enforce fire codes and standards in which primary goals will be to reduce the number of home fire deaths. This is both a local and community and national problem area for governments. To perform this service it is apparent that new concepts and approaches must be developed which can complement our present system of concensus codes. One of the new approaches to this problem is the investigation of codes which is based on the level of risk the public is willing to accept in terms of the fire hazard.

\section{LEVEL-OF-RISK FIRE CODES}

The acceptable risk associated with a specific hazard varies both with respect to the type of hazard, and, the local community standards. Thus, a much higher factor of risk is generally acceptable for loss of life in a single family dwelling unit as compared to loss of life in an airplane crash. Similarly, arson is common in many urban ghetto areas and rare in most suburban neighborhoods.

One of the implications of a variable acceptable risk is that for the same hazard, (e.g., loss of life in a domestic fire) there may be different political pressures on government for control and regulations. These demands reflect the relative order of priorities of a specific community. In the United States the major underlying philosophy of the Fire Prevention and Control Act of 1974 is that control of hazards associated with fire is a problem of local government. State and local officials are expected to make their own decisions on the level of safety they want and determine how much cost is reasonable. However, it is impractical for each local political subdivision to perform the necessary research, development, and evaluation to produce its own individualized fire safety code. This poses a dilemma. 
The current solution to this dilemma is for the local community to adopt one or more of the major model codes. At present there are at least 10 major model codes directed toward regulative fire safety in buildings and hundreds of voluntary technical standards. A major problem is that State and local officials lack an objective basis for comparing these model codes in terms of the safety provided and costs incurred.

One way to resolve this problem is to develop a single national concensus code. Either the prescriptive or performance codes could be utilized for this purpose. One major advantage of this approach would be a reduction of the problems incurred by manufacturers to produce and market on a national basis. Although a universal national code would reduce conflicts, it also limits the flexibility of local code groups to formulate requirements best suited to individual communities.

A second way to resolve the problem is to develop a form of fire code in which emphasis is given to providing the local official with an objective system for evaluating alternative solutions in terms of the acceptable levels of risk in the community but which also utilizes the benefits gained from the concensus standard system. Such a code would include a number of discrete elements. First, the risk associated with the hazard must be defined for the community. This requires a statistical data base either for the specific community or for a group of similar communities. Secondly, the acceptable level of risk must be specified. This requires a political insight into the sensitivity of the community with regard to the potential hazard. The sensitivity of the citizens of Southgate, Kentucky, toward interior finish and existing requirements in restaurants is currently very high after the recent Beverly Hills Supper Club fire. The code must be able to accommodate this selective sensitivity. A third desirable element is flexibility. The code should provide a mechanism where alternate solutions may be selected in order to have sufficient flexibility to allow new material and construction practices to be used on a national basis. Finally, to be effective any code must be administratively enforceable.

A hypothetical example of a level of risk code would be the development of building code criteria designed to reduce loss of fire fatalities in one and two-family dwelling units. Recognizing that individual fires in homes result in an estimated 8000 deaths per year an objective of a building code might be to reduce these by a "reasonable" number. Although limited reliable data is available, it would appear that the room of fire origin in fatal fires may, in many cases, be in a lower floor area. The reason for this fact is that smoke and heat rise from these lower areas often resulting in a threat to life safety on the upper floors. In other cases, the room of fire origin is the same as that in which the fire fatality occurs (e.g., a bedroom). The room of fire origin for one and two-family dwelling fatalities is summarized in Figure (1)*. It is noted that these data are obtained from national

*Fire Protection Handbook, 14th Edition, p. 1-8. 
statistical averages which may or may not represent the average for a specific community. Figure (2) lists the compartment level of risk normalized to an arbitrary basis of 100 . Assuming the statistical data is valid, the results indicate the areas in which most fatal fires originate are the basement, living room, and kitchen having values of $53.5,22.5$ and $16.7 \mathrm{LOR}^{+}$, respectively.

This information can be used by the code official to determine the relative risk associated with living in a specific dwelling unit. For example, in Figure (3), a plan drawing is given for an individual home. Multiplying the number of rooms of each type in this home by their national average risk value the level of risk is determined. Without a basement the relative level of risk is associated with living in this home is 81.1 LOR. With a basement it becomes 134.6 LOR.

The next step in the process involves an assessment of desirable community goals in terms of the "allowable" level of risk that will be acceptable as a community standard. This assessment is essentially a political judgment. A possible community standard might be to not allow construction of new homes having a LOR greater than 75 based on national averages. This level of risk would act to reduce fire facilities in the community as compared to a national norm. A second approach would be to establish a community-specific data base and use this base to provide similar guidance.

In order to more closely define the problem it is useful to determine the level of risk for individual compartment. Again since the data presented in Figure (1) is relative to a national statistical base for fires in one and two-family occupancy classes, the level of risk associated with individual areas of the home can be estimated from U.S. Census Bureau data. Once a community standard has been selected (e.g., 75 LOR) the code official can, thus, discuss with the builder various building options. Some of these options are listed in Figure (4), together with an itemization of other technical input that may be required to evaluate each option. Since the goal is to reduce the level of risk, judgment must be exercised regarding the effectiveness of each option when installed in the specific building. In this case, an efficiency of 100 percent effectiveness was assumed. In a practical code decision reference would be made to technical consensus values. Possible results for three contractor options are outlined in Figure (5). Installation of a sprinkler in the living room or area would reduce the LOR value to 55.6 for a non-basement house. In this case, a possible alternative of the installation of a sprinkler in the den would not be acceptable since the den is not in direct communication to the stairwell leading to the second floor level. Similarly, installation of a fire detector in the stairwell would provide protection from most fires

\footnotetext{
+ The unit LOR is defined as the level of risk associated with an average occupany class relative to the assumed hazard.
} 
starting in the lower floor area. In this example, no substantial protection would be required for the den area and the additional placement of additional detectors in every bedroom occupied by a person who smokes would be recommended.

As indicated previously, one of the problems associated with this approach is the determination of the relative effectivness of alternate fire suppression/fire warning systems. Before level of risk codes can be developed, much more technical information in this area will be needed. One point of concern is the fire control effectiveness of low rate of application water sprinklers. A second problem area involves the judgmental factors associated with "type of occupants" assumptions. For example, if non-ambulatory occupants are present the use of smoke or heat detectors may be less satisfactory than sprinkers. Because of the range of technical sophistication that is needed to effectively solve these problems it is probable that some form of consensus group opinion may be required from technical experts in the field. However, it is believed that these problems are amenable to reasonable solutions.

The principal advantages of a level-of-risk type code outlined in the above example are: (1) specific solutions may be formulated for individual communities and buildings, (2) these solutions can be highly flexible in providing alternate solutions and alternate goals, and (3) cost effectiveness to achieve a prescribed level of risk. The major disadvantages are (1) a need for a community-specific data base, and (2) a need to define community goals. It will be interesting to see how regulatory building codes in the future utilize these more formalized acceptable risk principles at national and local levels of government. 
The development and use of fire codes cannot be separated from other available community services such as fire suppression and public education. All are necessary components on a community program for fire safety. An effective fire code reduces the personnel and equipment requirements for fire service. An effective program of public fire education similarly is important to an effective fire code.

It is necessary to realize that fire codes are not simply a set of technical requirements. Rather, they involve a combination of technical, political, and administrative balances. What is important is that the general community believes that there is a clear and present danger and that the control measures taken are reasonable (i.e., cost effective, technically valid, and closely related to current community practices).

Technically, we have had the knowledge of how to implement an effective building code for at least two thousand years. Historically, this knowledge has been effectively used only periodically. Given a crisis caused by a major fire catastrophe, political and administration institutions are developed and implemented to reduce the probability of crisis reoccurrence. These rely on available technology for specific control measures and the absolute level of risk is less relevant than the visibility of the hazard. As the public awareness of the hazard recedes the enforcement becomes lax and a new cycle begins.

Building codes related to community fire safety are in a state of change. These changes reflect changing societal goals. In the recent past (i.e., the past 50 to 75 years) a major societal goal was to reduce mass conflagration in major urban areas. Our current building codes reflect these concerns. Recently there has been more emphasis on life safety. It is anticipated that more measures to reduce fire hazards which affect individual life safety will be incorporated into our building codes in the future.

Compared to our national net worth our losses are relatively low and the probability of a major urban conflagration is low. The major question is, "How can we do better with the political framework of our democratic nation?" particularly with regard to improving individual life safety in home fires. One answer to this question is a level-of-risk assessment. This new type of code provides a variety of technical solutions which can be adapted to the specific needs of individual local communities. In these codes the level-of-risk is estimated for alternate materials, equipment, and construction practices and then related to community priorities for specific occupancies. This new approach to the code regulatory problem provides a combination of technical, political, and administrative balances uniquely suited to the American form of democratic institutions. 


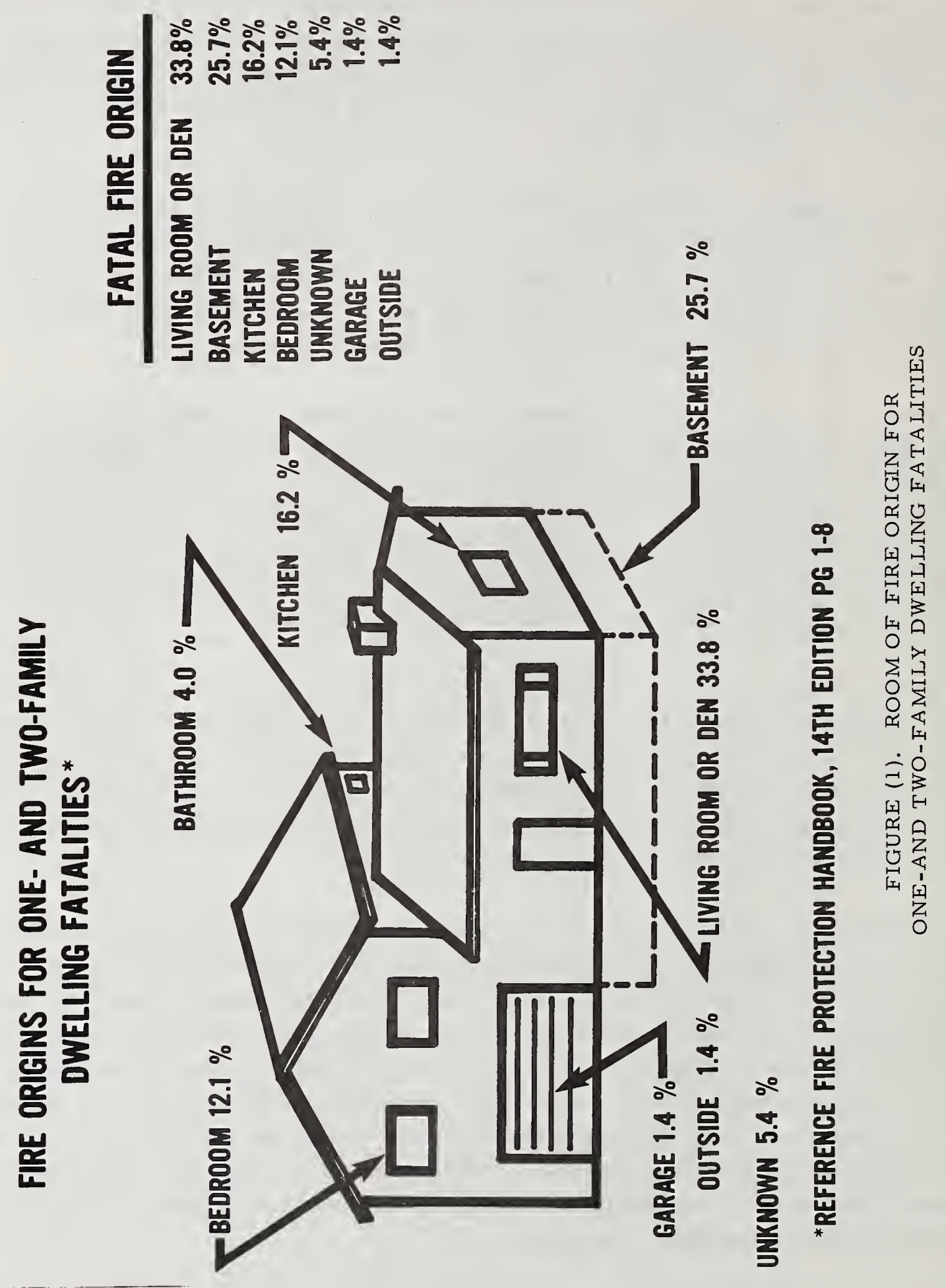




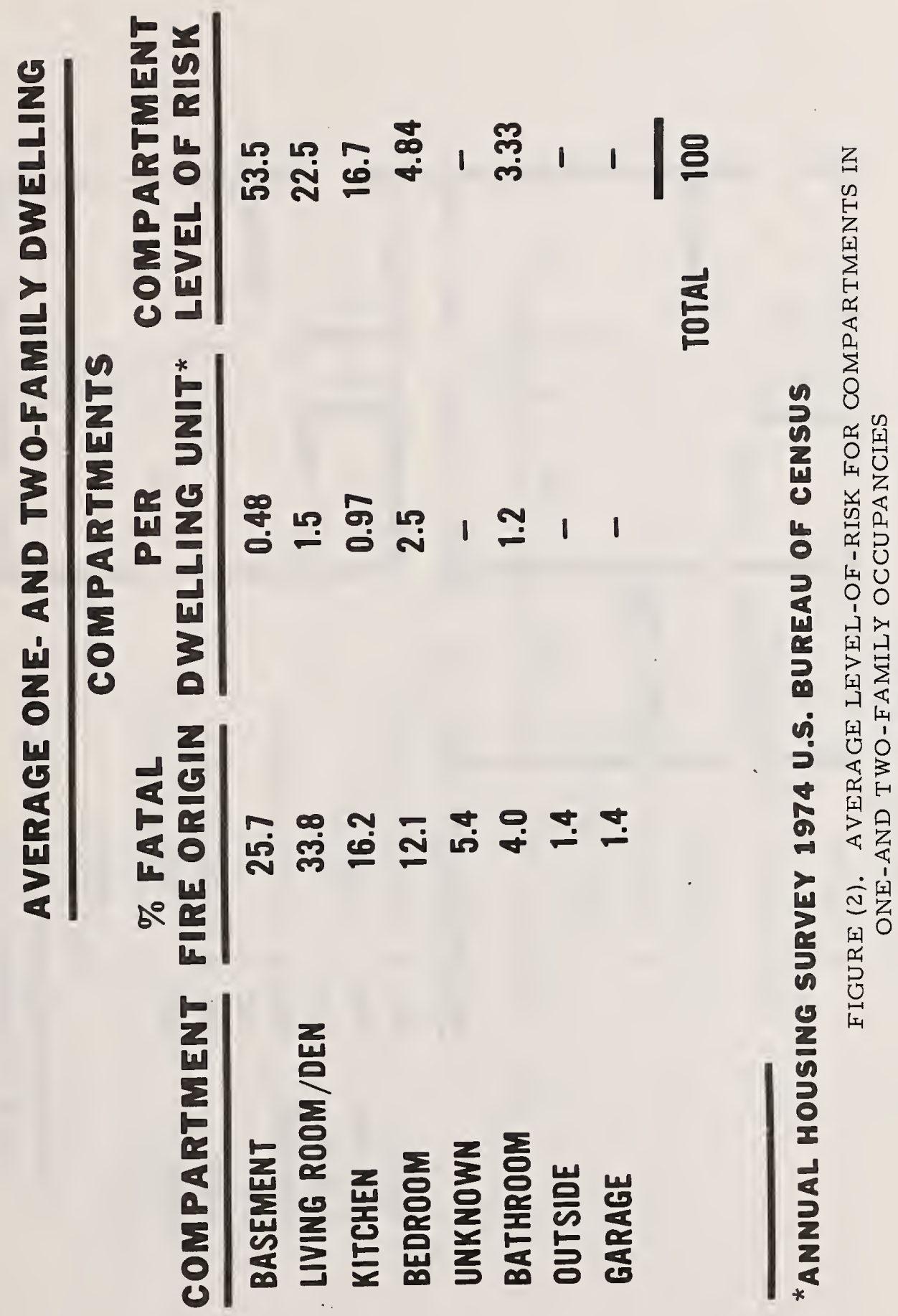




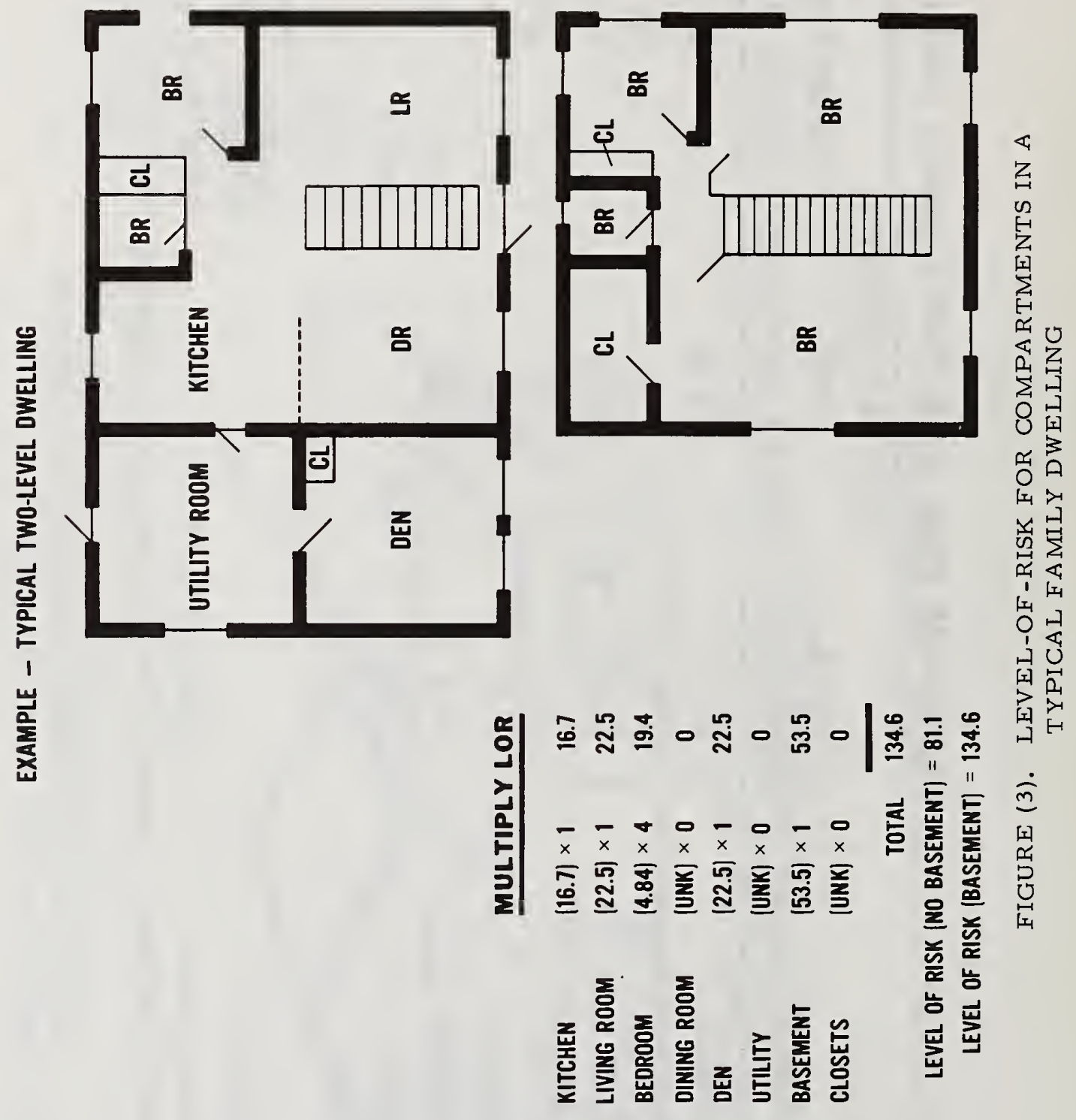




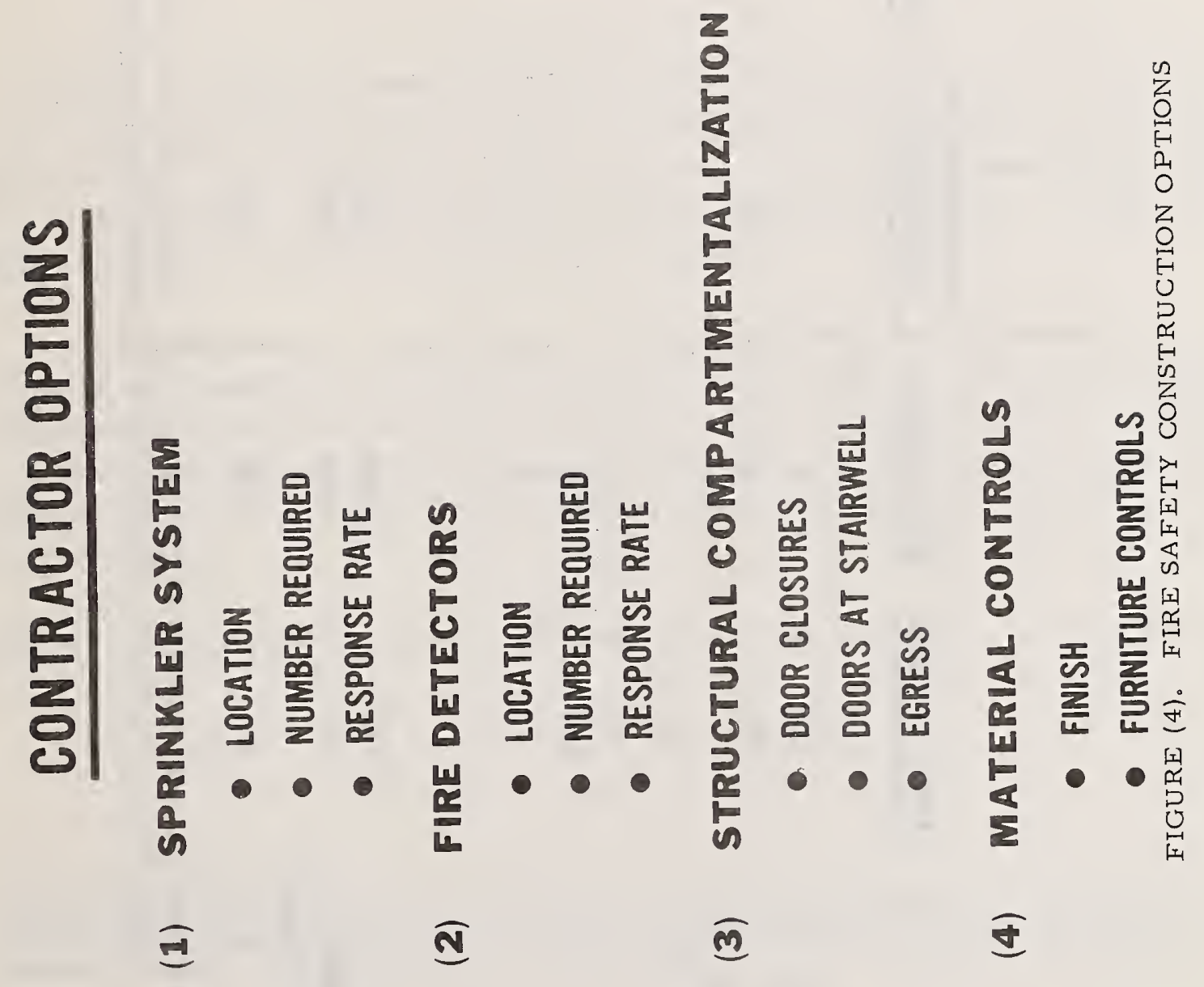




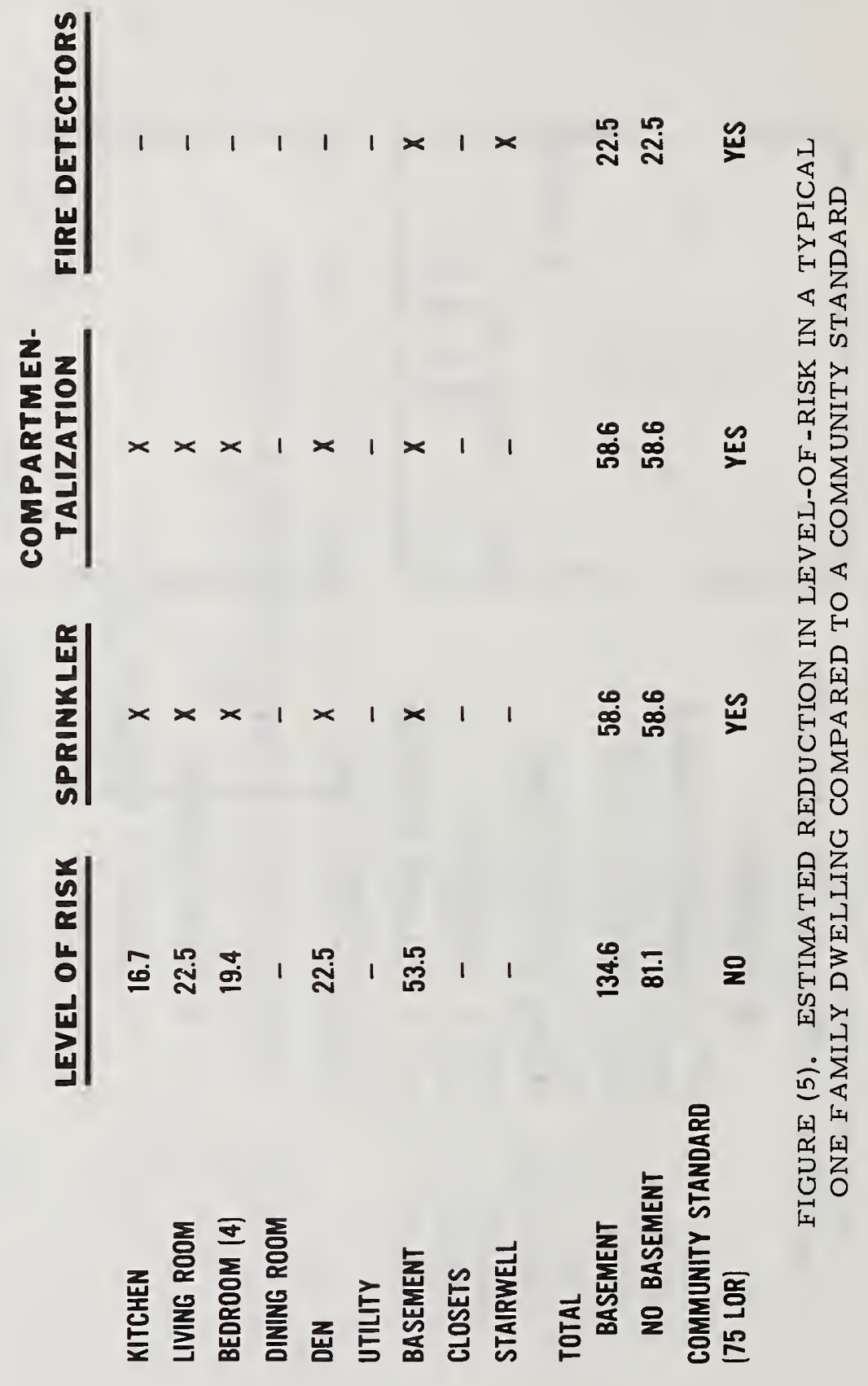


REHABILITATION AS AN INSTRUMENT IN MEETING HOUS ING NEED:

CAN IT REALLY WORK?

by

Jane Heron

Housing Programs Coordinator

Illinois Department of Local Government Affairs

Chicago, Illinois

There is an increasing trend in city planning toward rehabilitating older buildings and conserving neighborhoods that might have become slums, but the rehabilitation process is slow and unreliable. Few builders are interested in rehabilitation, most preferring new construction in the suburbs. A major question is: can the rehabilitation process be changed to attract more builders and become a high-volume business?

The suggested answer is that criteria to identify buildings needing rehabilitation and to specify what repairs need to be made must be developed, using the cumulative knowledge of builders who have done such work and the insight of people involved in building regulation. These criteria should deal with the fundamental structural and safety characteristics of bulldings, to provide a yardstick for selecting the right buildings and deciding how much work is required.

Keywords: Decision criteria; demolition; housing needs; physical condition rehabilitation.

* Reprinted from NBS Special Publication 518, "Research and Innovation in the Building Regulatory Process," (Proceedings of the Second NBS/NCSBCS Joint Conference held in Bozeman, Montana, September 20, 1977); pp. 251-257. 
Housing costs have risen dramatically in the past few years, as we all know. The average cost of new homes is over $\$ 50,000$; in 1970 , the FHA ceiling was $\$ 33,000$ against today's $\$ 55,000$. This kind of inflation has two consequences for the housing market. First, it stimulates demand for older buildings that are less expensive than new ones. Second, it puts more households into the "housing-poor" category, forcing them to spend too much income on housing or live in crowded or otherwise inadequate conditions. In today's market, even middle-class families are feeling the squeeze.

This situation has produced a growing market for older residential properties that calls for vastly improved rehabilitation techniques. Yet at present we lack even a method of assessing the magnitude of the problem, because we lack criteria for identifying dwellings that can and should be rehabilitated. Measuring housing need has historically been the business of sanitation specialists, social workers, and planners and economists working in government. The building industry has focused on supplying the buildings, once need is defined and incentive programs are in place. The result of this separation is the absence of any uniform standard of adequate physical condition for older buildings.

Many criteria have been tried by the Bureau of Census over the years, but each has been unsatisfactory in one way or another. Currently, HUD's criterion for adequate living conditions is that the dwelling contain complete plumbing, afford one room per person, and cost no more than 25 percent of household income. For owners, a building built before 1939 and valued under $\$ 10,000$ is deemed inadequate. Specific physical condition of the dwelling, however, is left out. Our studies of housing need in Illinois indicate that this standard underestimates housing need by 30 to 50 percent, possibly 400,000 households. Much of this need can and should be met through rehabilitation. Low-income households cannot afford new construction; many are elderly owners who do not want to move. With the high cost of land and energy, higher income young households are also being attracted to older buildings.

The potential for a vast market is there, but the market can only be tapped once we have the means to measure the need and identify the buildings. The burden of this paper is to suggest that the industry, and the regulatory sector in particular, must become involved in developing the standards that identify buildings needing rehabilitation, to further its own interests and also to play its role in meeting the country's housing needs and preserving our cities and towns as good places to work and live.

\section{MUST OLD BUILDINGS DIE OR ELSE JUST FADE AWAY?}

One-third of the occupied dwellings in the United States were built before 1939, and 51 percent of them are occupied by renters. The rental buildings particularly are likely to need 
substantial rehabilitation, since landlords frequently defer maintenance and repairs. Where 111-maintained older buildings are located, neighborhoods gradually deteriorate and become slums. People who can afford it move farther and farther out to the suburbs, leaving behind the old neighborhoods, the old buildings, and the people who cannot compete in the broader marketplace. Such neighborhoods are like a cancer within the larger community; eventually the entire city is seen as an inhospitable place to live. Factories and offices then relocate to the suburbs, leaving the city's vast capital facilities and investments underutilized and financially overburdened. In short, in the absence of effective rehabilitation, whole cities may die.

One historical cure for older buildings is the bulldozer. Vast numbers of older buildings were demolished between 1950 and 1970, through urban renewal programs that emphasized slum clearance. Conservation and rehabilitation were among the tools in the renewal kit, but they were used rarely and discussed seldom because clearance was the vogue. Clearance paved the way for large-scale redevelopment and new construction -- more visible, more immediately profitable and less trouble than remodeling and repairs. Peace to the people who were "urban removed."

In the past five years, while housing costs and interest rates rose out of sight, rehabilitation has become a major focus of housing and community development programs. Where new construction was seen as the answer to our housing problems just ten years ago, rehabilitation seems to be taking its place. From neighborhood organizations to Congress and HUD, the word is out: save our neighborhoods; preserve old buildings; no more demolition, we shall not be moved! HUD now requires all cities applying for community development funds to identify all dwellings "suitable for rehabilitation," notwithstanding the lack of criteria.

This sudden interest in rehabilitation is not so much a new respect for old buildings but a reaction to the cost of land, construction, and energy. It appears that the need to maintain and restore older residential neighborhoods will become a permanent part of public programs and private investment. Yet the cost of rehabilitation remains high, cost estimates are repeatedly low, and the construction and lending industries continue to be wary. Rehabilitation is largely the business of small contractors who handle a few buildings and of ten fail to serve the owners' best interests. The owners feel plagued by unreasonable code requirements and ineffectual job specifications and cost estimates.

Clearly something is amiss. Even if rehabilitation must be costly because of the problems likely to be found behind old walls, the cost of new construction should by now have eliminated the question "Is it worth it?" and substituted the question "How can it be made more worthwhile?" On this question, the building industry are the experts. 
Having approached a critical point in terms of high cost, perhaps we are on the verge of tackling the problem. One facet of the challenge is to identify the symptoms of the disease called deterioration and develop the criteria for deciding when minor surgery, or rehabilitation, is appropriate and when radical surgery -- demolition -- is required. These decision criteria operate on two levels. One is the national level, where we presently lack the criteria to estimate the total need and cost of undertaking rehabilitation where it is feasible. The other is the local level where we lack the systematic criteria to identify which buildings to rehabilitate; we select almost at random or oil the wheel that squeaks loudest.

Efforts have been made to develop these criteria, but a few examples illustrate the difficulty of the problem. The U.S. Bureau of Census has wrestled with the issue of identifying inadequate housing for 40 years and failed to come up with a satisfactory set of criteria. The one criterion which has persisted since 1940 is the absence of complete plumbing. On three occasions, however, the plumbing facilities specified to constitute "complete" plumbing have been changed. At the same time, with the extension of public water and sewer systems following World War II, incomplete plumbing has become almost statistically insignificant, found today in less than 4 percent of all dwellings.

From 1940 through 1960, enumerators were asked to identify various dwellings needing major repair, or dilapidated buildings, or deteriorating buildings. Owing to the subjectivity of the enumerators and geographic differences, the results were inconsistent and the findings were harshly criticized. The new result was the omission of physical condition questions in the 1970 Census. One new inferential criterion was developed in a special tabulation prepared by the Census Bureau for HUD in 1974; the age-to-value relationship for owner-occupied single-family dwellings. A single-family home built before 1939 and valued at less than $\$ 10,000$ in urban areas, or less than $\$ 7,500$ in rural areas, was deemed inadequate. This criterion, unfortunately, is just as subjective as those used in earlier years, because the owner completed the questionnaire and may easily have understated or over-rated the value of the property. It is also of little use in rural areas where frequently there is no market and decent homes may sell for $\$ 5,000$.

For the 1980 Census, the Bureau's housing advisory panel has thus far considered six factors and rejected three.

(1) The presence of rodents, rejected because rodents are common in less developed areas and field mice in surburban homes are not the issue.

(2) Bedrooms used as passageways, rejected because of probable misunderstanding and resentment among respondents and the possibility that all bedrooms with connecting doors to bathrooms might be counted. 
(4) Crumbling plaster or peeling paint.

(5) Holes in the roof, rejected on the grounds that it duplicated the above. In 1980, homes with roof and attic damage will not be identified, so long as the ceiling below is all right.

(6) Whether or not there is a home improvement loan outstanding on the property -- regardless whether the loan is for a new patio or major repairs.

My intention is not to ridicule the panel wrestling with these questions. Rather, it is to show the difficulty of coming up with apt questions. More important, such criteria will not enable us to identify dwellings to demolish or those to preserve. If, in fact, rehabilitation can be successful in conserving basically good dwellings (and commercial buildings too), the magnitude of the problem and its geographic locations must be determined, in order to decide how much money is needed and where. Once this question is answered, a market can emerge and the construction industry move in.

Now the scene shifts to the local level. Even if we can competently assess rehabilitation need at the national level, we lack a system for deciding which buildings to rehabilitate when and how much to invest, and political decisions of one sort or another prevail. Indeed it appears at present that considerable sums of Federal community development and weatherization money are being spent on bandaid and cosmetic repairs to very old, insubstantial dwellings which may remain in use just enough longer, because of these renovations, to become genuinely dangerous to life and health and to trigger or perpetuate the problem of neighborhood and community decay. In addition to criteria for when to rehabilitate and when to demolish, we need systematic criteria for determining what work must be done.

HOW MUCH REHAB IS ENOUGH?

The crux of the problem is to define a standard of adequacy and develop a sliding scale of physical condition for older buildings; for example, from "needing minor repairs" to "requiring demolition"--quantitative criteria by which buildings could be rated numerically. Some efforts have been made to design such a system, but none is widely used. A major problem is identifying the cutof $f$ at which rehabilitation is not economical or appropriate. A related problem is that our codes of ten seem to require too much, driving costs up, rather than relating improvements to existing defects. A sliding scale would quantify defects in the building and rank them, giving greater weight to structural defects or immediate safety hazards. A building with too many points or too many immediate safety hazards would qualify 
for demolition. Rehabilitation would be indicated by scores within a lower range. Neighborhoods needing systematic housing code enforcement for minor repairs would fall into the lowest category. A major asset of this type of system is that it provides the defining characteristics of "buildings suitable for rehabilitation" and identifies precisely the work which must done to rehabilitate a given building.

It may seem that codes do this job, but that is not the case. The codes contain all the requirements new buildings should meet, but some of them are inapplicable to older buildings because of difference in construction. In any case, the codes as we know them cannot directly be used to identify what is missing or what needs correction in a deteriorated old building. Nor can the codes be used to rate deficiencies by degree of hazard or rank buildings on a sliding scale. The code is not a policy tool, and these are policy decisions.

The codes in a sense, are part of the problem. For example, the codes state that the entire building shall meet the code when alterations valued at 50 percent or more of replacement cost are undertaken. Obviously this increases total rehabilitation cost. Perhaps not quite as obvious is the arbitrariness of this criterion. Surely it is the actual condition of the building, not the cost of alterations, that warrants spending the money to bring it up to code. A rating system that quantifies defects would provide a more reasonable basis for this decision.

On the other hand, if the 50 percent rule is removed from the code, the building department has no means of knowing what rules, that is, what code to apply. Where does the housing code stop and the building code begin? The answers to this question equally 1ie in the development of decision criteria based on experience to identify those conditions which must be corrected and those which may, while also affording some flexibility about the method of correction. It is not intuitively obvious that every feature of a building constructed in 1875 must comply with today's accepted standards -- which differ from those of only 20 years ago -- in order to afford safety and comfort to the occupants.

One argument frequently used against rehabilitation as a major tool in meeting housing needs is that each building is an individual case with its own problems which make the cost of time and materials totally unpredictable. This belief has also kept most builders out of the business and left the work to small short-lived firms. However, in the 12 years since the 1965 HUD Act introduced the rehabilitation loan program, several thousand dwellings of various types and sizes have been rehabilitated all over the country. By now enough experience has been logged to enable us to discover what types of hazards are most common, what kinds of repairs and new installations are most often needed, and what problems are most frequently encountered during rehabilitation in various types of construction. This kind of information could be the basis for a system to identify buildings needing and suitable for rehabilitation, and the cumulative experience could provide a more efficient approach to rehabilitation which would open the door to high-volume construction work. 
This is not a plea for "softness" or unsound decisions which jeopardize the inhabitants of buildings and the inspectors who determine compliance with codes. On the contrary, it is a plea for hard criteria based on actual construction experience to systematize the process of rehabilitation, from identification of suitable buildings to prompt completion of the work. This will enable us to rehabilitate more buildings faster and to eliminate those buildings harmful to occupants and communities more readily. If building regulation places emphasis on maintaining the quality of existing housing, it will make building maintenance and renovation a major component of the construction industry. 



\title{
BUILDING CODES AND HISTORIC PRESERVATION
}

IN SAVANNAH GEORGIA*

by

\author{
Mires Rosenthal \\ Director \\ Department of Inspections \\ Savannah, Georgia
}

The City of Savannah has the largest registered urban historical district in the United States. Over 900 structures have been restored or are awaiting restoration. Building code barriers that once existed were overcome through cooperation and communications with results that satisfy the intent of code criteria while also maintaining the integrity of historic preservation. The experience gained in Savannah suggests that code compliance responsibilities in historic preservation projects rests jointly with designers, preservationists, owners and builders as well as code enforcement personnel. Recommendations include the need for guidelines in the use of codes for dealing realistically with building rehabilitation projects.

Key Words: Barriers; building codes; code enforcement; historic district; historic preservation; rehabilitation; regulations; safety.

* This paper was presented at a meeting of the Codes Administration Committee of the Nationa 1 Conference of States on Building Codes and Standards; September 14, 1978; Annapolis, Maryland. Reprinted with permission. 
The conflicts that are presented by building codes when historic preservation projects are undertaken can have many diverse perspectives among those who may be directly or indirectly involved in such projects. This dilemma is viewed by some as "..... how to bend the codes without really breaking them." Others may have such reactions as .... "Do we really have to do all that, remember I am a taxpayer." Or, "boy will I show those historical nuts." Or, "that old building what's historical about it?" Yes, all of us connected with code enforcement have heard this before, and no doubt will hear it again.

Specifically, this discussion deals with historic preservation in Savannah, Georgia. It describes how the codes in Savannah have been equated with revitalization and renovation of historic structures.

The April 1978 Newsletter of the National Conference of States on Building Codes and Standards (NCSBCS) which reported on the appearance of NCSBCS President Charles Dinezio before the U.S. Senate Banking, Housing and Urban Affairs Committee concerning the impact of building codes on the revitalization of cities and towns was of great interest. His remarks on the development of codes from the basic provisions for occupant safety (e.g., structural safety and fire safety) to a "complex system of standards, codes, laws and statutes" and how "they then advanced to regulating healthful living conditions such as ventilation, light, and minimum areas" touched a tender spot and summates problems of code enforcement.

Mr. Dinezio continued with the problems incurred that negatively affect rehabilitation, revitalization, and re-use of existing buildings. He also recognized the importance of "the backgrounds and skills of code enforcement personnel." This in my opinion, is one of the most important elements of a successful code enforcement program in government.

To overcome apparent shortcomings, it is necessary to upgrade the status of code enforcement personnel. This can be accomplished by requiring necessary competencies, educational and experience background, continuing education, and lastly, salaries commensurate with ability and responsibility. In addition, Mr. Dinezio amplified on the needs for a program of education and training and, may $I$ add, for not only code enforcement personnel, but all those responsible for the structure including the interior decorator, owner, and insurance carrier. Education on code requirements should also begin with the future designer's undergraduate studies.

In my opinion, laws should be changed to specifically place the responsibility of code compliance with those responsible for the design, construction, and maintenance as well as code enforcement personnel. If they are not so changed, the U.S. will be faced with the 
most damaging statistics of having the highest rate per capita of deaths and property damage resulting from fires than any other civilized country in the world.

With regard to historic preservation, rehabilitation and the building code, "Savannah style" - the present day trend is towards preservation of the past in order to leave a heritage for the future. Probably no where in the code enforcement field is the code enforcement officer called upon to do more soul searching than in the preservation of historic structures. In addition, his decisions are scrutinized for more self-serving interests. No one is less inhibitive in his desire to preserve the past than the preservationist. No one group can bring to bear pressure to accomplish their aim than the preservationist groups. These groups can either be individuals who are self-appointed do-gooders or formally organized preservation groups.

As code enforcement officials, are we prepared for the onslaught where we are pressured to turn our backs on the code or to sacrifice safety? Are we prepared to make decisions that, were a tragedy to occur, our professional careers would be seriously affected and where backing from top level management just cannot be found? The answer is "we are not."

So, "what can be done about it?" We should start with a basic definition.

What is an historic structure? The word "historic" is variously defined. For our purposes, an historic structure should be considered as any structure which is deliberately preserved beyond its normal life because of historic association, architectural interest, or public policy. Would it then qualify for special historic building code provisions? I trust the following will provide the answer.

Preservation of such structures can be accomplished by a wide variety of means. At one end of the spectrum is pure restoration, in which the structure is returned to its original condition; at the opposite end is total redesign, in which the structure bears little or no resemblance to its original state. Most preservation work falls somewhere between the two extremes. Pure restoration would often produce an unliveable building by modern standards, while total redesign is usually a singularly pointless exercise.

Good preservation practice usually encompasses a range from almost pure restoration to a thorough adaptive reuse involving extensive interior rework, and a possible change of occupancy.

Changes are made as necessary for comfort and safety in cases of pure restoration; however, every effort is made to minimize such changes. For adaptive reuse, changes may be more significant. In some cases, only the exterior walls and perhaps an important feature such as a grand stairway, lobby, or similar element may be retained. The choice of approach is probably the most critical decision in the entire preservation process. It determines the 
acceptability of incursions upon the historic fabric. While the approach must be based on the historic value of the building, it must also allow enough flexibility for the amelioration of hazardous conditions.

In the process of restoration of historic buildings, a conflict frequently occurs between the code requirements for life safety and the preservationists' desire to maintain the historic integrity of the original building. Recent changes in the model codes have permitted alternative life safety systems which are sometimes not readily available. In some cases these alternative systems hinder the code official from having a ready solution because of economic and esthetic problems.

The use of codes in their literal wording for the revitalization of buildings also causes much concern. It has hindered preserving the existing housing stock throughout the country, leaving in its wake the most prolific cause of deterioration of whole communities -- barren property, a refuse of rats, vermin, junk and weeds.

In the past, old buildings were demolished because of economic conditions where a surface level parking lot, small office buildings, or tax incentives were the alternates. Fortunately, through the effects of various preservation groups, the old buildings have been found to be of valuable use. Several means of financing are used to prevent the destruction of valuable landmarks, resulting in areas of viable living and productive structures and still keeping the charm of a bygone day.

Codes usually are not enforced retroactively. However, existing buildings encounter code problems when they are moved, restored, reoccupied, or refurbished for a new use. In some areas, flexible interpretation of codes has insured that safe buildings are not penalized for literal nonconformance. In other areas, building and fire officials enforce codes to the letter, -- often to the detriment of buildings under consideration.

Somewhere between the two should be the medium where historic preservation can continue, where the historic integrity is not destroyed and where the completed work is within the intent of the codes, producing a safe building.

Non-varying enforcement of codes frequently stems from a lack of available information about code intent and alternatives, and also the lack of judgment on the part of code enforcement personnel. Understanding of the methods by which codes are formulated has prompted interest in the development of alternative means for satisfying code intent.

I do not wish to imply that there is always a solution or that the code official must abrogate his responsibility for historic restoration. Safe occupancy and type of construction are prime considerations for determining to what extent the alternative methods may be used. 
If properly constituted with individuals that can make the proper professional decision, the Building Code Board of Adjustments and Appeals is an instrument that can provide a path of travel for the code official whenever an impasse is reached. This approach has been used in Savannah with good results. The professional board used in Savannah has met the challenge. Some of the methods which have been employed are: increased use of fire resistive materia1s; smoke detection and fire suppression systems; increased emergency access pane1s; and, change in hardware schedules. Other codes are a1so brought into the picture, especially the Electrical, Plumbing and Mechanical Codes. These codes may require new wiring, additional service ampacity, removal of old, unused wiring, adequate sanitation and ventilation facilities, and the use of qualified personnel to install and inspect. This lessens the chance of building failure.

A11 available background publications pertaining to historic preservation have been searched in preparation for this discussion, including model ordinances and adopted ordinances. No where are there any guidelines for the use of codes in historic preservation. Generally, many ordinances are set up to rule on the compatibility of proposed exterior work to the existing vicinity. However, some ordinances govern interior work relating to the original historic compatibility and sometimes on the use intended. A policy has been formulated and must be followed by the code enforcement personnel in Savannah's Department of Inspections. It is imperative that good communications are maintained between the Department of Inspections and the historic preservationists and both sides demonstrate a willingness to meet and work out problems. This has assisted in solving problems on the mystique of historic preservation and the building codes.

Surveys have been taken of State and local adoptions of historic preservation sections in codes. One survey in particular, was carried out by the National Bureau of Standards. 1 / There was much discrepancy in answers resulting in interpretations; therefore, the answer did not best describe local conditions. The National Bureau of Standards survey report made the following recommendations:

"Further research is necessary to resolve problems of conflict between historic preservation objectives and those of building codes.

"In the case of the codes, it is necessary to evaluate the significance of individual code provisions, since provisions for life safety, structural safety, sanitation, electrical standards, heating standards, fire districts, and many others exist side-by-side without reference to individual necessity or importance. Some of these provisions are absolutely essential to the safe operation of a building,

1/ Melvyn Green and Patrick W. Cooke, "Survey of Building Code Provisions for Historic Structures," NBS Technica1 Note 918, September, 1976. 
others represent desirable levels of amenity which would not endanger public health or safety if abrogated in special cases.

"Where code provisions are abrogated, serious questions concerning the designer's liability may arise, further study of this problem is also indicated.

"The effectiveness of existing historic preservation clauses and codes should be evaluated in terms of their ability to facilitate historic preservation and to provide an acceptable degree of safety to the building's users.

"Initial efforts should be directed towards a better definition of the problem of preservation and building codes. Such a study could consist of a series of indepth interviews with building regulatory authorities in urban and rural areas, architects engaged in historic preservation, and individuals and organizations involved in historic preservation. The result of such a study would provide a better focus on the problem, permitting the identification and development of solutions." $\underline{2} /$

The question arises, "Should codes give special dispensation for historic preservation?" An affirmative answer, in my opinion, would invite all special interests to expect the same.

The work of the Department of Inspections of the City of Savannah encompasses historic preservation.

The Savannah Historic District is the largest registered urban historical area in the United States. It covers $21 / 2$ square miles, contains 1100 structures, is a national landmark, and is in the process of expanding. From 1940 to the present time, over 900 structures have been restored or are awaiting restoration. All of this has been accomplished by private initiative. What has been accomplished? A $21 / 2$ square mile slum area has been converted to a viable living monument, resulting in a retrograded movement from suburban to urban living.

The dominant organization in this movement is the Historic Savannah Foundation. In communicating with a former Executive Director of the Foundation, the answer to the questions concerning historic preservation and codes were resolved. No special code compliance sanctions was given and no undue hardship was placed on those involved in restoration. The Executive Director expressed the sincere belief that using the codes as written would strengthen his position and create a more favorable atmosphere in his contacts with the entire community.

2/ Ibid., pp. 24-25. 
There are four reasons for codes:

1. To protect the owner.

2. To protect the adjacent property owner.

3. To protect the occupant of the structure.

4. To protect the fire fighting personnel.

What can be done to solve the problem of historic preservation compliance with the building code?

The property owners, architects and contractors must be made to realize that the building official's role is to assist, not to hinder. The building official must be cooperative and sympathetic. For the Department of Inspections, the restoration movement in the Savannah area has not been an easy road to travel. However, barriers that once existed have now fallen. By cooperation and communication among the property owners, their agents, and the city government, we have been able not only to save our precious heritage, but also to permit property owners to make full utilization of their property within the confines of existing laws and ordinances.

There is a way to satisfy code criteria and still keep the integrity of historic preservation. Some of the steps involved are as follows:

1. Confidence must be instilled in those who seek building permits.

2. Cooperation must exist between the code enforcement personnel and the other party or his representative. Each project should be handled as an individual case.

3. Certain criteria should be set that even though deviating from the literal wording of the code, would make allowances for those situations that still meet its intent and satisfies the forementioned reasons for codes.

The Riverfront part of Savannah originally consisted of warehouses and offices, has in the past several years, been the largest restoration area. The buildings once were used to store cotton and other commodities below the Bay Street or main city level, with offices of brokers on the Bay Street level and above. As King Cotton faded, the upper level of offices was taken over by insurance firms, lawyers, shipping companies, architects, and other business and professional people, and a few apartments. This riverfront property rises six stories above River Street and two to three stories above the Bay Street level. The riverfront level has its back against a bluff. The lower three floors are used as an entrance for shops and businesses. This is allowable because there is an entry on two of the lower floors from ramps used as city thoroughfares and an entry on the Bay Street level. Where assembly occupancy occurs, in restaurants, bars, etc., the letter of the code must be met with no exceptions. Each floor must have two means of egress and all the other requirements, as necessary. 
Kitchen ventilation with fire suppression systems is required per NFPA No. $96 . \underline{3}$ These vents run to the top of buildings on the outside, much to the dismay of the preservationists. However, the use of color to blend in with the exterior walls lessens the impact.

The use of code boards are necessary, but only to substitute not to abrogate.

Full cooperation by all concerned parties has resulted in the accomplishment of the preceding activities in the City of Savannah. This cooperation negated having to resort to the section on existing buildings in the codes, which conceivably could stop some of our efforts.

The City of Savannah has a strong condemnation program. We have been able to rid the city of some of the most derelict buildings imagined. The same applies to historically rated buildings. Although we do not demolish, we do require boarding up until restoration is started. Consequently, we have saved buildings from squatters, fires, vandalism and other forces that ultimately require a building to be demolished.

I do not mean to imply that there is always a solution. It has been necessary to deny building permits when the fire code requirements could not be met, or when to permit occupancy would endanger surrounding property and those in occupancy.

This presentation has dealt with restoration and rehabilitation for reuse of the historic structure for living or commercial uses. But what about reuse for history preservation. For instance, a structure reused as a museum piece, where the structure is multi-story and the interior architectural features must be preserved and a mode of past living exemplified, with no added life-saving systems except for a fire detection system. Again, it is impossible to adapt codes that would take care of all situations. Referring to the above statements, the structure must be evaluated in terms of use and anticipated occupancy content. Consultation with the design and preservation groups, again making proper use of the appeals board, has made it possible to accomplish the purpose of the project and keep within confines of the intent of the code.

In conclusion, it is impossible to write codes to fully cover all aspects of rehabilitation, revitalization, and reuse of buildings. Therefore, it is my recommendation that rather than fill up code books with rhetoric, confusing and otherwise, a set of guidelines should be formulated that will give the designers, builders, and code enforcement personnel the necessary tools to equate with the adapted codes for a safe, viable, and reuseable structure for its intended purpose.

3/ "Standard for the Installation of Equipment for the Removal of Smoke and Grease-Laden Vapors from Commercial Cooking Equipment," National Fire Protection Association, Boston, Massachusetts. 
NBS-114A (REV. 9-78)

\begin{tabular}{|c|c|}
\hline $\begin{array}{c}\text { U.S. DEPT. OF COMM. } \\
\text { BIBLIOGRAPHIC DATA } \\
\text { SHEET }\end{array}$ & 1. PUBLICATION OR REPORT NO. \\
\hline
\end{tabular}

4. TITLE AND SUBTITLE

Selected Papers Dealing With Regulatory Concerns of Building Rehabilitation

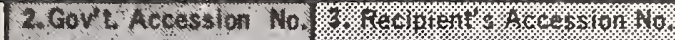

7. $\operatorname{AUTHOR}(S)$

Patrick W. Cooke, Editor

9. PERFORMING ORGANIZATION NAME AND ADDRESS

NATIONAL BUREAU OF STANDARDS

DEPARTMENT OF COMMERCE

WASHINGTON, DC 20234

12. SPONSORING ORGANIZATION NAME AND COMPLETE ADDRESS (Street, City, State, ZIP)

National Bureau of Standards

Department of Commerce

Washington, D.C. 20234

10. Project/Task/Work Unit No.

5. Publication Date

February 1979

6. Performing Organization Code

8. Performing Organ. Report No.

11. Contract/Grant No.

13. Type of Report \& Period Covered

Final

14. Sponsoring Agency Code

\section{SUPPLEMENTARY NOTES}

Library of Congress Catalog Card Number: 79-600012

$\square$ Document describes a computer program; SF-185, FIPS Software Summary, is attached.

16. ABSTRACT (A 200-word or less factual summary of most sigrificant information. If document includes a significant bibliography or literature survey, mention it here.)

This publication consists of a collection of six papers common to the subject of rehabilitation and preservation of existing buildings and how our present system of regulating construction for the public benefit presents various barriers that must be more fully understood in order that rational solutions can be developed and implemented. The papers have been reprinted from the Proceedings of previous national conferences dealing with building regulatory research held under the joint sponsorship of NBS and the National Conference of States on Building Codes and Standards. The titles of the papers are:

"Building Codes: Preservation and Rehabilitation" by Robert J. Kapsch

"Information Structure of Building Codes and Standards for the Needs of Existing Buildings" by Baird Smith

"Contractor Understanding Relative to Rehab Costs" by Richard S. Harrington

"The Role of Fire Prevention and Control on Building Construction and Regulation" by William H. McLain

"Rehabilitation as an Instrument in Meeting Housing Need: Can It Really Work?" by Jane Heron

"Building Codes and Historic Preservation in Savannah,Georgia" by Mires Rosenthal

17. KEY WORDS (six to twelve entries; alphabetical order; capitalize only the first letter of the first key word unless a proper name; separated by semicolons)

Adaptive reuse; buildings; building codes; building safety; code enforcement; construction; fire safety; housing; preservation; regulations; rehabilitation.

18. AVAILABILITY

For Official Distribution. Do Plot Release to NTIS

X Order From Sup. of Doc., U.S. Government Printing Office, Washington, DC 20402, SD Stock No. SN003-003-02032-0

Order From National Technical Information Service (NTIS), Springfield, VA. 22161

\begin{tabular}{|l|c|}
\hline $\begin{array}{l}\text { 19. SECURITY CLASS } \\
\text { (THIS REPORT) }\end{array}$ & $\begin{array}{c}\text { 21. NO. OF } \\
\text { PRINTED PAGES } \\
\text { UNCLASSIFIED }\end{array}$ \\
\hline $\begin{array}{l}\text { 20. SECURITY CLASS } \\
\text { (THIS PAGE) }\end{array}$ & 93 \\
UNCLASSIFIED & $\$ 2.75$ \\
\hline
\end{tabular}



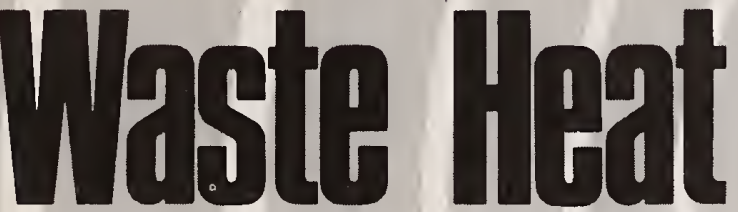

Wian

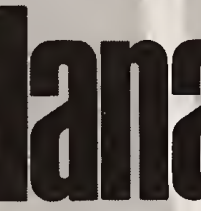

filinting

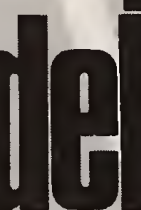

,
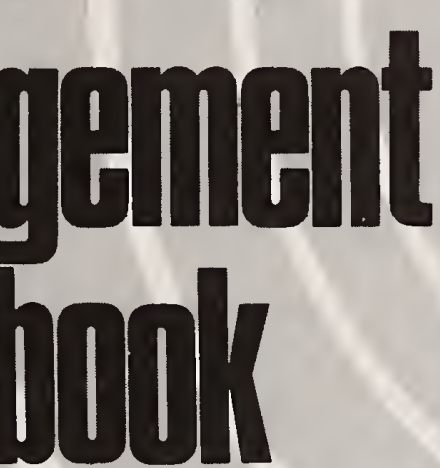

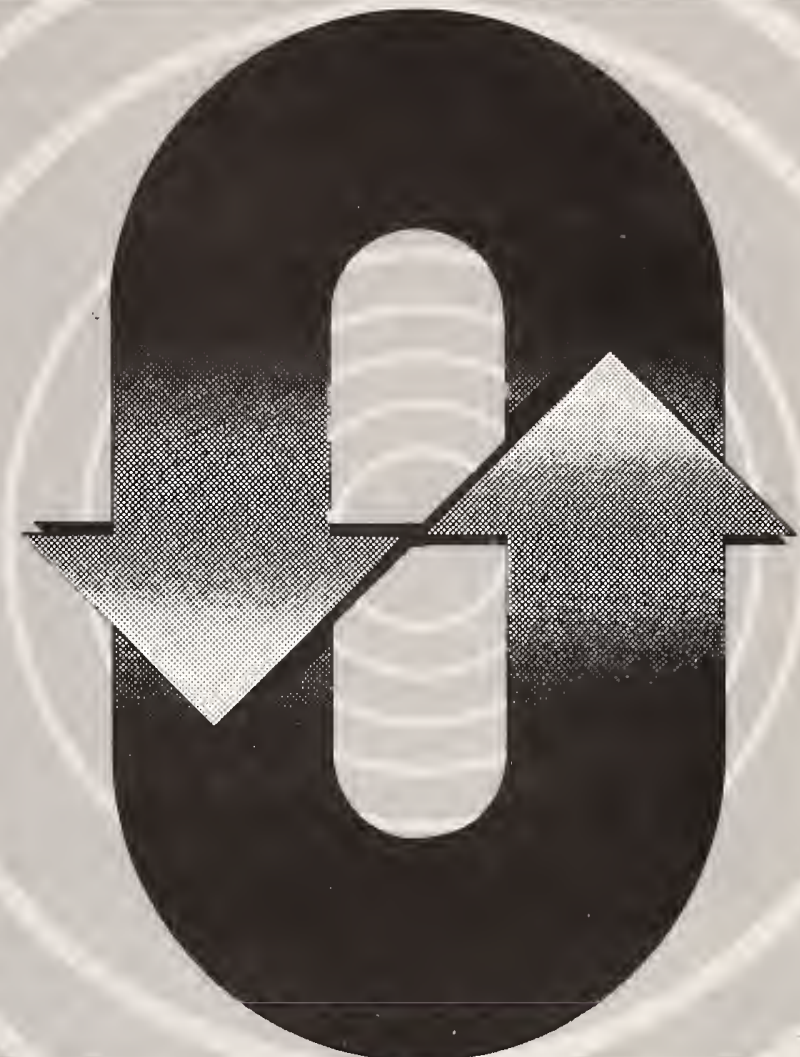

A typical plant can save about 20 percent of its fuel-just by installing waste heat recovery equipment. But with so much equipment on the market, how do you decide what's right for you?

Find the answers to your problems in the Waste Heat Management Guidebook, a new handbook from the Commerce Department's National Bureau of Standards and the Federal Energy Administration.

The Waste Heat Management Guidebook is designed to help you, the cost-conscious engineer or manager, learn how to capture and recycle heat that is normally lost to the environment during industrial and commercial processes.

The heart of the guidebook is 14 case studies of companies that have recently installed waste heat recovery systems and profited. One of these applications may be right for you, but even if it doesn't fit exactly, you'll find helpful approaches to solving many waste heat recovery problems.
In addition to case studies, the guidebook contains information on:

- sources and uses of waste heat

- determining waste heat requirements

- economics of waste heat recovery

- commercial options in waste heat recovery equipment

- instrumentation

- engineering data for waste heat recovery

- assistance for designing and installing waste heat systems

To order your copy of the Waste Heat Management Guidebook, send $\$ 2.75$ per copy (check or money order) to Superintendent of Documents, U.S. Government Printing Office, Washington, D.C. 20402. A discount of 25 percent is given on orders of 100 copies or more mailed to one address.

The Waste Heat Management Guidebook is part of the EPIC industrial energy management program aimed at helping industry and commerce adjust to the increased cost and shortage of energy. 




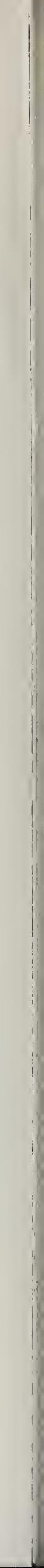





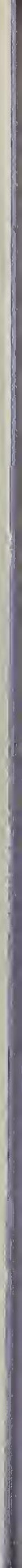




\section{NBS TECHNICAL PUBLICATIONS}

\section{PERIODICALS}

JOURNAL OF RESEARCH-The Journal of Research of the National Bureau of Standards reports NBS research and development in those disciplines of the physical and engineering sciences in which the Bureau is active. These include physics, chemistry, engineering, mathematics, and computer sciences. Papers cover a broad range of subjects, with major emphasis on measurement methodology, and the basic technology underlying standardization. Also included from time to time are survey articles on topics closely related to the Bureau's technical and scientific programs. As a special service to subscribers each issue contains complete citations to all recent NBS publications in NBS and nonNBS media. Issued six times a year. Annual subscription: domestic $\$ 17.00$; foreign $\$ 21.25$. Single copy, $\$ 3.00$ domestic; $\$ 3.75$ foreign.

Note: The Journal was formerly published in two sections: Section A "Physics and Chemistry" and Section B "Mathematical Sciences."

\section{DIMENSIONS/NBS}

This monthly magazine is published to inform scientists, engineers, businessmen, industry, teachers, students, and consumers of the latest advances in science and technology, with primary emphasis on the work at NBS. The magazine highlights and reviews such issues as energy research, fire protection, building technology, metric conversion, pollution abatement, health and safety, and consumer product performance. In addition, it reports the results of Bureau programs in measurement standards and techniques, properties of matter and materials, engineering standards and services, instrumentation, and automatic data processing.

Annual subscription: Domestic, \$11.00; Foreign \$13.75

\section{NONPERIODICALS}

Monographs-Major contributions to the technical literature on various subjects related to the Bureau's scientific and technical activities.

Handbooks - Recommended codes of engineering and industrial practice (including safety codes) developed in cooperation with interested industries, professional organizations, and regulatory bodies.

Special Publications-Include proceedings of conferences sponsored by NBS, NBS annual reports, and other special publications appropriate to this grouping such as wall charts, pocket cards, and bibliographies.

Applied Mathematics Series-Mathematical tables, manuals, and studies of special interest to physicists, engineers, chemists, biologists, mathematicians, computer programmers, and others engaged in scientific and technical work.

National Standard Reference Data Series-Provides quantitative data on the physical and chemical properties of materials, compiled from the world's literature and critically evaluated. Developed under a world-wide program coordinated by NBS. Program under authority of National Standard Data Act (Public Law 90-396).
NOTE: At present the principal publication outlet for these data is the Journal of Physical and Chemical Reference Data (JPCRD) published quarterly for NBS by the American Chemical Society (ACS) and the American Institute of Physics (AIP). Subscriptions, reprints, and supplements available from ACS, 1155 Sixteenth St. N.W., Wash., D.C. 20056.

Building Science Series-Disseminates technical information developed at the Bureau on building materials, components, systems, and whole structures. The series presents research results, test methods, and performance criteria related to the structural and environmental functions and the durability and safety characteristics of building elements and systems. Technical Notes-Studies or reports which are complete in themselves but restrictive in their treatment of a subject. Analogous to monographs but not so comprehensive in scope or definitive in treatment of the subject area. Often serve as a vehicle for final reports of work performed at NBS under the sponsorship of other government agencies. Voluntary Product Standards-Developed under procedures published by the Department of Commerce in Part 10, Title 15, of the Code of Federal Regulations. The purpose of the standards is to establish nationally recognized requirements for products, and to provide all concerned interests with a basis for common understanding of the characteristics of the products. NBS administers this program as a supplement to the activities of the private sector standardizing organizations.

Consumer Information Series-Practical information, based on NBS research and experience, covering areas of interest to the consumer. Easily understandable language and illustrations provide useful background knowledge for shopping in today's technological marketplace.

Order above NBS publications from: Superintendent of Documents, Government Printing Office, Washington, D.C. 20402.

Order following NBS publications-NBSIR's and FIPS from the National Technical Information Services, Springfield, Va. 22161.

Federal Information Processing Standards Publications (FIPS PUB)-Publications in this series collectively constitute the Federal Information Processing Standards Register. Register serves as the official source of information in the Federal Government regarding standards issued by NBS pursuant to the Federal Property and Administrative Services Act of 1949 as amended, Public Law 89-306 (79 Stat. 1127), and as implemented by Executive Order 11717 (38 FR 12315, dated May 11, 1973) and Part 6 of Title 15 CFR (Code of Federal Regulations).

NBS Interagency Reports (NBSIR)-A special series of interim or final reports on work performed by NBS for outside sponsors (both government and non-government). In general, initial distribution is handled by the sponsor; public distribution is by the National Technical Information Services (Springfield, Va. 22161) in paper copy or microfiche form.

\section{BIBLIOGRAPHIC SUBSCRIPTION SERVICES}

The following current-awareness and literature-survey bibliographies are issued periodically by the Bureau:

Cryogenic Data Center Current Awareness Service. A litera. ture survey issued biweekly. Annual subscription: Domestic, \$25.00; Foreign, \$30.00.

Liquified Natural Gas. A literature survey issued quarterly. Annual subscription: $\$ 20.00$.
Superconducting Devices and Materials. A literature survey issued quarterly. Annual subscription: $\$ 30.00$. Send subscription orders and remittances for the preceding bibliographic services to National Bureau of Standards, Cryogenic Data Center (275.02) Boulder, Colorado 80302. 
